УДК 004.8

06.02.00 Ветеринария и Зоотехния

АВТОМАТИЗИРОВАННЫЙ СИСТЕМНО-
КОГНИТИВНЫЙ АНАЛИЗ В ВЕТЕРИНАРИИ
(НА ПРИМЕРЕ РАЗРАБОТКИ
ДИАГНОСТИЧЕСКИХ ТЕСТОВ)

Луценко Евгений Вениаминович

д.э.Н., к.Т.н., профессор

Scopus Author ID: 57191193316

РИНЦ SPIN-код: 9523-7101

prof.lutsenko@gmail.com http://lc.kubagro.ru

Кубанский государственный аграрный университет имени И.Т.Трубилина, Россия, 350044, Краснодар, Калинина, 13,

В статье рассмотрено применение Автоматизированного системно-когнитивного анализа (АСКанализ) и его программного инструментария интеллектуальной технологи «Эйдос» для реализации уже разработанных ветеринарных и медицинских диагностических тестов без программирования в форме, удобной для индивидуального и массового тестирования, анализа его результатов и выработки индивидуальных и групповых рекомендаций. Возможно объединение нескольких ветеринарных тестов в один супертест

Ключевые слова: АВТОМАТИЗИРОВАННЫЙ СИСТЕМНО-КОГНИТИВНЫЙ АНАЛИЗ, ИНТЕЛЛЕКТУАЛЬНАЯ СИСТЕМА «ЭЙДОС», ВЕТЕРИНАРНЫЕ И МЕДИЦИНСКИЕ ДИАГНОСТИЧЕСКИЕ ТЕСТЫ

Doi: 10.21515/1990-4665-137-031
UDC 004.8

Veterinary and Zootechnics

\section{AUTOMATED SYSTEM-COGNITIVE ANALYSIS IN VETERINARY SCIENCE (ON THE EXAMPLE OF DIAGNOSTIC TESTS DEVELOPMENT)}

\author{
Lutsenko Evgeny Veniaminovich \\ Dr.Sci.Econ., Cand.Tech.Sci., professor \\ Scopus Author ID: 57191193316 \\ RSCI SPIN-code: 9523-7101 \\ prof.lutsenko@gmail.com http://lc.kubagro.ru
}

Kuban State Agrarian University, Krasnodar, Russia

\begin{abstract}
The article considers the application of Eidos intellectual technologies for implementation of developed veterinary and medical diagnostics statistical tests without programming in the convenient form for the individual and mass testing, the analysis of the results and development of the individual and group recommendations. It is possible to merge several tests in one supertest
\end{abstract}

Keywords: COMPUTERIZED SYSTEMCOGNITIVE ANALYSIS, EIDOS INTELLECTUAL SYSTEM, VETERINARY AND MEDICAL DIAGNOSTIC TESTS

В последнее время особую актуальность приобретает повышение качества (достоверности) постановки диагнозов в ветеринарии и медицине. Одним из направлений работы, направленных на достижение этой цели, является обеспечение возможности накопления профессиональных знаний экспертов в этой области в форме баз знаний систем искусственного интеллекта с обеспечением общего доступа к этим базам знаний для осуществления диагностики всех специалистов. Особенно полезно это может быть для молодых специалистов, не облагающих профессиональным опытом, достаточным для постановки высокодостоверного диагноза. Но и для опытных специалистов применение подобных диагностических систем может быть оправданным как при массовых обследованиях (диспансеризации) просто для экономии времени и сил для выявления случаев, требующих специального внимания, так и при индивидуальной диагностике, т.к. способно застраховать от грубых диагностических ошибок, цена которых может быть максимально высокой. 
Недостатка в информации о симптоматике различных заболеваний не ощущается. Однако информации о том, в какой степени тот или иной симптом характерен для данного конкретного заболевания уже меньше, а информации о диагностической ценности различных симптомов и синдромов для общей или дифференциальной диагностики различных классов заболеваний вообще недостаточно. А это значит, что конкретный врач должен сам решать задачу определения этой диагностической ценности и соответственно с учетом этого строить план получения дополнительной информации путем специальных лабораторных исследований. Ощущается также дефицит в программном инструментарии, обеспечивающем создание диагностических тестов и супертестов и их массовое применение в адаптивном режиме с сохранением и накоплением всех исходных данных и результатов с возможностью их использования дальнейшем после верификации диагноза для адаптации модели. В принципе подобные разработки есть за рубежом. Однако зарубежные разработчики никогда принципиально не продают сам инструментарий или технологию, а предоставляют лишь возможность использования продукта или результат этих технологий, т.е. самих диагностических тестов. У российских пользователей эти тесты, как правило, нелицензионные и требуют локализации (привязки к особенностям места применения), а также адаптации (учета динамики предметной области).

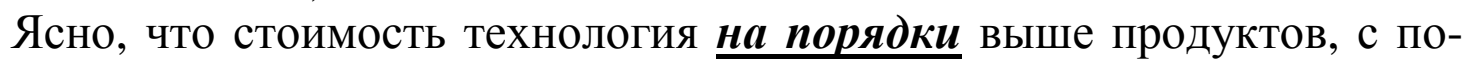
мощью нее созданных, а для локализации и адаптации продуктов необходимо владение технологией, по сути, очень сходной с разработкой этих продуктов, а значит, эти работы по локализации адаптации продуктов могут быть проведены только разработчиками этих продуктов или их представителями, в распоряжении которых есть эти технологии. Конечно, работы по локализации и адаптации ветеринарных и медицинских диагностических тестов стоят дешевле самих технологий, необходимых для их проведения, однако и эти работы являются весьма наукоемкими и достаточно дорогими. По всем этим причинам на практике, как правило, они не могут быть проведены, более того, фактически их просто некому проводить, т.к. просто нет специалистов с соответствующей компетенцией в этой области.

В данной статье предлагается содержательное рассмотрение этих проблем и их решение с помощью интеллектуальной системы «Эйдос$\mathrm{X}++»$, являющейся программным инструментарием автоматизированного системно-когнитивного анализа [1-4]. Отметим, что впервые применить систему Эйдос для реализации тестов различного назначения без программирования предложено в монографии [5] в 1996 году. Медицинские диагностические методики и даже списки симптомов в медицинских фолиантах с описаниями болезней тоже вполне можно считать слабоформализованными и не очень профессионально разработанными тестами. При этом 
уровень сложности работ соответствует требованиям к лабораторным работам по дисциплинам «Интеллектуальные информационные системы» и «Представление знаний в интеллектуальных информационных системах», которые ведут авторы в своих вузах. Мы этим хотим сказать, что наши студенты (по крайней мере, те, которые посещали занятия) вполне способны решать эти проблемы. Таким образом, проблемы с дефицитом интеллектуальных технологий и специалистов полностью снимаются.

Итак, рассмотрим технологию и методику, не требующую программирования, обеспечивающую реализацию в среде системы «Эйдос-X++» тестов различного назначения. Сделаем это на примере теста ветеринарного назначения, предназначенного для диагностики заболеваний кошек. Данный тест взят с сайта: http://mau.ru/pub/health/?p=table [6] и выбран в качестве примера потому, что он является достаточно актуальным, очень наглядным и в тоже время достаточно простым, т.к. тестовый материал и ключи представляет собой дихотомические текстовые шкалы (лингвистические переменные). С другой стороны он может служить хорошей иллюстрацией технологии и прототипом для разработки подобных тестов, но другого назначения, в ветеринарии и медицине.

Мы бы хотели отметить, что для иллюстрации интеллектуальной технологии «Эйдос» выбор того или иного конкретного диагностического теста для примера не имеет принципиального значения, т.к. статья посвящена не диагностике кошек, а технологии переноса диагностических тестов в среду системы искусственного интеллекта «Эйдос-Х++», хотя и для повышения качества диагностики кошек, мы надеемся, наша статья также может быть полезной.

Интеллектуальную технологию, необходимую для решения поставленных проблем, реализует сама универсальная автоматизированная система «Эйдос-X++» [1-4].

Эта методика включает следующие этапы (рисунок 1):

1. Подготовка Excel-файла исходных данных на основе стимульного материала и ключей (шкал) теста.

2. Автоматизированный ввод данных в систему Эйдос-X++ из Excelфайла исходных данных с помощью стандартного программного интерфейса системы (формализация предметной области, т.е. разработка классификационных и описательных шкал и градаций и обучающее выборки).

3. Синтез и верификация 3-х статистических и 7 интеллектуальных моделей. щей.

4. Определение наиболее достоверной модели и назначение ее теку-

5. Решение задач тестирования и выработки рекомендаций.

6. Исследование предметной области путем исследования ее моделей. 
Последовательность обработки данных, информации и знаний в системе Эйдос-Х++

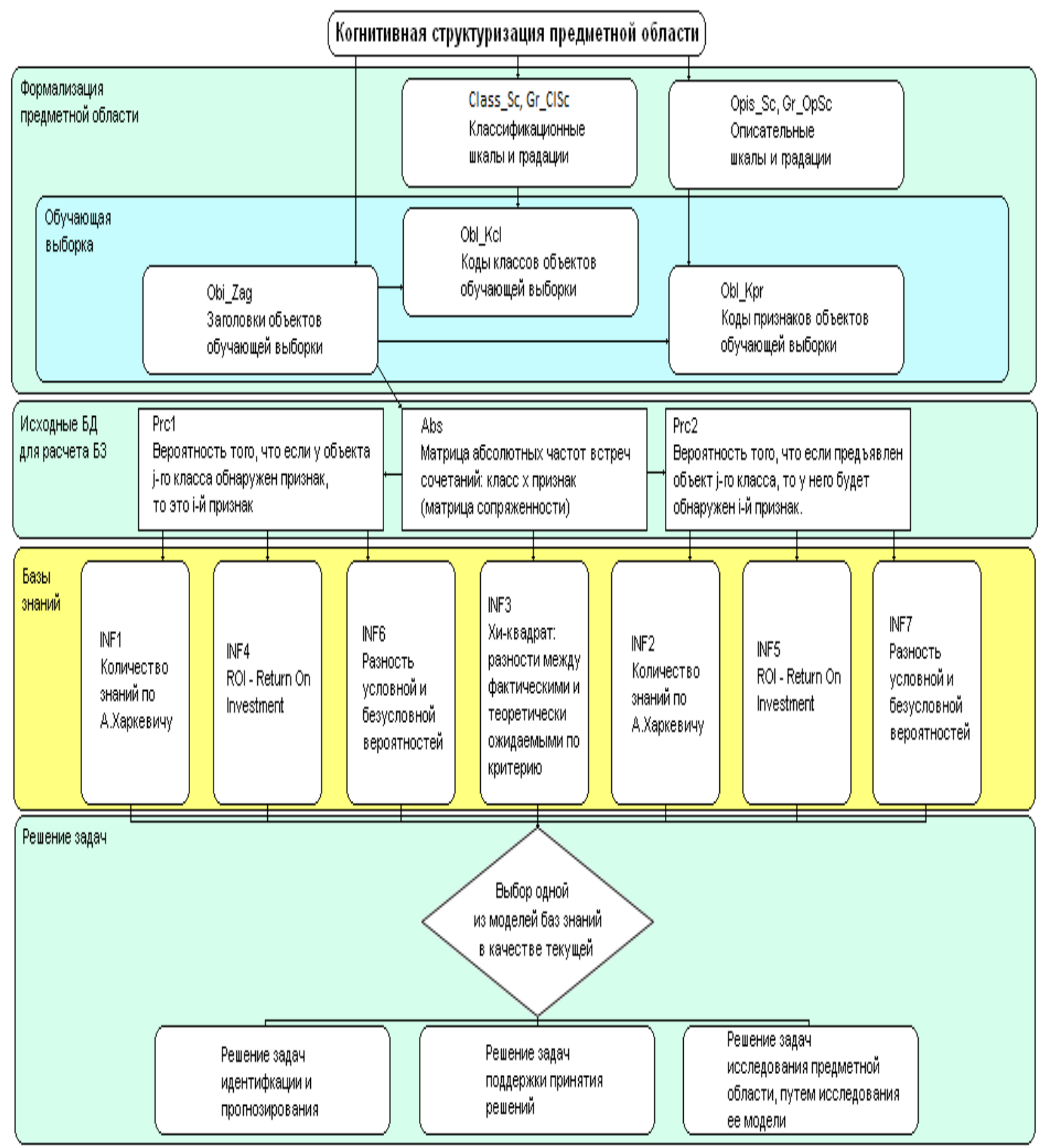

Рисунок 1. Последовательность обработки данных, информации и знаний в системе Эйдос-X++

На первом этапе подготовим Excel-файл, который может быть непосредственно введен в систему Эйдос-X++ с помощью одного из ее стандартных программных интерфейсов с внешними базами данных (режим 2.3.2.2). Для этого используем методику из 4 шагов.

На рисунке 2 приведен Help данного режима, в котором приведены требования к этому Excel-файлу, из которых вытекает данная методика. 
Помощь по режиму 2.3.2.2 аля случая Ехсеl-файлов исходных данных

Режим 2.3.2.2: Универсальный программный интерфейс импорта данных из внешней базы данных "Inp_data.xls" в системy "Эйдос-x++" и формализации предметной области.

Данный программный интерфейс обеспечивает автоматическое формирование классификационных и описательных шкал и градаций, а также обучающей и распознаваемой выборки, Т. е. формализацию предметной области, на основе XLS или XLSX-файла с исходными данными приведенного ниже стандарта.

Ф айл исходных данных должен иметь имя: INP_DATAXXLS или INP_DATAXLSX и может бьпь получен в Ехсеl-2003[2007-2010), а файл распознаваемой выборки имя: INP_RASP.XLS или INP_RASPXLSX. Файлы INP_DATAXXLS (INP_DATAXXLSX) и INP_RASP.XLS или INP_RASP.XLSX) должны находиться в папке /AIDOS-X/AID_DATA/np_data/ и имеют совершенно одинаковую структуру.

- 1-я строка этого файла должна содержать наименования колонок на любом языке, в т. ч. и русском. Эти наименования должны быть во всех колонках, при этом объединение ячеек и переносы слов не допускаются. Желательно, чтобы эти наименования были не очень длинными, Т.К. К ним еще будут добавляться интервальные числовые или текстовые значения.

- Каждая строкаэтого файла, начиная со 2-й, содержит данные об одном объекте обучающей выборки. Если Ехсе-2003, в листе может бьть до 65536 строк и до 256 колонок. В листе Exсеl-2007(2010) возможно до 1048576 строк и 16384 колонок.

- Столбцы, начиная Со 2-го, являются классификационными и описательными шкалами и могут бьпь текстового (номинального) или числового типа (с десятичными знаками после запятой).

- Столбцу присваивается числовой тип, если все значения его ячеек числового типа. Если хотя бы одно значение является текстовым (не числом, в т.4. пробелом), то столбцу присваивается текстовый тип. Это означает, что нули должны быпь указаны нулями, а не пробелами. - 1-й столбец содержит наименование источника данных длиной до 255 символов, но желательно, чтобы эти наименования были не очень длинными.

- Столбцы со 2-го по N-й являются классификационными шкалами (выходными параметрами) и содержат данные о классах [бцдущих состояниях объекта управления), к которым принадлежат объекты обучающей выборки.

- Столбцы с $\mathrm{N}+1$ по последний являются описательными шкалами (факторами] и содержат данные о признаках [значениях факторов], характеризующих объекты обучающей выборки.

- В результате работы режима формируется файл INP_NAME.TXT стаңдарта MS DOS (кириллица), в котором наименования классификационных и описательных шкал являются СТРОКАМИ. Система формирует классификационные и описательные шкалы и градации. Для этого в каждом числовом столбце система находит минимальное и максимальное числовые значения и формирует заданное количество числовых интервалов, после чего числовые значения заменяются их интервальными значениями. В текстовых столбцах система находит уникальные текстовые значения. Каждое ЧНИКАЛЬНОЕ интервальное числовое или текстовое значение считается градацией классификационной или описательной шкалы, характеризующей объект. С их использованием генерируется обучающая выборка, каждый объект которой соответствует одной строке файла исходных данных NP_DATA и содержит коды классов, соответствующие фактам совпадения числовых или уникальных текстовых значений классов с градациями классификационных шкал и кады признаков, соответствующие фактам совпадения числовых или уникальных текстовых значений признаков с градациями описательных шкал.

- Распознаваемая выборка формируется на основе файла INP_RASP аналогично, за исключением того, что классификационные и описательные шкалы и градации не создаются, а используются ранее созданные в модели, и базы распознаваемой выборки могут не включать коды классов, если столбцы классов в файле INP_RASP были пустыми. Структура файла INP_RASP должна быпь такая же, как INP_DATA, т.е. они должны ПОЛНОСТЬЮ совпадать по столбцам, но могцт иметь разное количество строк.

Принцип организации таблицы исходных данных:

\begin{tabular}{|c|c|c|c|c|c|c|}
\hline $\begin{array}{l}\text { Наименование объекта } \\
\text { обучающей выборки }\end{array}$ & $\begin{array}{l}\text { Наименование 1-й } \\
\text { классификационной } \\
\text { шкалы }\end{array}$ & $\begin{array}{l}\text { Наименование 2-й } \\
\text { классификационной } \\
\text { шкалы }\end{array}$ & $\ldots$ & $\begin{array}{l}\text { Наименование 1-й } \\
\text { описательной } \\
\text { шкалы }\end{array}$ & $\begin{array}{l}\text { Наименование 2-й } \\
\text { описательной } \\
\text { шкалы }\end{array}$ & $\ldots$ \\
\hline 1-й объект обучающей выборки & Значение показателя & 3начение показателя & $\ldots$ & $\begin{array}{l}\text { Значение } \\
\text { показателя }\end{array}$ & $\begin{array}{l}\text { Значение } \\
\text { показателя }\end{array}$ & $\ldots$ \\
\hline 2-й объект обучающей выборки & Значение показателя & Значение показателя & $\ldots$ & $\begin{array}{l}\text { Значение } \\
\text { показателя }\end{array}$ & $\begin{array}{l}\text { Значение } \\
\text { показателя }\end{array}$ & $\ldots$ \\
\hline$\ldots$ & $\ldots$ & $\ldots$ & $\ldots$ & $\ldots$ & $\ldots$ & $\ldots$ \\
\hline
\end{tabular}

Рисунок 2. Неlp программного интерфейса системы Эйдос-X++ с вешними базами данных 2.3.2.2.

Шаг 1-й. Откроем на сайте http://mau.ru/pub/health/table1.php таблицу, которая на называется: «Таблица симптомов заболеваний кошек».

Конечно, эта таблица названа на сайте несколько неверно, т.к. является не только таблицей симптомов, но и содержат нозологические образы, т.е. сами названия заболеваний или диагнозов, а также взаимосвязь между симптомами и заболеваниями, указанную в форме символов.

Шаг 2-й. Затем скопируем эту таблицу через буфер обмена в MS Excel начиная с ячейки A1. Потом уберем объединение ячеек в названиях 
колонок и сделаем названия вертикальными. В результате получим таблицу исходных данных (таблица 1):

Таблица 1 - Исходная таблица данных с сайта: http://mau.ru/pub/health/table1.php для создания ветеринарного диагностического теста*

Симптом заболевания
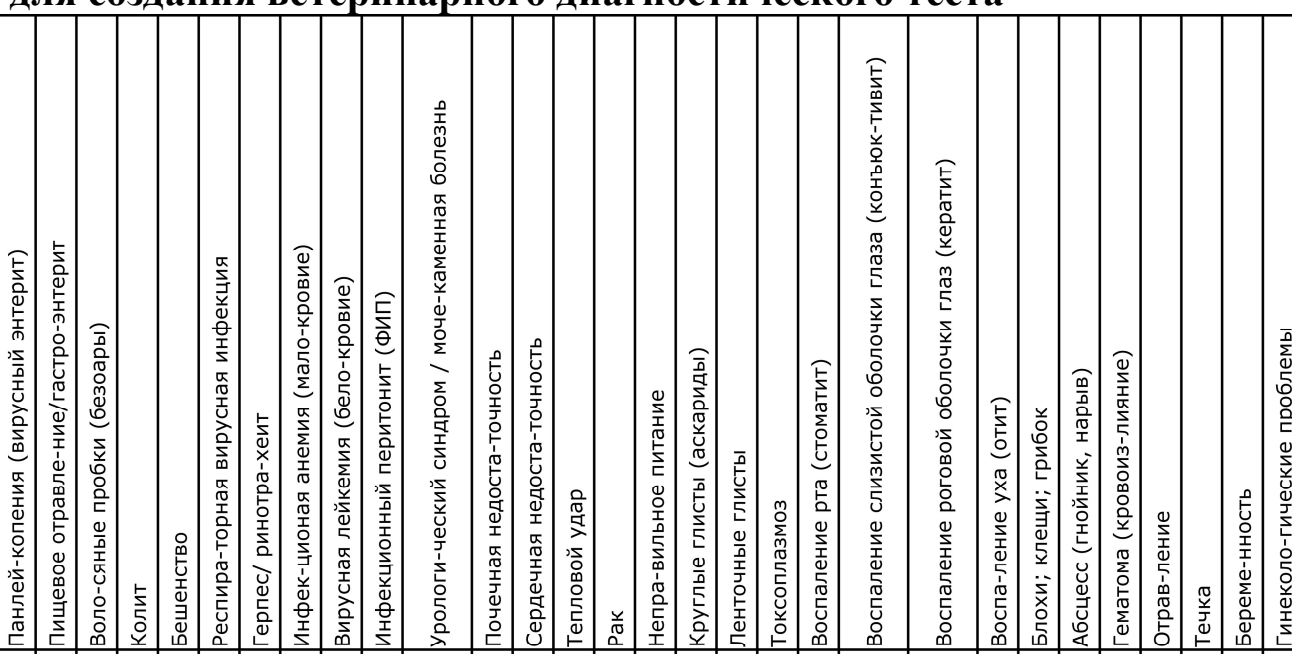

Рвота

\begin{tabular}{l|c|c|c|c|c|c|c|c|c|c|c|}
\hline Диарея(понос) & $!$ & $!$ & $!$ & $! !$ & & & & & $?$ & $?$ & ? \\
\hline
\end{tabular}

\begin{tabular}{|l|l|l|l|l|l|l|l|l|l|l|l|l|l|l|l|}
\hline Запор & & & & & \\
\hline
\end{tabular}

Кровь в кале

Отсутствие аппетита

Чрезмерная жажда

Ненормальное

мочеиспускание

Слюнотечение

Кашель и чихание

Выпячивание третьего

века

Выделения из глаз

Выделения из ушей

Выделения из носа

Анальные выделения

Генитальные

выделения

Обезвоживание

Потеря веса

Бледность десен

Затредненное дыхание

Потеря сознания

Паралич

Внезапная смерть

Лихорадка(высокая

температура)

Пониженная

температура

Вздутие живота

\begin{tabular}{ll|l|l|l}
\hline & $?$ & $?$ & \\
\hline & & & $!$
\end{tabular}

\begin{tabular}{l|l|l|}
\hline$!$ & $!$ & $!$
\end{tabular}

\begin{tabular}{llllll|l|l}
\hline & & $!$ & $!$ & $!$ & $!$
\end{tabular}

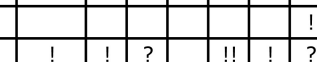

!! $1 !$

\begin{tabular}{lllllll} 
& & & & & & \\
\hline
\end{tabular}

Вздутие под кожей

Раздражение кожи

Поражение

кожи/слизистых/рогов

ицы

Потеря шерсти

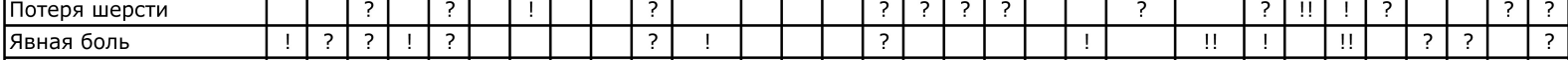

Хромота

Ненормальное

поведение

Шок

Отсутствие явных

симптомов

* Источник: http://mau.ru/pub/health/?p=table 
Шаг 3-й. На этом шаге мы приводим таблицу 1 к виду, необходимому для того, что она воспринималась универсальным программным интерфейсом системы Эйдос с внешними базами данных (эти требования приведены на рисунке 2). Для этого необходимо транспонировать таблицу 1 , чтобы в строках были классы (заболевания), а в колонках симптомы, а также добавить еще один столбец с информацией об источнике данных (для этого мы используем колонку с классами, т.е. диагнозами).

Шаг 4-й. На сайте http://mau.ru/pub/health/table1.php говорится о различной характерности диагностических признаков (симптомов), приведенных в таблице 1 , для постановки различных диагнозов:

\section{Условные обозначения:}

!! - главные, наиболее характерные симптомы, имеющие место всегда при данном заболевании или состоянии;

! - симптомы, обычно наблюдающиеся при данном заболевании, но не имеющие решающего значения;

? - второстепенные симптомы

То, что признаки должны иметь различную характерность видно уже из того (см. таблицу 1), что одни признаки встречаются у многих заболеваний, тогда как другие только у нескольких, один заболевания описываются большим количеством симптомов, а другие гораздо меньшим.

Однако на сайте это различие имеет качественньй уровень и выражено в текстовом виде обозначениями: «!!», «!» и «?». В системе Эйдос$\mathrm{X}++$ эта степень характерности симптома для заболевания выражена количественно причем система определяет ее сама. Кроме того в системе Эйжос-X++ расчет значимости признаков (т.е. средней характерности по всем заболеваниям) - это одна из основных особенностей применяемых в системе интеллектуальных моделей и не требует ввода разных вариантов симптомов, если у них различная характерность. Мы еще рассмотрим этот вопрос на 6-м этапе методики.

Поэтому заменяем в транспонированной таблице исходных данных все «!!» на «*», затем все «!» на «*» и все « ?» ${ }^{1}$ на «*». После этого таблица 1 приобретает вид, представленный в таблице 2.

Колонка классов выделена желтым фоном.

\footnotetext{
${ }^{1}$ Символ « » перед знаком вопроса используется для экранирования его как спецсимвола, используемого для обозначения любого одного символа, и для рассмотрения его как обычного символа
} 
Таблица 2 - Таблица исходных данных для ввода в систему Эйдос-X++ с помощью стандартного программного интерфейса с внешним базами данных

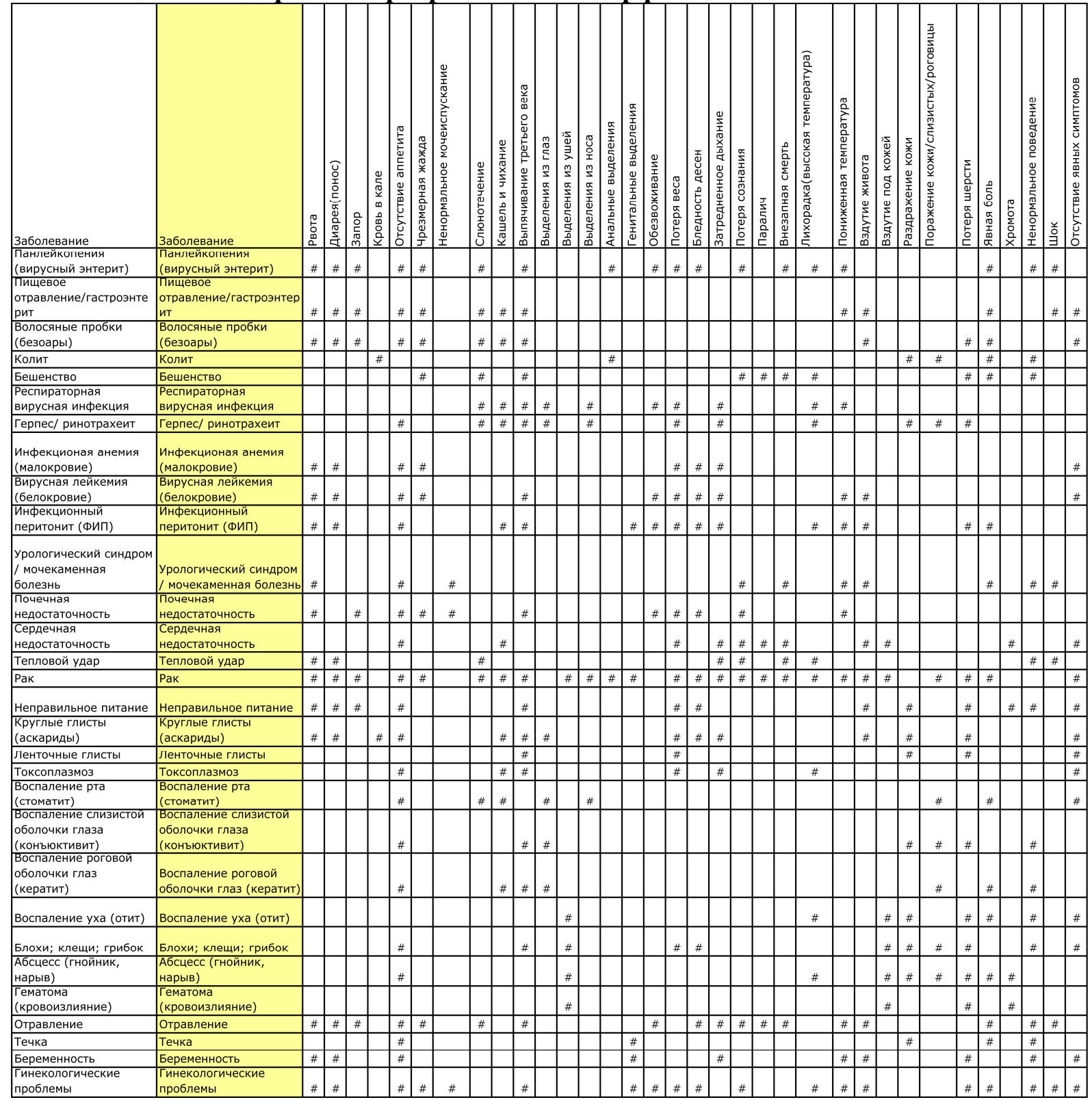

На первый взгляд данная методика может выглядеть несколько усложненной, однако реализация на компьютере этих шагов занимает буквально считанные минуты и фактически осуществляется очень просто.

На втором этапе вводим Excel-файл исходных данных в систему «Эйдос-Х++» с помощью программного интерфейса 2.3.2.2 с параметрами, приведенными на рисунке 3. Обратим внимание на то, что, знак диез «\#» обозначает в таблице 2 наличие симптома у заболевания, а пробел - его отсутствие. И первое, и второе мы считаем значимой информацией, поэтому на экранной форме, приведенной на рисунке 3 справа вверху задана опция, считать нуди и пробелы значениями данных. 
2.3.2.2. Универсальный программный интерфейс импорта данных в систему "ЭЙдОС-Х++"

Автоматическая формализация предметной области: генерация классификационных и описательных шкал и градаций, а также обучающей и распознаваемой выборки на основе базы исходных данных: "Inp_data"

-Задайте тип файла искодных данных: "Inp_data":

c XLS - MS Excel-2003

C XLSX-MS Excel-2007(2010]

C DBF - DBASE IV (DBF/NTX)

$C$ CSV - Comma-Separated Values

Стандарт XLS-файла

Стандарт DBF-файла

Стандарт CSV-файла

Задайте диапазон столбцов классификационных шкал:

Начальный столбец классификационных шкал:

Конечный столбец классификационных шкал:

Задайте режим:

(- Формализации предметной области (на основе "Inp_data")

ᄃ Генерации распознаваемой выборки (на основе "Inp_rasp")
Запайте параметры:-

C Нули и пробелы считать ОТСЧТСТВИЕМ данных

(* Нули и пробелы считать ЗНАЧЕНИЯМИ данных

$Г$ Создавать БД средних по классам "Inp_dav. dbf" ? Требования к файлу искодных данных

Задайте диапазон столбцов описательных шкал:

Начальный столбец описательных шкал:

Конечный столбец описательных шкал:

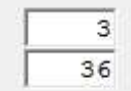

Задайте способ выбора размера интервалов:

- Равные интервалы с разным числом наблюдений

С Разные интервалы с равным числом наблюдений

-Задание параметров формирования сценариев или способа интерпретации текстовых полей "Inp_data":

6. Не применять сценарный метод АСК-анализа

Г Применить сценарный метод АСК-анализа

Г Применить спец.интерпретацию текстовых полей классов

Г Применить спец.интерпретацию текстовых полей признаков

Параметры интерпретации значении́ текстовых полеи́ "Inp_data":

Интерпретация ТХТ-полей классов:

Значения полей текстовых классификационных шкал файла

исходных данных "Inp_data" рассматриваются как целое
Интерпретация ТХТ-полей признаков:

Значения полей текстовых описательных шкал файла

исходных данных "Inp_data" рассматриваются как целое

Какие наименования ГРАДАЦИЙ числовых шкал использовать:

- Только интервальные числовые значения

[например: "1/3-\{59873.0000000, 178545.6666667\}")

С Только наименования интервальных числовых значений (например: "Минимальное")

С И интервальные числовые значения, и их наименования (например: "Минимальное: 1/3-\{59873.0000000, 178545.6666667\}")

$\underline{\underline{a}}$ Eancel

Рисунок 3. Вид первого окна программного интерфейса системы Эйдос-X++ с вешними базами данных 2.3 .2 .2 с параметрами для ввода обучающей выборки

Для этого используем методику, приведенную ниже и основанную, как и предыдущая, на требованиях, приведенных в Help режима 2.3.2.2 (рисунок 2). Эта методика включает следующие 4 шага.

Шаг 1-й. Копируем приведенный выше Excel-файл в папку: «Место расположения системы на диске»\AID_DATAlInp_datal с именем "Inp_data.xls".

Шаг 2-й. Запускаем режим 2.3.2.2 системы Эйдос-Х++ и задаем в окне, представленном на рисунке 3 , следующие параметры:

- тип файла исходных данных: XLS-MS Excel-2003;

- нули и пробелы считаются отсутствием данных;

- диапазон колонок классификационных шкал: 2-2; 
- диапазон колонок описательных шкал: 3-36;

- формализация предметной области (файл исходных данных Inp_data.xls);

- равные интервалы с разным числом наблюдений;

- сценарный метод прогнозирования СК-анализа не применять.

Шаг 3-й. После нажатия кнопки ОК появляется отображение процесса открытия и загрузки Excel-файла, а затем появляется второе окно режима 2.3.2.2, представляющее собой специальный калькулятор, позволяющий при наличии числовых классификационных и/или описательных шкал подбирать количество интервалов (градаций) в числовых шкалах (рисунок 4):

\begin{tabular}{|c|c|c|c|c|c|c|}
\hline \multicolumn{6}{|c|}{ () 2.3.2.2. Задание размерности модели системы "ЭйдОС-X++" } & \begin{tabular}{|l|l|l|} 
& $\square$ & $X$ \\
\end{tabular} \\
\hline \multirow{2}{*}{\multicolumn{7}{|c|}{$\begin{array}{l}\text { ИНФОРМАЦИЯ О РАЗМЕРНОСТИ МОДЕЛИ } \\
\text { СЧММарНое количество градаций классификационных и описательных шкал: [30 × 68] }\end{array}$}} \\
\hline & & & & & & \\
\hline Tип шкалы & $\begin{array}{r}\text { Количество } \\
\text { класоифи: } \\
\text { кационнык } \\
\text { шкал }\end{array}$ & $\begin{array}{r}\text { Кояичество } \\
\text { грапаций } \\
\text { классифи } \\
\text { кационных }\end{array}$ & $\begin{array}{r}\text { Cреднеe } \\
\text { kоличество } \\
\text { градаций } \\
\text { на knacc. ukany }\end{array}$ & $\begin{array}{r}\text { Количество } \\
\text { описательных } \\
\text { щкал }\end{array}$ & $\begin{array}{r}\text { Колинество } \\
\text { градаций } \\
\text { описательнык } \\
\text { шкал }\end{array}$ & $\begin{array}{r}\text { Среднее } \\
\text { количество } \\
\text { градаций } \\
\text { на опис. шкалу }\end{array}$ \\
\hline Числовые & 0 & 0 & 0,00 & 0 & 0 & 0,00 \\
\hline Текстовые & 1 & 30 & 30,00 & 34 & 68 & 2,00 \\
\hline ВСЕГО: & 1 & 30 & 30,00 & 34 & 68 & 2,00 \\
\hline \multicolumn{7}{|c|}{ - Задайте число интервалов (градаций) в шкале: } \\
\hline \multicolumn{2}{|c|}{ Пересчитать шкалы и градации } & & & & \multicolumn{2}{|c|}{ Выйти на создание модели } \\
\hline
\end{tabular}

Рисунок 4. Вид второго окна программного интерфейса системы Эйдос-X++ с вешними базами данных 2.3.2.2.

В данном случае числовые шкалы отсутствуют, и число градаций задавать нет необходимости и возможности.

Шаг 4-й. При клике на кнопке «Выйти на создание модели» появляется отображение стадии процесса формализации предметной области (рисунок 5):

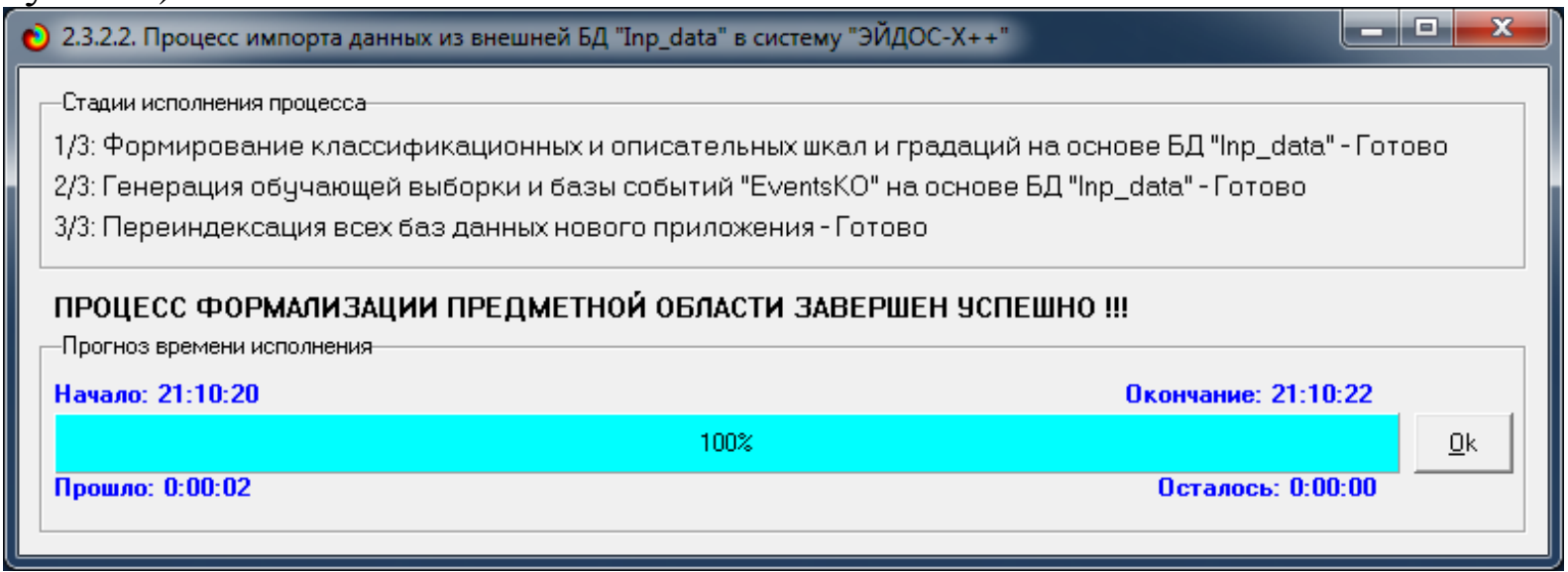

Рисунок 5. Вид третьего окна программного интерфейса системы Эйдос-X++ с вешними базами данных 2.3.2.2. 
Таким образом, на втором этапе на основе Excel-файла исходных данных создаются классификационные и описательные шкалы и градации, а потом с их использованием и обучающая выборка, т.е. осуществляется формализация предметной области (рисунки $6,7,8$ ):

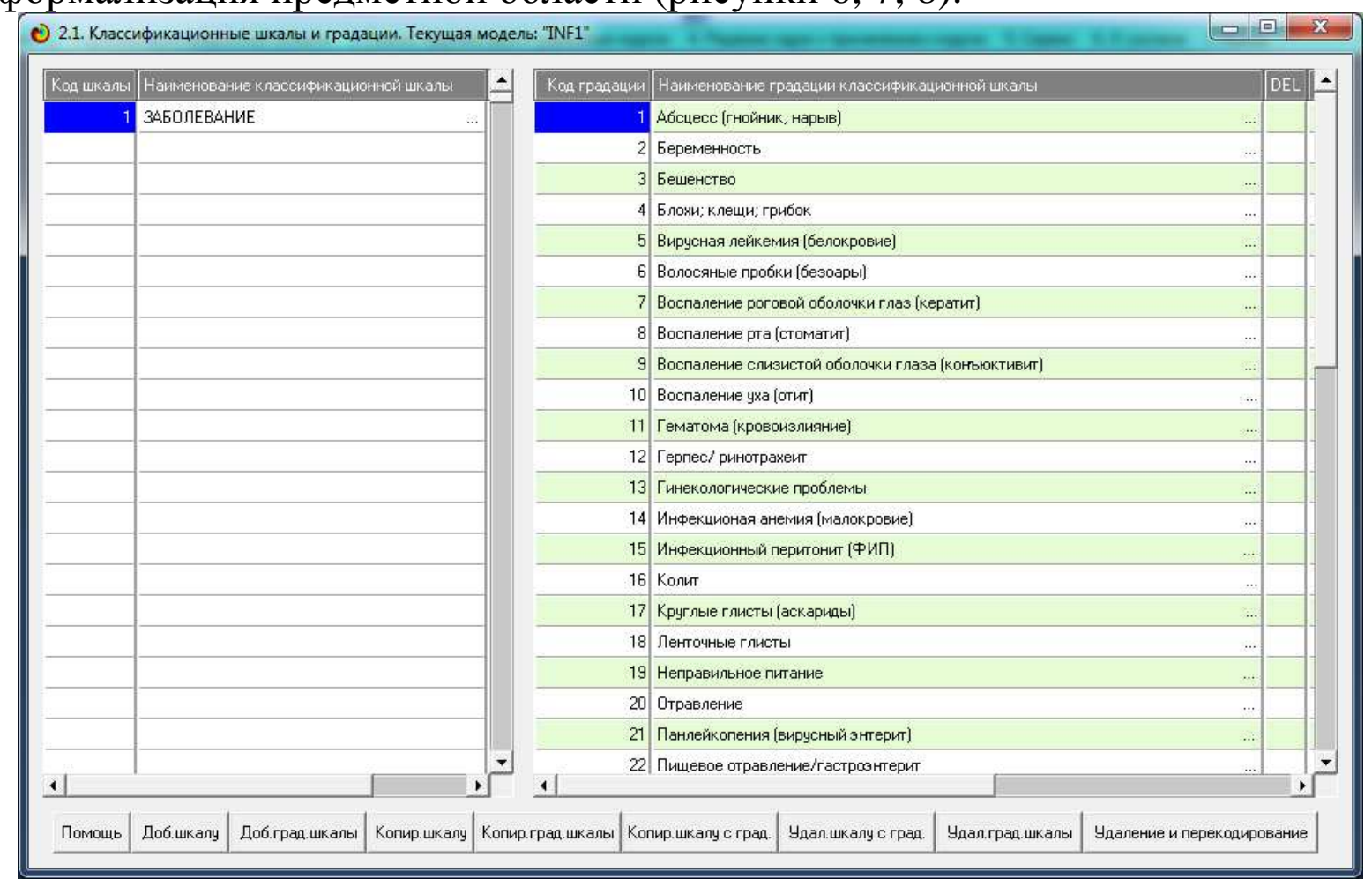

Рисунок 6. Экранная форма режима 2.1 просмотра и корректировки классификационных шкал и градаций системы Эйдос-X++ (фрагмент)

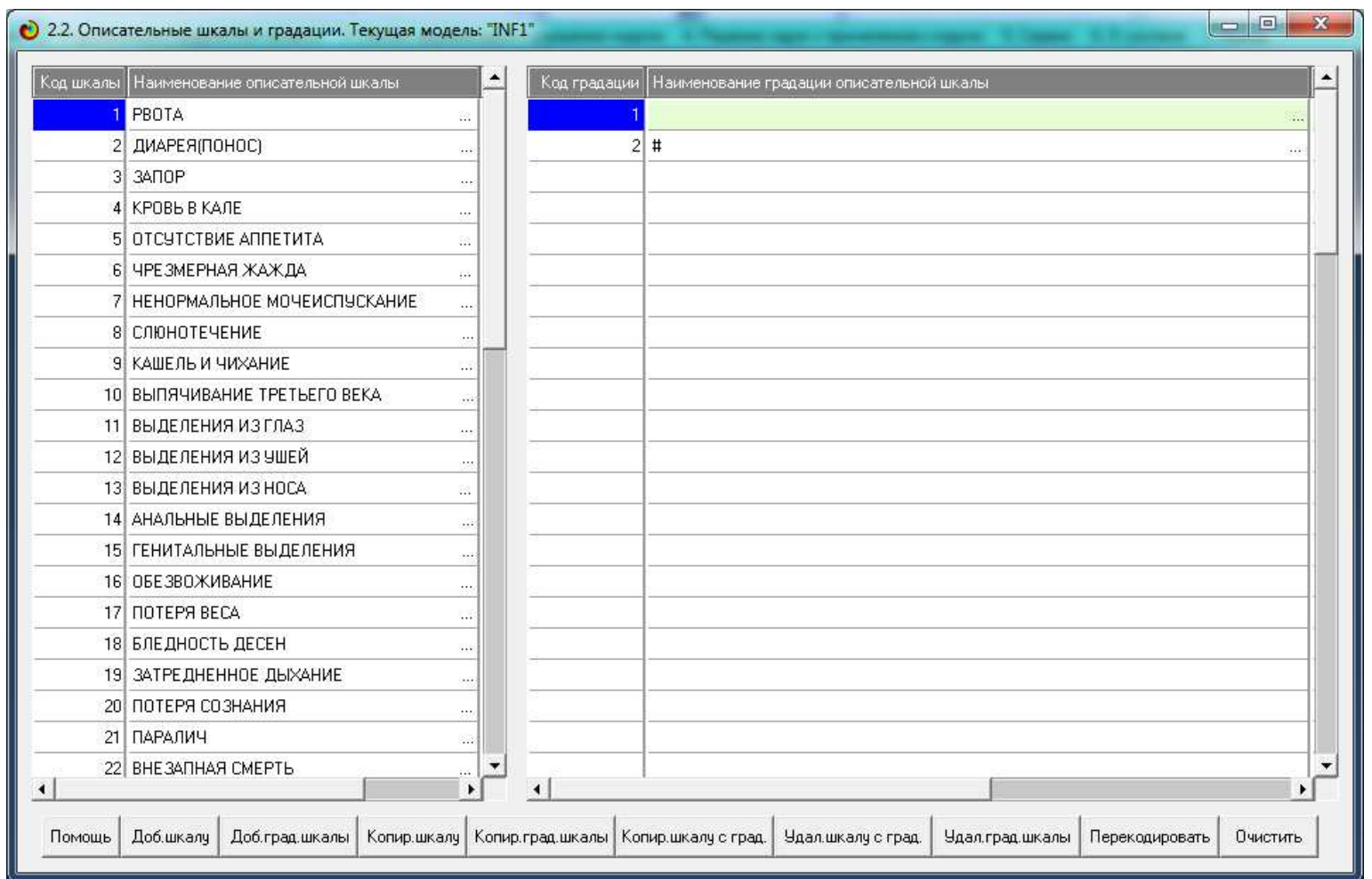

Рисунок 7. Экранная форма режима 2.2 просмотра и корректировки описательных шкал и градаций системы Эйдос-X++ (фрагмент) 

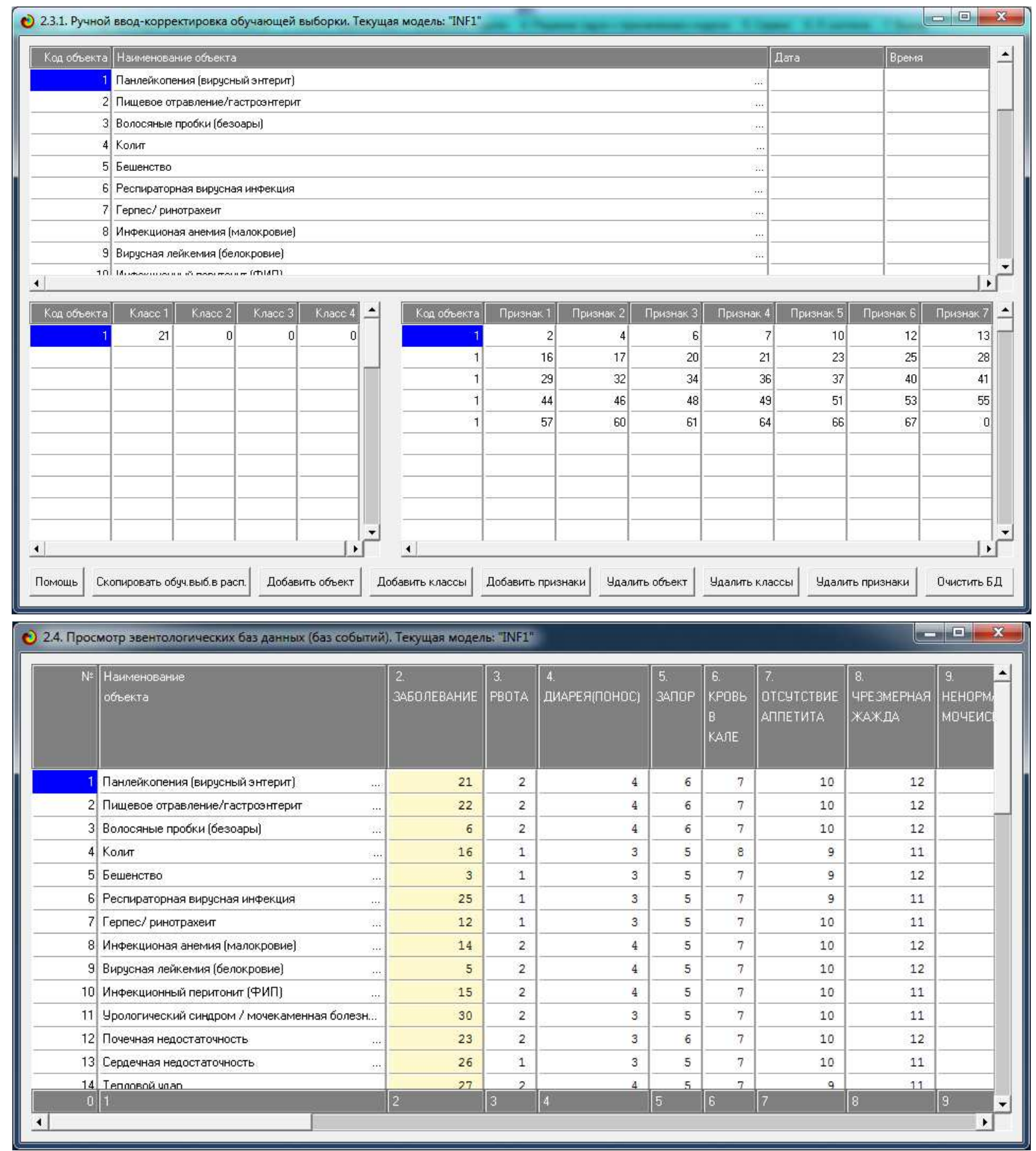

Рисунок 8. Экранная форма режима 2.3.1 просмотра и корректировки обучающей выборки системы Эйдос-X++ (фрагмент)

На третьем этапе запускается режим 3.5 системы Эйдос-X++, который обеспечивает синтез и верификацию 3 статистических и 7 системнокогнитивных моделей (моделей знаний). Окно задания параметров данного режима приведено на рисунке 9 (вид по умолчанию). 


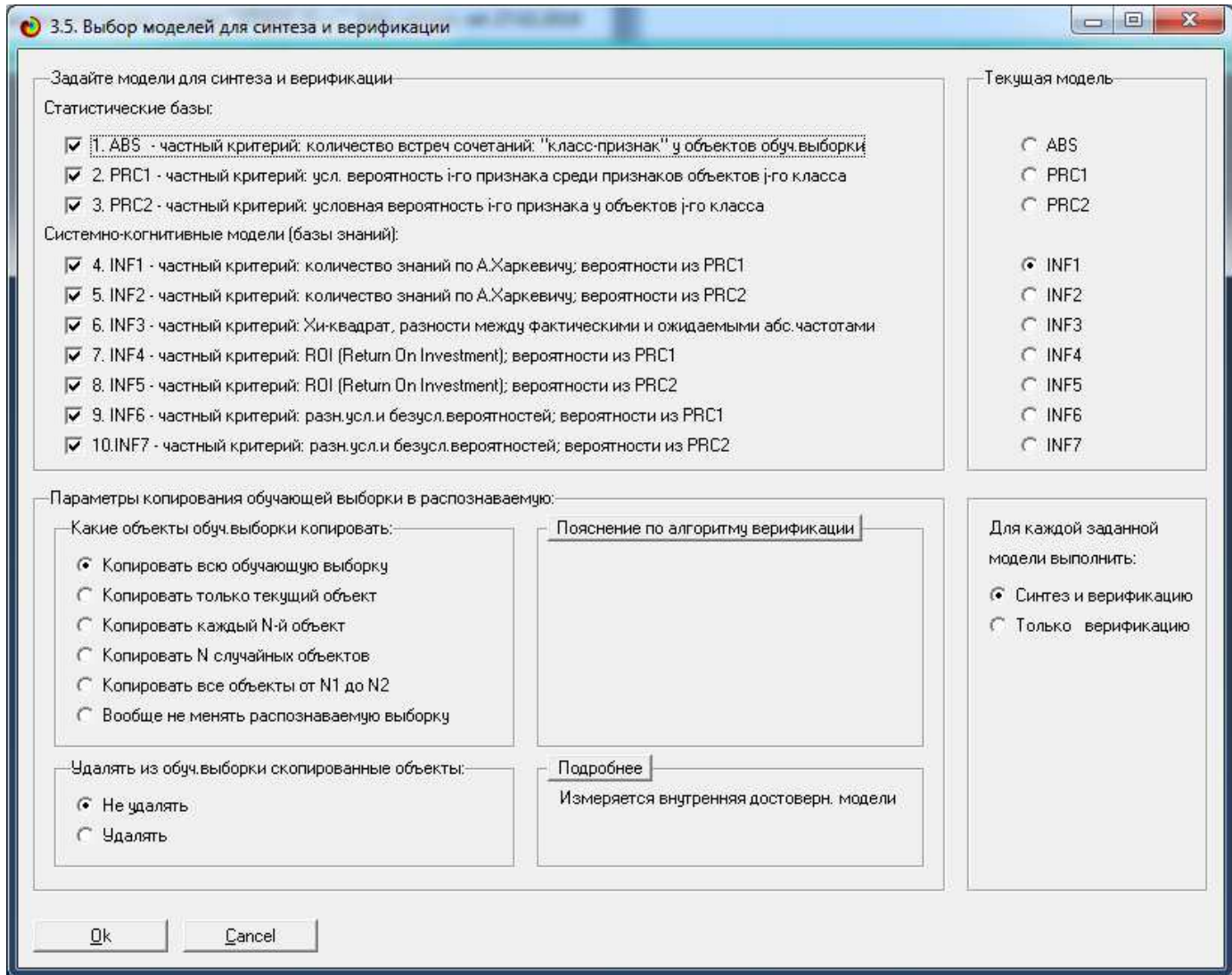

Рисунок 9. Вид окна задания параметров режима 3.5 системы Эйдос-X++

На рисунке 10 приведено окно отображения стадии процесса исполнения данного режима (на рисунке вид по окончании работы режима).

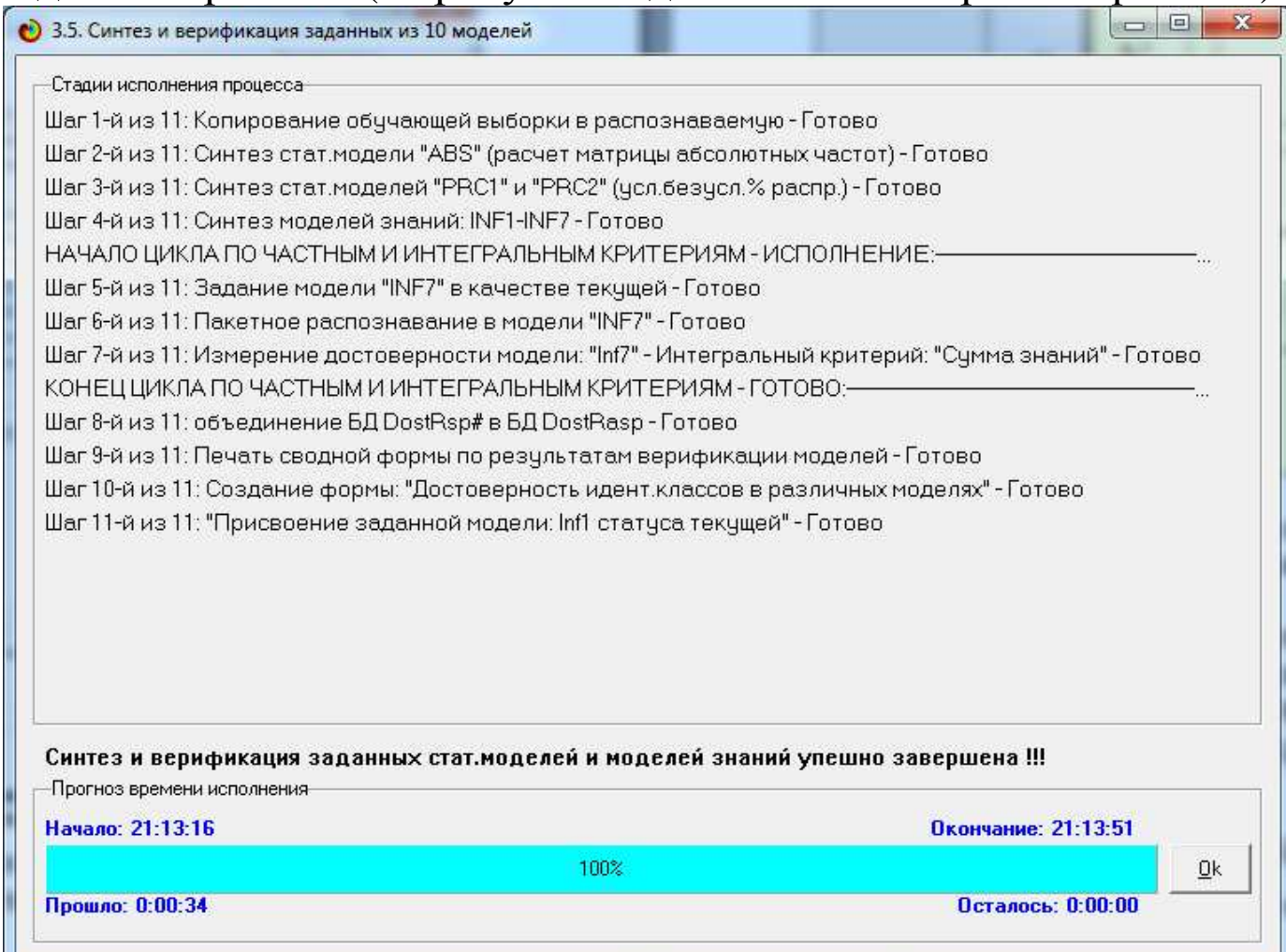

Рисунок 10. Окна отображения стадии исполнения режима 3.5 системы Эйдос-X++ (вид по окончании работы режима) 
Видно, что процесс синтеза и верификации 3 статистических и 7 системно-когнитивных моделей предметной области занял 34 секунды машинного времени.

Ниже дано краткое математическое описание расчетов, проводимых в системе «Эйдос» при синтезе и верификации моделей.

Непосредственно на основе эмпирических данных рассчитывается матрица абсолютных частот (таблица 1).

Таблица 3 - Матрица абсолютных частот

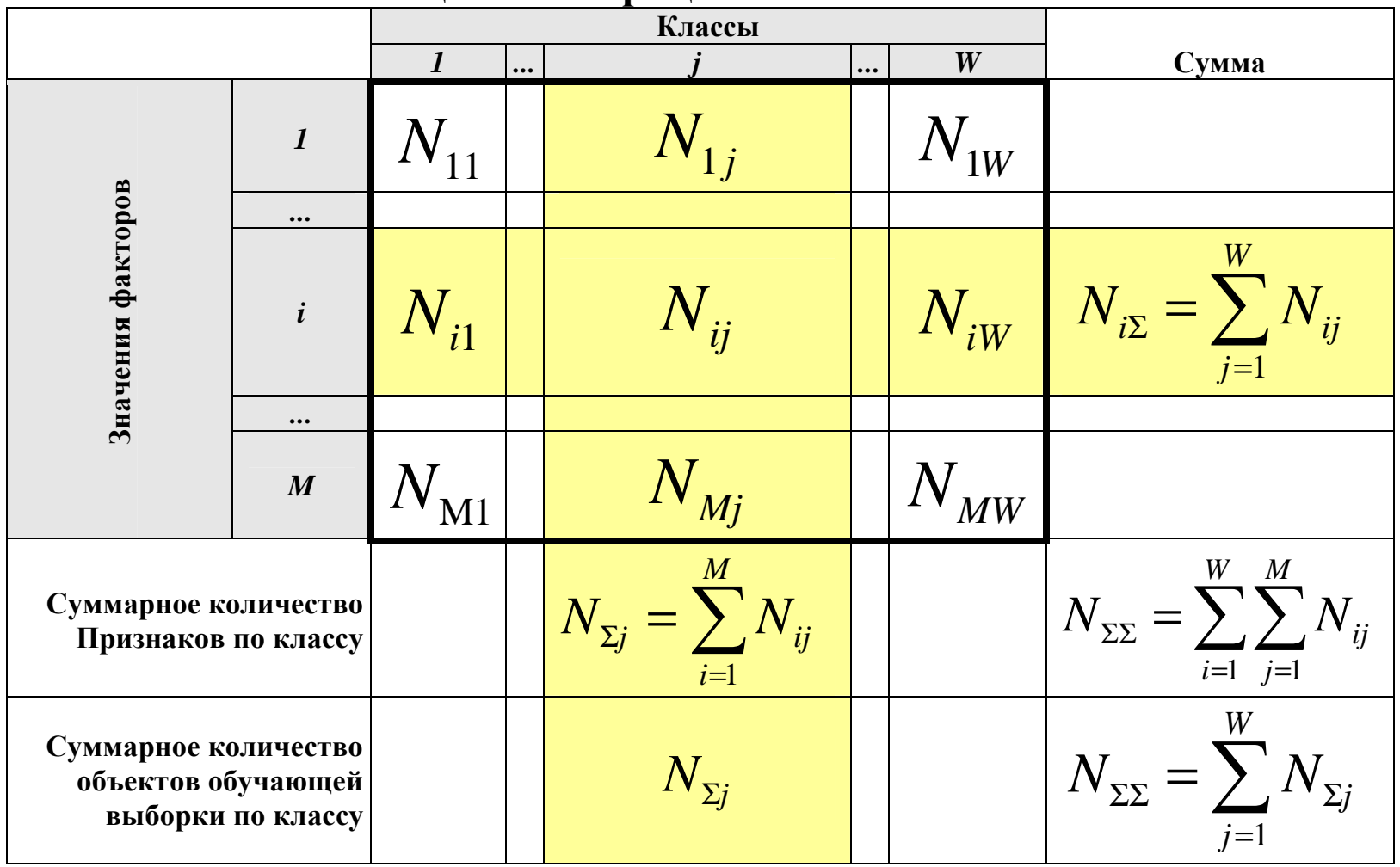

На ее основе рассчитываются матрицы условных и безусловных процентных распределений (таблица 2).

Отметим, что в АСК-анализе и его программном инструментарии интеллектуальной системе «Эйдос» используется два способа расчета матриц условных и безусловных процентных распределений:

1-й способ: в качестве $N_{\Sigma j}$ используется суммарное количество признаков по классу;

2-й способ: в качестве $N_{\Sigma j}$ используется суммарное количество объектов обучающей выборки по классу. 
Таблица 4 - Матрица условных и безусловных процентных распределений

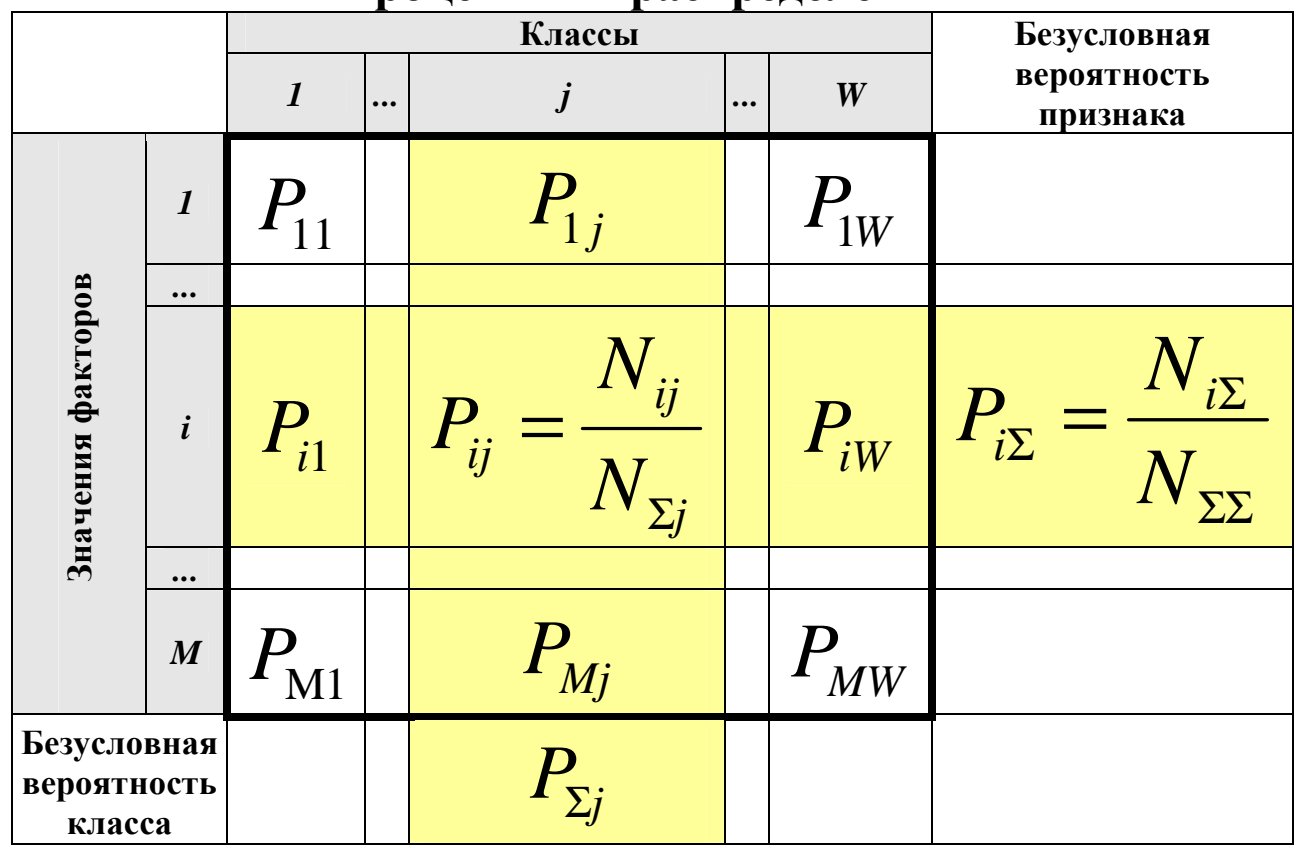

Затем на основе таблицы 2 с использованием частных критериев, приведенных таблице 3 рассчитываются матрицы системно-когнитивных моделей (таблица 4).

\section{Таблица 5 - Различные аналитические формы} частных критериев знаний

\begin{tabular}{|c|c|c|}
\hline \multirow[b]{2}{*}{$\begin{array}{c}\text { Наименование модели знаний } \\
\text { и частный критерий }\end{array}$} & \multicolumn{2}{|c|}{ Выражение для частного критерия } \\
\hline & $\begin{array}{c}\text { через } \\
\text { относительные часто- } \\
\text { ты }\end{array}$ & $\begin{array}{c}\text { через } \\
\text { абсолютные частоты }\end{array}$ \\
\hline ABS, матрица абсолютных частот & --- & $N_{i j}$ \\
\hline $\begin{array}{l}\text { PRC1, матрица условных и без- } \\
\text { условных процентных распределе- } \\
\text { ний, в качестве } N_{\Sigma j} \text { используется } \\
\text { суммарное количество признаков по } \\
\text { классу }\end{array}$ & --- & $P_{i j}=\frac{N_{i j}}{N_{\Sigma j}}$ \\
\hline $\begin{array}{l}\text { PRC2, матрица условных и без- } \\
\text { условных процентных распределе- } \\
\text { ний, в качестве } N_{\Sigma j} \text { используется } \\
\text { суммарное количество объектов } \\
\text { обучающей выборки по классу }\end{array}$ & --- & $P_{i j}=\frac{N_{i j}}{N_{\Sigma j}}$ \\
\hline $\begin{array}{l}\text { INF1, частный критерий: количе- } \\
\text { ство знаний по А.Харкевичу, } 1-\text { й } \\
\text { вариант расчета вероятностей: } N j- \\
\text { суммарное количество признаков по } \\
\text { j-му классу. Вероятность того, что } \\
\text { если у объекта ј-го класса обнару- }\end{array}$ & $I_{i j}=\Psi \times \log _{2} \frac{P_{i j}}{P_{i}}$ & $I_{i j}=\Psi \times \log _{2} \frac{N_{i j} N}{N_{i} N_{j}}$ \\
\hline
\end{tabular}




\begin{tabular}{|c|c|c|}
\hline жен признак, то это і-й признак & & \\
\hline $\begin{array}{l}\text { INF2, частный критерий: количе- } \\
\text { ство знаний по А.Харкевичу, 2-й } \\
\text { вариант расчета вероятностей: } N j- \\
\text { суммарное количество объектов по } \\
\text { j-му классу. Вероятность того, что } \\
\text { если предъявлен объект ј-го класса, } \\
\text { то у него будет обнаружен і-й при- } \\
\text { знак. }\end{array}$ & $I_{i j}=\Psi \times \log _{2} \frac{P_{i j}}{P_{i}}$ & $I_{i j}=\Psi \times \log _{2} \frac{N_{i j} N}{N_{i} N_{j}}$ \\
\hline $\begin{array}{l}\text { INF3, частный критерий: Хи- } \\
\text { квадрат: разности между фактиче- } \\
\text { скими и теоретически ожидаемыми } \\
\text { абсолютными частотами }\end{array}$ & --- & $I_{i j}=N_{i j}-\frac{N_{i} N_{j}}{N}$ \\
\hline $\begin{array}{l}\text { INF4, частный критерий: ROI - } \\
\text { Return On Investment, 1-й вариант } \\
\text { расчета вероятностей: } \mathrm{Nj} \text { - суммар- } \\
\text { ное количество признаков по } j \text {-му } \\
\text { классу }\end{array}$ & $I_{i j}=\frac{P_{i j}}{P_{i}}-1=\frac{P_{i j}-P_{i}}{P_{i}}$ & $I_{i j}=\frac{N_{i j} N}{N_{i} N_{j}}-1$ \\
\hline $\begin{array}{l}\text { INF5, частный критерий: ROI - } \\
\text { Return On Investment, 2-й вариант } \\
\text { расчета вероятностей: } N j \text { - суммар- } \\
\text { ное количество объектов по } j \text {-му } \\
\text { классу }\end{array}$ & $I_{i j}=\frac{P_{i j}}{P_{i}}-1=\frac{P_{i j}-P_{i}}{P_{i}}$ & $I_{i j}=\frac{N_{i j} N}{N_{i} N_{j}}-1$ \\
\hline $\begin{array}{l}\text { INF6, частный критерий: разность } \\
\text { условной и безусловной вероятно- } \\
\text { стей, } 1 \text {-й вариант расчета вероятно- } \\
\text { стей: } N j \text { - суммарное количество } \\
\text { признаков по j-му классу }\end{array}$ & $I_{i j}=P_{i j}-P_{i}$ & $I_{i j}=\frac{N_{i j}}{N_{j}}-\frac{N_{i}}{N}$ \\
\hline $\begin{array}{l}\text { INF7, частный критерий: разность } \\
\text { условной и безусловной вероятно- } \\
\text { стей, 2-й вариант расчета вероятно- } \\
\text { стей: } N j \text { - суммарное количество } \\
\text { объектов по j-му классу }\end{array}$ & $I_{i j}=P_{i j}-P_{i}$ & $I_{i j}=\frac{N_{i j}}{N_{j}}-\frac{N_{i}}{N}$ \\
\hline
\end{tabular}

Обозначения к табличе 3:

$i$ - значение прошлого параметра;

j - значение будущего параметра;

$N_{i j}$ - количество встреч j-го значения будущего параметра при i-м значении прочлого параметра;

$M$ - суммарное число значений всех прошльх параметров;

$W$ - суммарное число значений всех будущих параметров.

$N_{i}$ - количество встреч і-м значения прошлого параметра по всей выборке;

$N_{j}$ - количество встреч j-го значения будущего параметра по всей выборке;

$N$ - количество встреч $j$-го значения будущего параметра при $i$-м значении промлого параметра по всей выборке.

$I_{i j}$ - частный критерий знаний: количество знаний в факте наблюдения $і$-го значения прошлого параметра о том, что объект перейдет в состояние, соответствующее јму значению будущего параметра; 
$\Psi$ - нормировочный коэффициент [1], преобразующий количество информачии в формуле А.Харкевича в биты и обеспечивающий для нее соблюдение приниипа соответствия с формулой Р.Хартли;

$P_{i}$ - безусловная относительная частота встречи $і$-го значения прошлого параметра $в$ обучающей выборке;

$P_{i j}$ - условная относительная частота встречи $і$-го значения прошлого параметра при j-м значении будущего параметра .

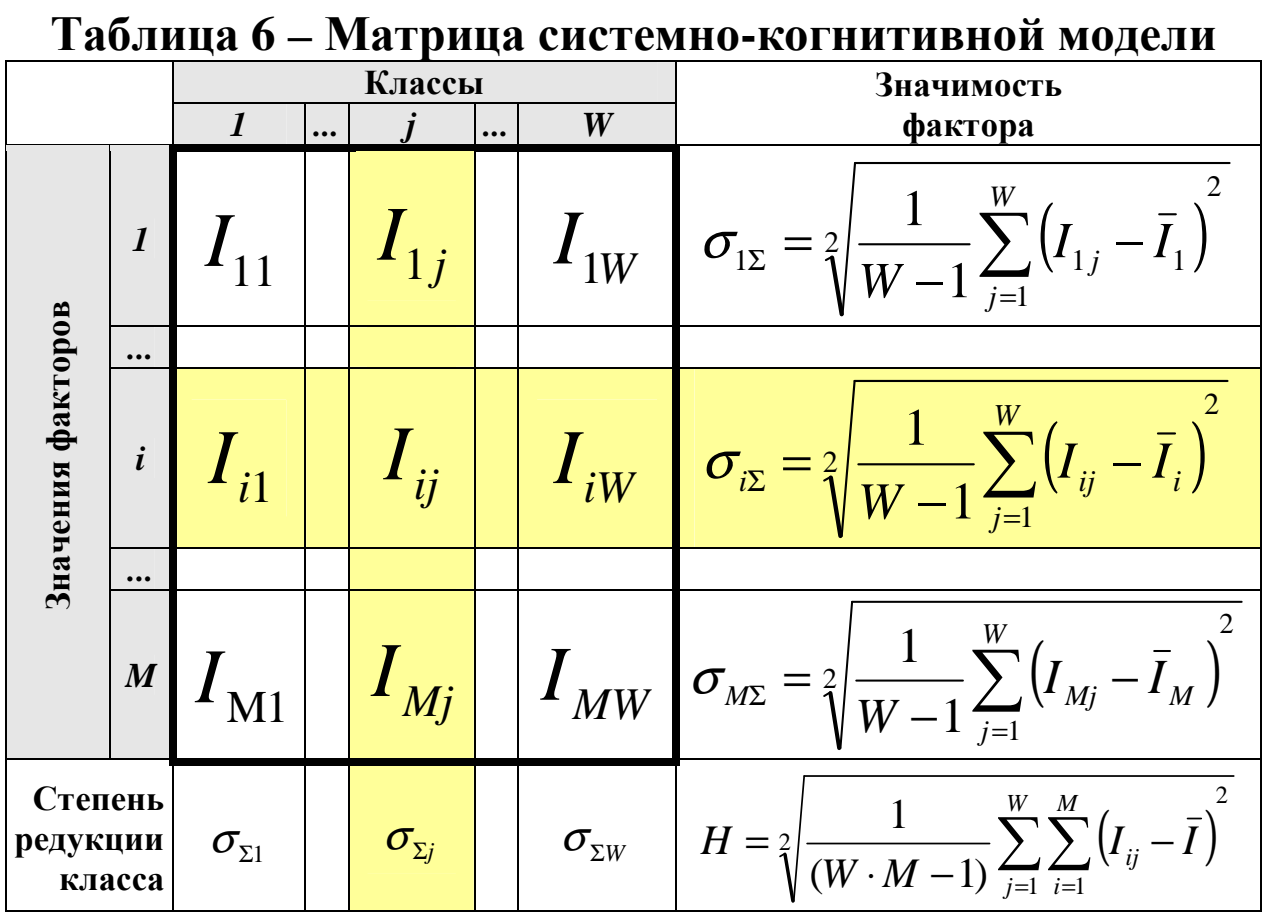

Суть этих методов в том, что вычисляется количество информации в факте наличия или определенной степени выраженности того или иного личностного свойства о том, что обладающий им кандидат будет проявлять определенную степень успешности профессиональной деятельности, работая на той или иной должности. Это позволяет сопоставимо и корректно обрабатывать разнородную информацию о респондентах, полученную с помощью различных тестов и других различных источников [7].

На основе системно-когнитивных моделей, представленных в таблице 4 (отличаются частыми критериями), решаются задачи идентификации (классификации, распознавания, диагностики, прогнозирования), поддержки принятия решений (обратная задача прогнозирования), а также задача исследования моделируемой предметной области путем исследования ее системно-когнитивной модели [1-4].

Для решения этих задач в АСК-анализе и системе «Эйдос» в настоящее время используется два интегральных критерия, кратко описанные ниже.

Задача принятия управляющих решений представляет собой обратную задачу прогнозирования. Если при прогнозировании на основе значений факторов, воздействующих на объект управления, определяется в какое 
состояние он под их воздействием перейдет, но при принятии решений наоборот, по желательному (целевому) состоянию объекта управления определяется система значений факторов, обуславливающих переход объекта в это целевое состояние.

Не все модели обеспечивают решение обратной задачи прогнозирования. Для этого они должны обеспечивать многопараметрическую типизацию, т.е. создавать обобщенные образы в будущих состояний объекта управления. Как влияет на поведение объекта управления одно значение фактора отражено в системно-когнитивных моделях. Как влияние система факторов определяется с помощью интегральных критериев. В настоящее время в системе «Эйдос» используется два аддитивных интегральных критерия:

- сумма знаний;

- резонанс знаний.

1-й интегральный критерий «Сумма знаний» представляет собой суммарное количество знаний, содержащееся в системе значений факторов различной природы, характеризующих сам объект управления, управляющие факторы и окружающую среду, о переходе объекта в будущие целевые или нежелательные состояния.

Интегральный критерий представляет собой аддитивную функцию от частных критериев знаний:

$$
I_{j}=\left(\vec{I}_{i j}, \vec{L}_{i}\right)
$$

В выражении круглыми скобками обозначено скалярное произведение. В координатной форме это выражение имеет вид:

$$
I_{j}=\sum_{i=1}^{M} I_{i j} L_{i}
$$

где: $\mathrm{M}$ - количество градаций описательных шкал (признаков);

$\overrightarrow{\mathrm{I}}_{\mathrm{ij}}=\left\{\mathrm{I}_{\mathrm{ij}}\right\}$ - вектор состояния $\mathrm{j}-$ го класса;

$\overrightarrow{\mathrm{L}}_{\mathrm{i}}=\left\{\mathrm{L}_{\mathrm{i}}\right\}-$ вектор состояния распознаваемого объекта, включающий все виды факторов, характеризующих сам объект, управляющие воздействия и окружающую среду (массив-локатор), т.е.:

$$
\vec{L}_{i}=\left\{\begin{array}{l}
1, \text { если } i-\check{u} \text { фактор действует; } \\
n, \text { где : } n>0, \text { если } i-\check{u} \text { фактор действует с истинностью } n ; \\
0, \text { если } i-\check{u} \text { фактор не действует. }
\end{array}\right.
$$

В текущей версии системы «Эйдос-Х++» значения координат вектора состояния распознаваемого объекта принимались равными либо 0, если признака нет, или n, если он присутствует у объекта с интенсивностью n, 
т.е. представлен n раз (например, буква «о» в слове «молоко» представлена 3 раза, а буква «м»- один раз).

2-й интегральный критерий «Семантический резонанс знаний» представляет собой нормированное суммарное количество знаний, содержащееся в системе факторов различной природы, характеризующих сам объект управления, управляющие факторы и окружающую среду, о переходе объекта в будущие целевые или нежелательные состояния.

Интегральный критерий представляет собой аддитивную функцию от частных критериев знаний и имеет вид:

$$
I_{j}=\frac{1}{\sigma_{j} \sigma_{l} M} \sum_{i=1}^{M}\left(I_{i j}-\bar{I}_{j}\right)\left(L_{i}-\bar{L}\right)
$$

где:

M - количество градаций описательных шкал (признаков);

$\overline{\mathrm{I}}_{\mathrm{j}} \quad$ - средняя информативность по вектору класса;

$\overline{\mathrm{L}} \quad$ - среднее по вектору объекта;

$\sigma_{\mathrm{j}}-$ среднеквадратичное отклонение частных критериев знаний вектора класса;

$\sigma_{1}$ - среднеквадратичное отклонение по вектору распознаваемого объекта.

$$
\begin{aligned}
& \overrightarrow{\mathrm{I}}_{\mathrm{ij}}=\left\{\mathrm{I}_{\mathrm{ij}}\right\} \text { - вектор состояния j-го класса; } \\
& \overrightarrow{\mathrm{L}}_{\mathrm{i}}=\left\{\mathrm{L}_{\mathrm{i}}\right\}-\text { вектор состояния распознаваемого объекта, включающий }
\end{aligned}
$$
все виды факторов, характеризующих сам объект, управляющие воздействия и окружающую среду (массив-локатор), т.е.:

$$
\vec{L}_{i}=\left\{\begin{array}{l}
1, \text { если } i-\check{u} \text { фактор действует; } \\
n, \text { где : } n>0, \text { если } i-\check{u} \text { фактор действует с истинностью } n ; \\
0, \text { если } i-\check{u} \text { фактор не действует. }
\end{array}\right.
$$

В текущей версии системы «Эйдос-Х++» значения координат вектора состояния распознаваемого объекта принимались равными либо 0 , если признака нет, или n, если он присутствует у объекта с интенсивностью $\mathrm{n}$, т.е. представлен n раз (например, буква «о» в слове «молоко» представлена 3 раза, а буква «м»- один раз).

Свое наименование интегральный критерий сходства «Семантический резонанс знаний» получил потому, что по своей математической форме является корреляцией двух векторов: состояния ј-го класса и состояния распознаваемого объекта. 
Интеллектуальные модели, некоторые из которых приведены в таблицах 7-9, отличающиеся частными критериями знаний (таблица 5) в непосредственной декларативной форме содержат знания о принадлежности и непринадлежности распознаваемого объекта, обладающего некоторым признаком, к каждому из классов, т.е. содержат информацию о силе и направлении влияния каждого признака на принадлежность объекта с этим признаком к каждому из классов.

\section{Таблица 7 - МАТРИЦА АБСОЛЮТНЫХ ЧАСТОТ (ABS) (фрагмент)}

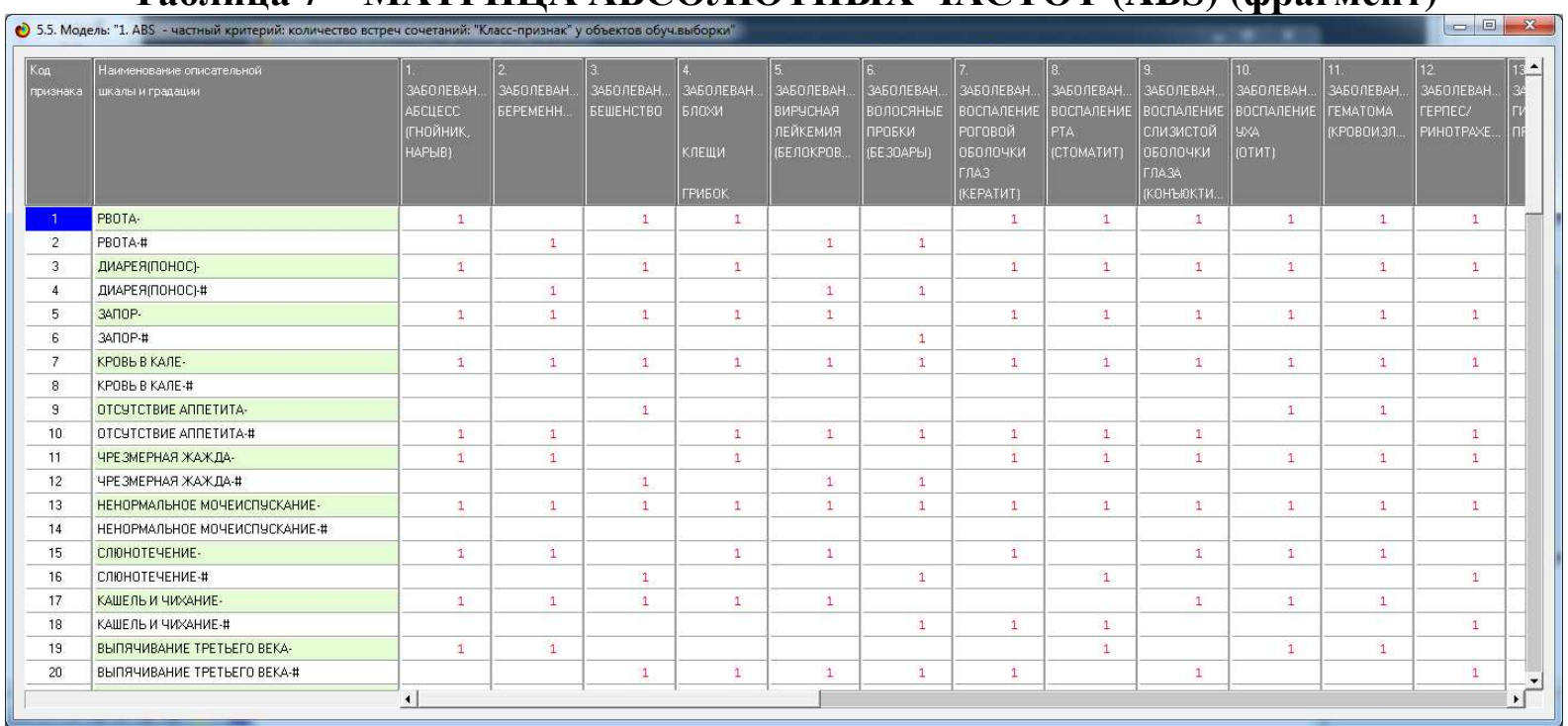

Таблица 8 - МАТРИЦА ЗНАНИЙ INF1 (фрагмент)

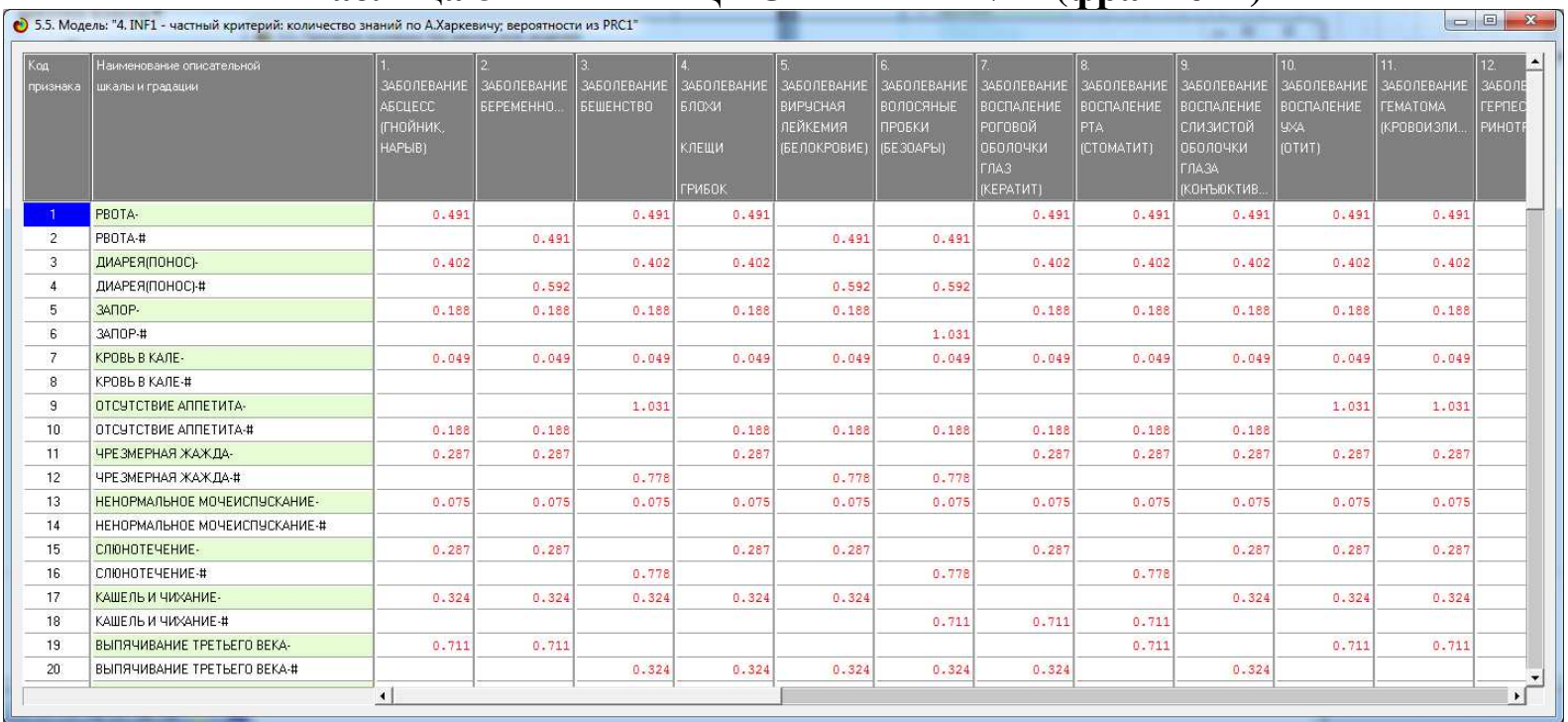


Таблица 9 - МАТРИЦА ЗНАНИЙ INF3 (фрагмент)

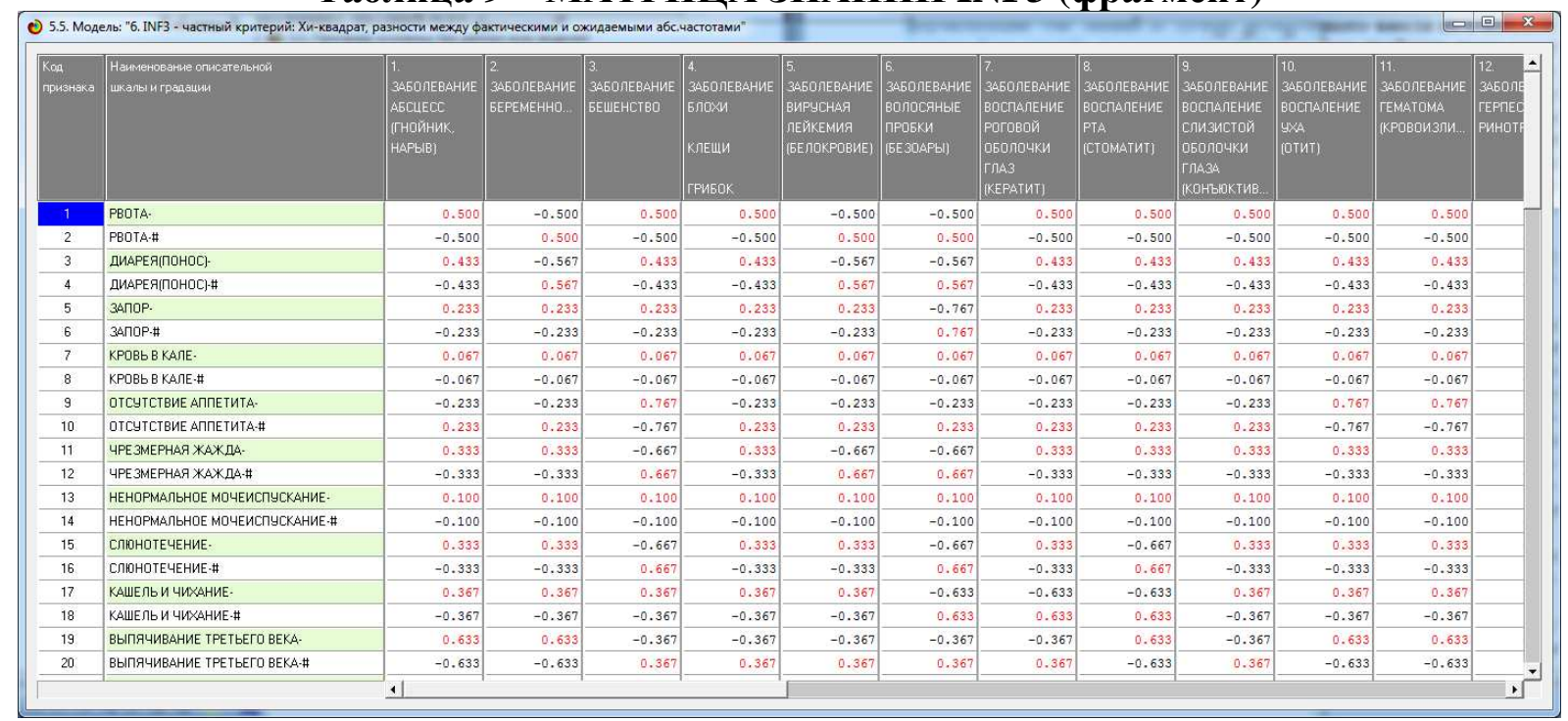

Необходимо обратить внимание на то, что весовые коэффициенты в моделях системы Эйдос-X++, созданные на основе исходных данных, отличаются друг от друга, в частности в интеллектуальных моделях в общем случае отличаются не только весами, но и знаками весовых коэффициентов (например, в приведенных моделях INF1- количество знаний по А.Харкевичу и INF3 - Хи-квадрат).

Базы знаний, представленные в таблицах 4, 5, 6, имеют декларативную форму и содержат $30 \times 34=1020$ элементов, отражающих силу и направление причинно-следственной связи между значениями факторов и градациями классификационных шкал, которые могут быть представлены в продукционной форме в виде 1020 продукций вида: «Если то». Это количество продукций близко к максимальному пределу для большинства систем искусственного интеллекта, основанного на классических продукциях с Аристотелевской логикой «истина-Ложь». Это связано с тем, что «При большом числе продукций в продукционной модели усложняется проверка непротиворечивости системы продукций, т.е. множества правил. Поэтому число продукций, с которыми работают современные системы ИИ, как правило, не превышают тысячи» ${ }^{2}$. Однако в системе «Эйдос» используются нечеткие продукции с переменной степенью истинности импликаций. Поэтому в системе «Эйдос» нет проблемы, с которыми сталкиваются экспертные системы, состоящей в необходимости проверка непротиворечивости системы продукций, и они все учитываются в интегральном критерии со своей степенью истинности.

В результате, как показали численные эксперименты, в текущей версии системы «Эйдос-Х++» может быть до $10000 \times 10000=100000000$ нечетких продукций, что примерно в 100000 раз больще, чем в самых мощных экспертных системах с продукционными моделями. Даже если бы продук-

\footnotetext{
${ }^{2}$ См., например: http://prof9.narod.ru/doc/016/index.html
} 
ционные модели такой мощности было бы возможно реализовать, то для их работы были бы необходимы суперкомпьютеры. Декларативные же базы знаний системы «Эйдос» служат лишь основой для решения различных задач идентификации (прогнозирования), принятия решений и исследования предметной области, которые на продукционных моделях такой размерности, по-видимому, невозможно решать и на суперкомпьютерах.

Очевидно, что знания такого объема и детализации невозможно получить от экспертов по ряду причин, среды которых основными являются следующие:

1. Большинство экспертов пользуются знаниями в слабо формализованной форме, т.е. интуитивными невербализованными знаниями, основанными на опыте и профессиональной компетенции. Повышение степени формализации этих знаний до уровня, позволяющего внести их в компьютерные базы знаний, представляет собой большую проблему, чаще всего неразрешимую для эксперта, которые являясь экспертами в своей профессиональной области при этом обычно не имеют подготовки инженера по знаниям (когнитолога). Кроме того известно, что при любой формализации происходит необратимая потеря адекватности знаний. Даже начальный этап формализации: вербализация требует больших усилий, труда, времени и еще таланта писателя, хотя вербализации совершенно недостаточна для внесения в компьютерные базы знаний, т.е. для этого требуется более высокий уровень формализации.

2. На практике могут встречаться такие мотивы принятия решений, которые эксперт не просто не станет вербализовать, т.к. они предосудительны и вместо истинных мотивов и знаний сообщит неистинные.

3. Часто эксперт осознает процесс получения знаний от него и их формализации как процесс отчужсденя от него тех знаний, которые он добывал всю профессиональную жизнь и на владении которыми основано его материальное, профессиональное и социальное благополучие. Поэтому он отрицательно относится к самой идее извлечения из него профессиональных знаний и придания им такой формы, в которой они могли бы быть включены в компьютерные базы знаний систем искусственного интеллекта, обобществлены и стать общим достоянием. Сами же системы искусственного интеллекта и специалистов в этой области он рассматривает как представляющих угрозу его благополучию.

По этим причинам эксперты часто не могут и не хотят делиться своими знаниями, и даже если они настроены доброжелательно это не всегда получается качественно.

В системе же «Эйдос» все эти проблемы вообще не возникают, т.к. степень истинности импликаций нечетких продукций, представленных в декларативной форме, вычисляется автоматически непосредственно на основе эмпирических данных без участия экспертов. 
На четвертом этапе определяется наиболее достоверная модель и назначается текущей для дальнейшего применения.

Шаг 1-й. Из режима 4.1.3.6 видно (см. рисунок 11), что наивысшей достоверностью идентификации и не идентификации обладает модель Inf3 с частными критериями, приведенными в таблице 6 и интегральным критерием «сумма знаний», описанным выше.

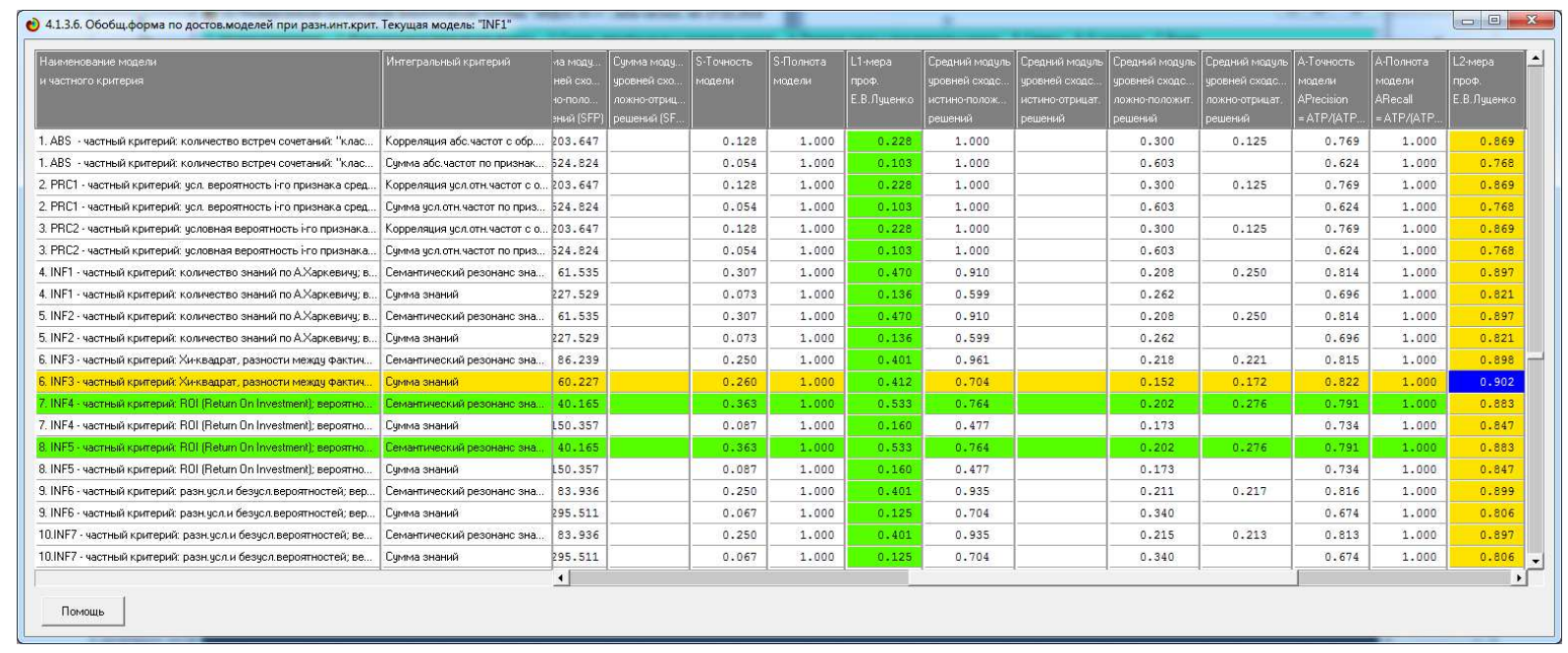

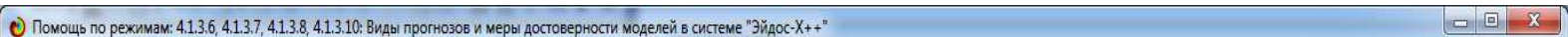

помощь по рехимам: $4.1 .3 .6,4.1 .3 .7,4.1 .3 .8,4.1 .3 .10$ : виды прогнозов и меры достоверности моделей в системе "Эйдос-Х++".

предположим, модель дает такой прогноз: выпадет 1, 2, 3, 4, 5 или 6. в этом случае у нее будет $100 \%$ достоверность идентификации, т.е. не будет ни одного объекта, не отнесенного к тому классу, к которому он действительно относится, но при этом будет очень большая ошибка лохной идентификации, Т. К. огромное количество объектов будет отнесено к классам, к которым они не относятся (и именно за счет этого у модели и будет очень высокая достоверность идентификации). ясно, что такой прогноз бесполезен, поэтому он и назван мной псевдопрогнозом.

Представим себе, что мы выбрасываем кубик с 6 гранями, и модель предсказывает, что не выпадет: 1, 2, 3, 4, 5 и 6, а что-то из этого естественно выпало. конечно, модель дает ошибку в прогнозе в том плане, что не предсказала, что выпадет, зато она очень хорошо угадала, что не выпадет. Но ясно, что выпадет что-то одно, а не все, что предсказано, поэтому такого рода предсказания хорошо оправдываются в том, что не

ИДЕАЛЬНЫЙ ПРОГНОЗ

ЕСли в случае с кубиком мы прогнозируем, что выпадет, например 1 , и соответственно прогнозируем, что не выпадет $2,3,4,5$, и 6 , то это идеальный прогноз, имеющий, сли он осуществляется, $100 \%$ достоверность идентификации и не идентификации. идеальный прогноз, Прогнозирования,

на практике мы чаще всего сталкиваемся именно с этим видом прогноза. Реальный прогноз уменьшает неопределенность о будущем состоянии объекта прогнозирования, но не полностью, как идеальный прогноз, а оставляет некоторую неопределенность не снятой. например, для игрального кубика делается такой прогноз: выпадет 1 или 2, и, соответственно, не выпадет 3, 4, 5 или 6. Понятно, что полностью на практике такой прогноз не мохет осуществиться, Т. к. варианты выпадения кубика альтернативны, т.е. не может выпасть одновременно и $1, и$ 2. поэтому у реального прогноза всегда будет определенная ошибка идентификации. соответственно, если не осуществится один или прогноз его поведения, а тысячи. Тогда мохно посчитать средневзвешенные характеристики всех этих видов прогнозов.

Таким образом, если просуммировать число верно идентифицированных и не идентифицированных объектов и вычесть число ошибочно идентифицированных и не идентифицированных объектов, а затем разделить на число всех объектов то это и будет критерий качества модели (классификатора), учитываюций как ее способность верно относить обьекты к классам, которым они относятся, так и ее способность верно не относить обьекты к тем классам, к которым они не относятся. этот критерий предложен и реализован в системе "Эйдос" проф. Е. В. Луценко в 1994 году. Эта мера достоверности модели
L1 $=($ TP + TN - FP $-F N)$ ( $($ TP + TN + FP + FN $)$ (нормировка: $\{-1,+1\})$

где количество: TP - истино-положительных решений; TN - истино-отрицательных решений; FP - ложно-положительных решений; FN - ложно-отрицательных решений; классическая F-мера достоверности моделей ван Ризбергена (колонка выделена ярко-годубым фоном):

F-mera $=2^{*}($ Precision*Recal1) $/($ PrecisiontRecall)

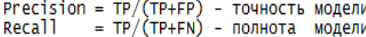

1-мера проф.Е. В. Луценко - нечеткое мультиклассовое обобщение классической F-меры с учетом сумм уровней сходства (колонка выделена ярко-зеленым фоном):

1-mera $=2^{*}$ (SPrecision*SRecal1) $/($ SPrecision+sRecal1)

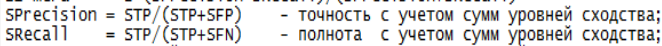

STP - сумма модулей сходства истино-полохительных решений; STN - Сумма модулей сходства истино-отрицательных решений;

STP - Сумма модулей сходства истино-положительных решении; STN - Сумма модулей сходства истино-отрицательных решений;
SFP - Сумма модулей сходства лохно-положительных решений; SFN - сумма модулей сходства лохно-отрицательных решений.

L2-мера проф.Е.В. Луценко - нечеткое мультиклассовое обобщение классической F-меры с учетом СРЕдних уровней сходства (колонка выделена желтым фоном):

L2-mera $=2^{*}$ (APrecision*ARecal1) $/$ (APrecision+ARecall)

$\begin{array}{ll}\text { APrecision }=\text { ATP/(ATP+AFP) } & - \text { точность с учетом средних уровней сходства; } \\ \text { ARecall }=\text { ATP } /(\text { ATP+AFN) } & - \text { полнота с учетом средних уровней сховтеа; }\end{array}$

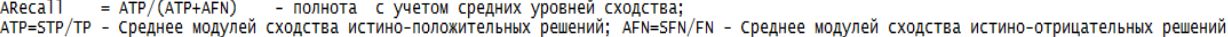

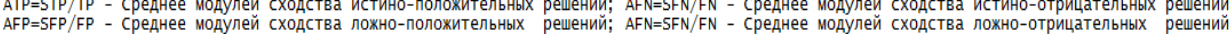

строки с максимальными значениями F-меры, L1-меры и L2-меры выделены фоном цвета, соответствующего колонке.

луценко Е. В. инвариантное относительно объемов данных нечеткое мультиклассовое обобщение F-меры достоверности моделей ван Ризбергена в Аск-анализе, и системе "Эйдос" / Е.В. Луценко // Политематический сетевой электронный научный журнал кубанского государственного аграрного университета (научный журнал кубгау) [электронныи ресурс]. - краснодар:
http://ej. kubagro.ru/2017/02/pdf/01. pdf, 2 y. п. л.

Рисунок 11. Данные о достоверности статистических моделей и моделей знаний системы Эйдос-X++ в созданном интеллектуальном приложении 
Для пояснения на рисунке 11 приведен Help данного режима:

На рисунке 12 приведено Частотное распределение уровней сходства-различия объектов с классами в наиболее достоверной модели INF3:
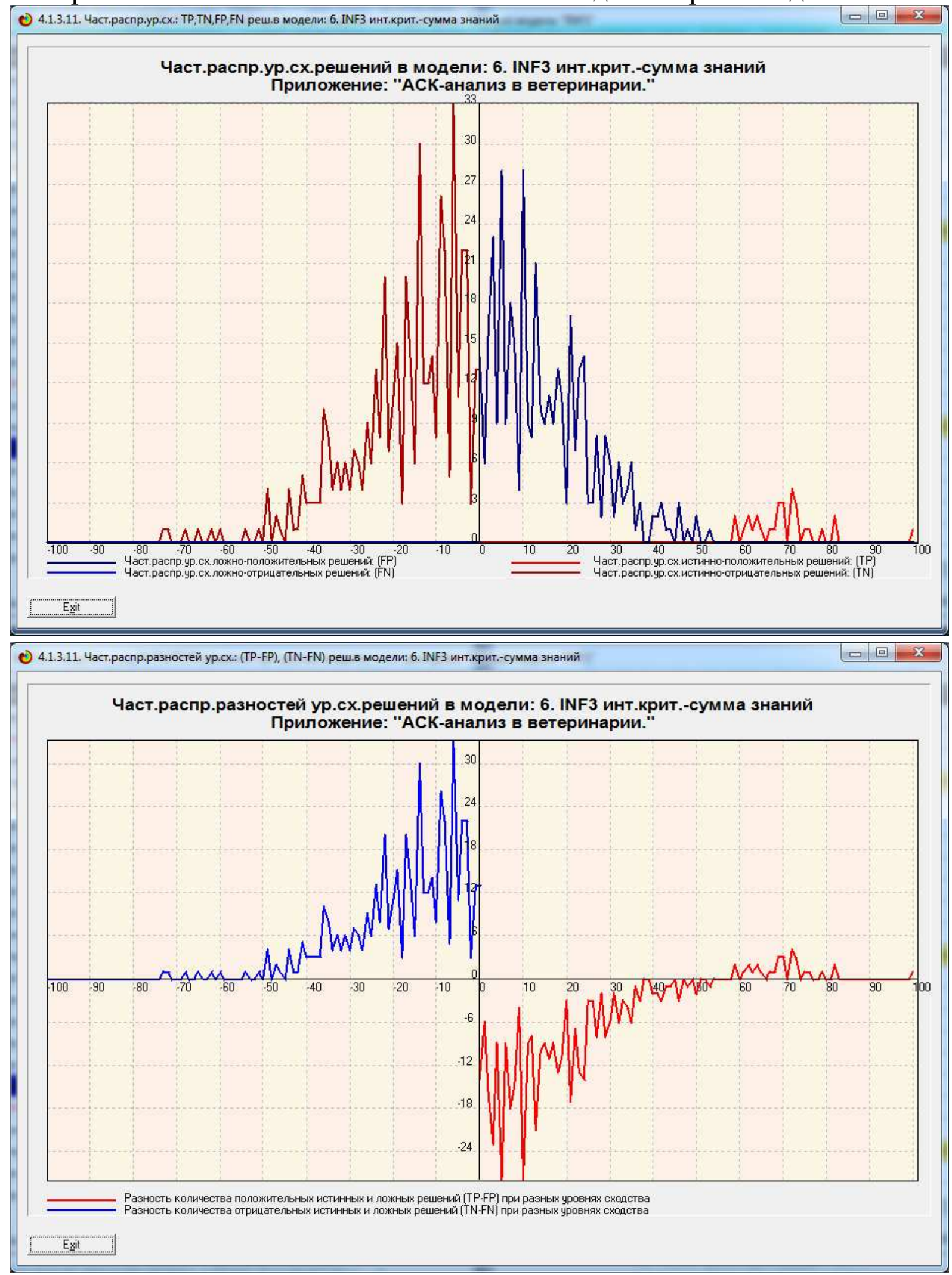

Рисунок 12. Частотное распределение уровней сходства-различия объектов с классами в наиболее достоверной модели INF3 
Из этого рисунка видно, что:

- отрицательные решения (т.е. решения о непринадлежности объекта к классу) всегда истинные;

- положительные решения (т.е. решения о принадлежности объекта к классу) с уровнями сходства ниже 55\% всегда ложные;

- положительные решения с уровнями сходства выше $55 \%$ всегда истинные.

При этом чем выше уровень сходства, тем выше вероятность истинной классификации. Все это вполне разумные результаты.

Шаг 2-й. Модель, показавшая наивысшую достоверность (см. рисунок 11) принимается текущей, для чего применяется режим 5.6 (рисунки 13 и 14):

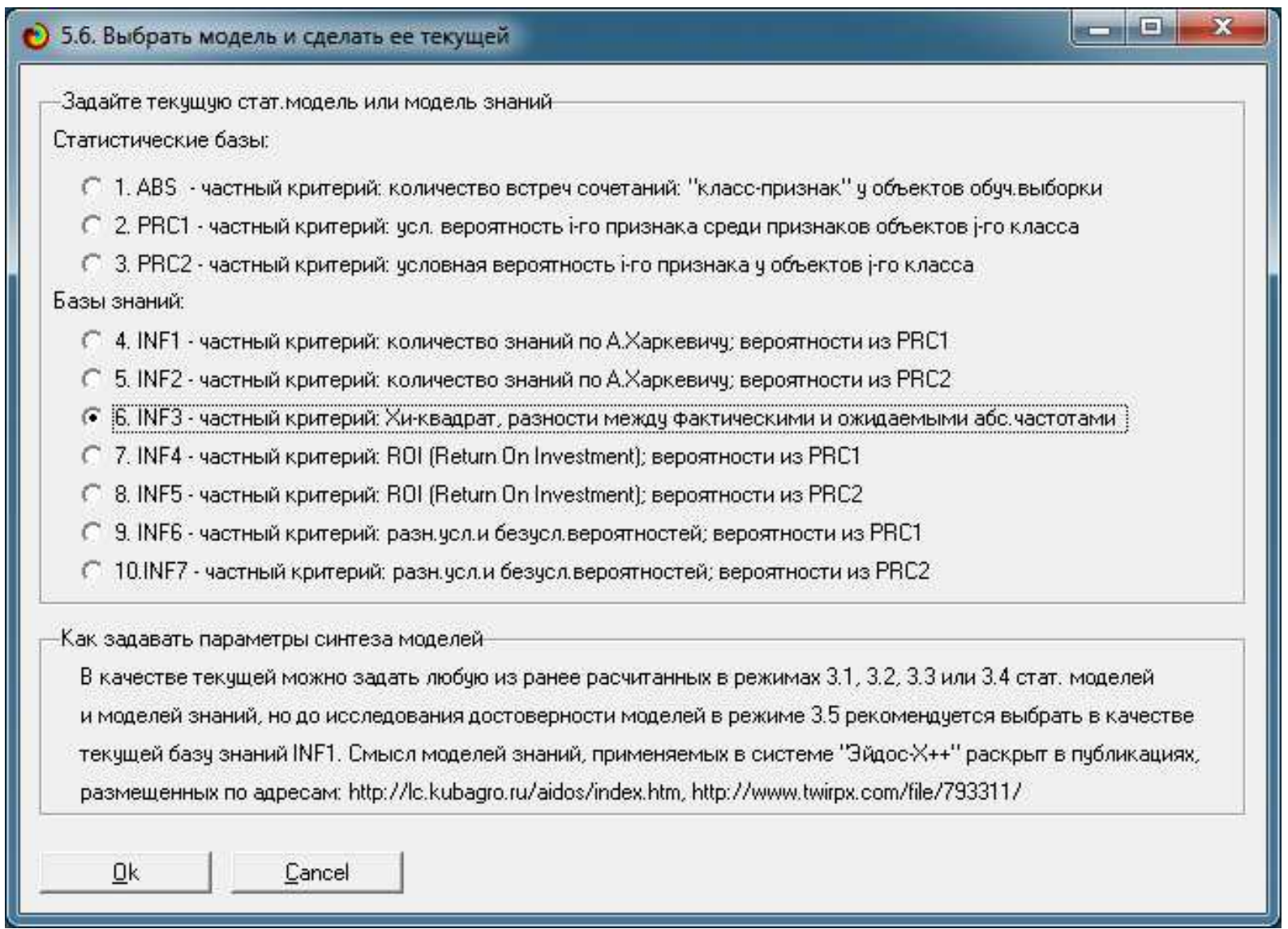

Рисунок 13. Окно режима 5.6 задания в качестве текущей модели, показавшей наивысшую достоверность 
(О) 5.6. Выбрать модель и сделать ее текущей

Стадии исполнения процесса

ОПЕРАЦИЯ: ПРИСВОЕНИЕ МОДЕЛИ "INF3" СТАТУСА ТЕКЧЩЕЙ МОДЕЛИ:

1/7: Копирование в массивы итоговых строк и столбцов текущей модели -Готово

2/7: Перенос информации из текущей модели в базы классов: Classes и Gr_ClSc-Готово

3/7: Перенос информации из текущей модели в базы признаков: Attributes и Gr_OpSc-Готово

4/7: Расчет значимости класс.и опис.шкал-Сброс сумматоров-Готово

5/7: Расчет значимости класс.и опис.шкал-Накопление данных-Готово

6/7: Расчет значимости класс.и опис.шкал-Дорасчет - Готово

7/7: Запись информации о текущей модели -Готово

Выбор модели знании́ "INF3" в качестве текущеи́ прошел успешно!!!

Прогноз времени исполнения

Начало: 21:21:13

Окончание: 21:21:15

Прошло: 0:00:02

Осталось: 0:00:00

Рисунок 14. Окно отображения стадии исполнения режима 5.6, задания в качестве текущей модели, показавшей наивысшую достоверность

Шаг 3-й. Распознавание в наиболее достоверной модели проводится в режиме 4.1.2 (рисунок 15):

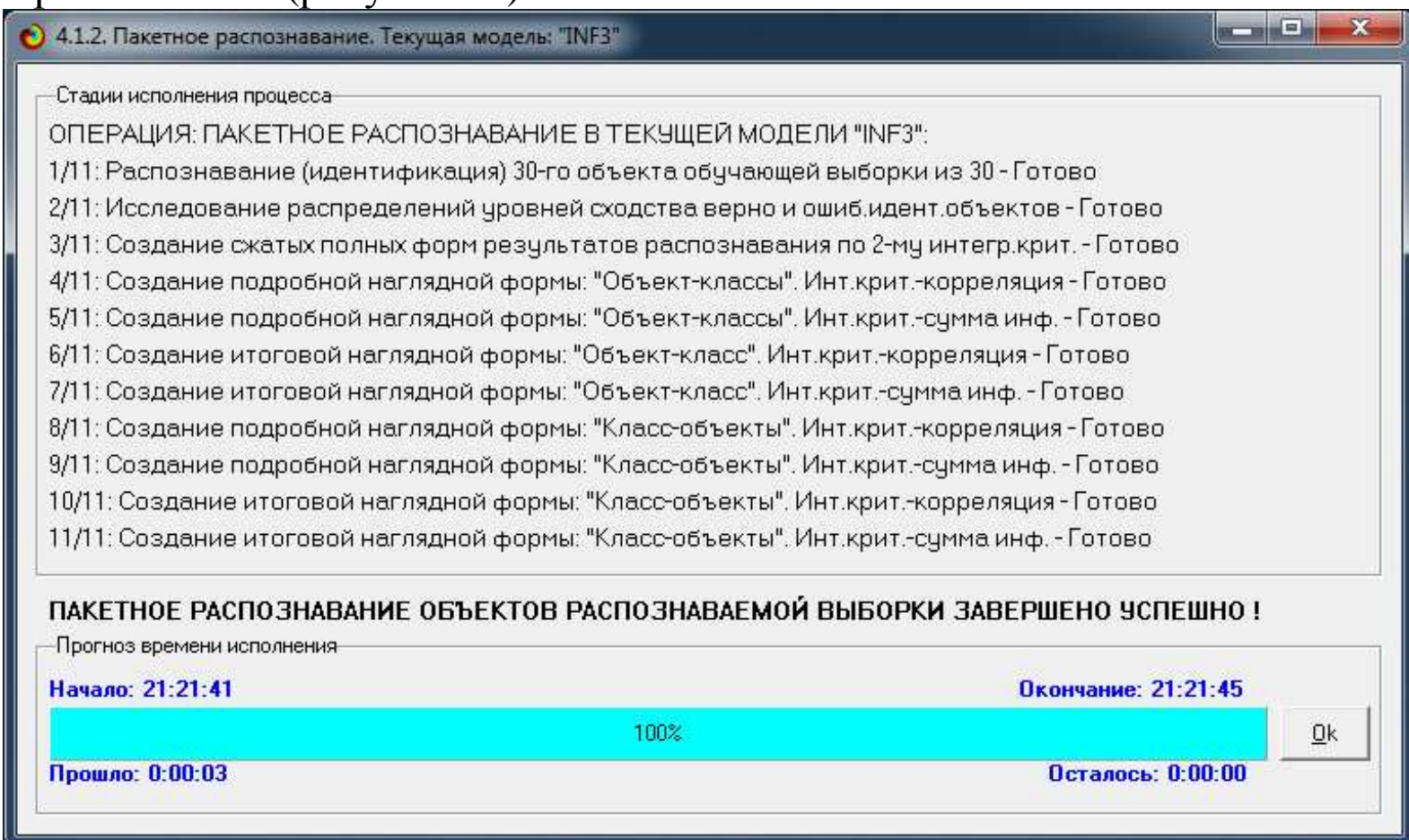

Рисунок 15. Окно отображения стадии исполнения режима 5.6, задания в качестве текущей модели, показавшей наивысшую достоверность

Результаты контрольного распознавания отображаются в режиме 4.1.3.1 (рисунки 16), а также в ряде других режимов: 


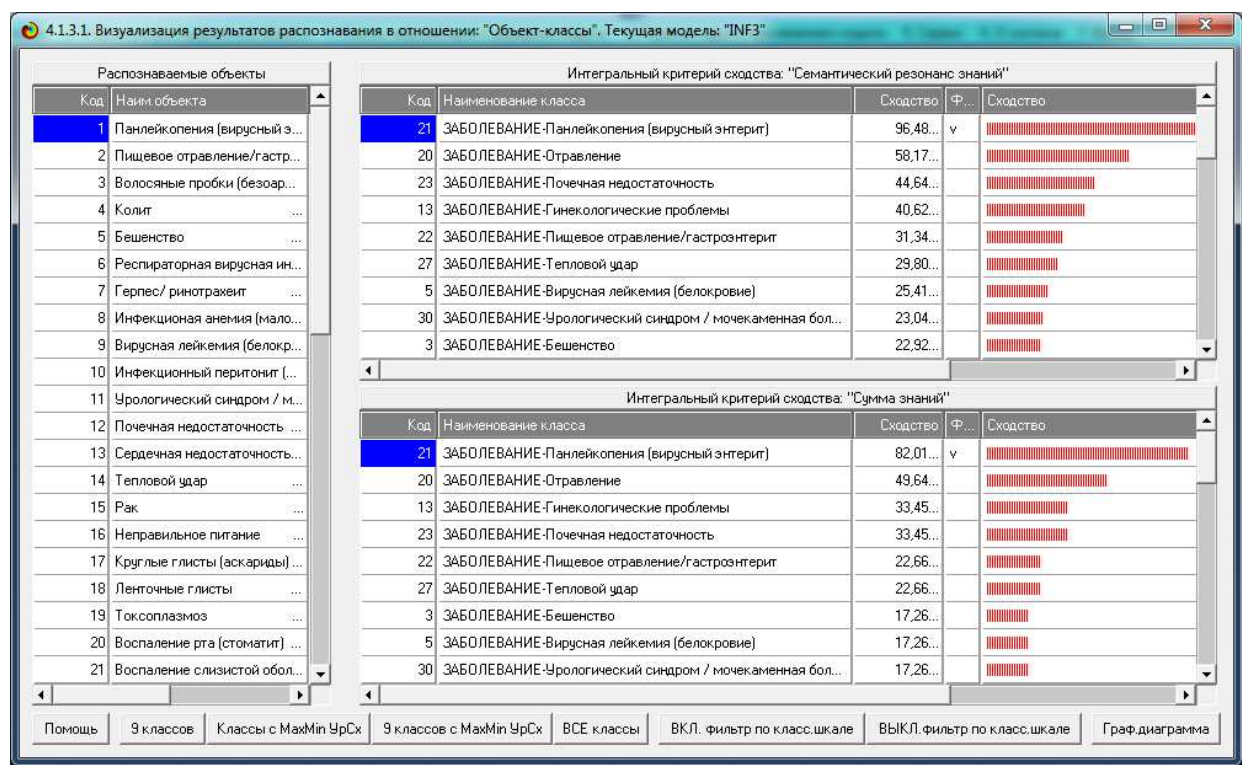

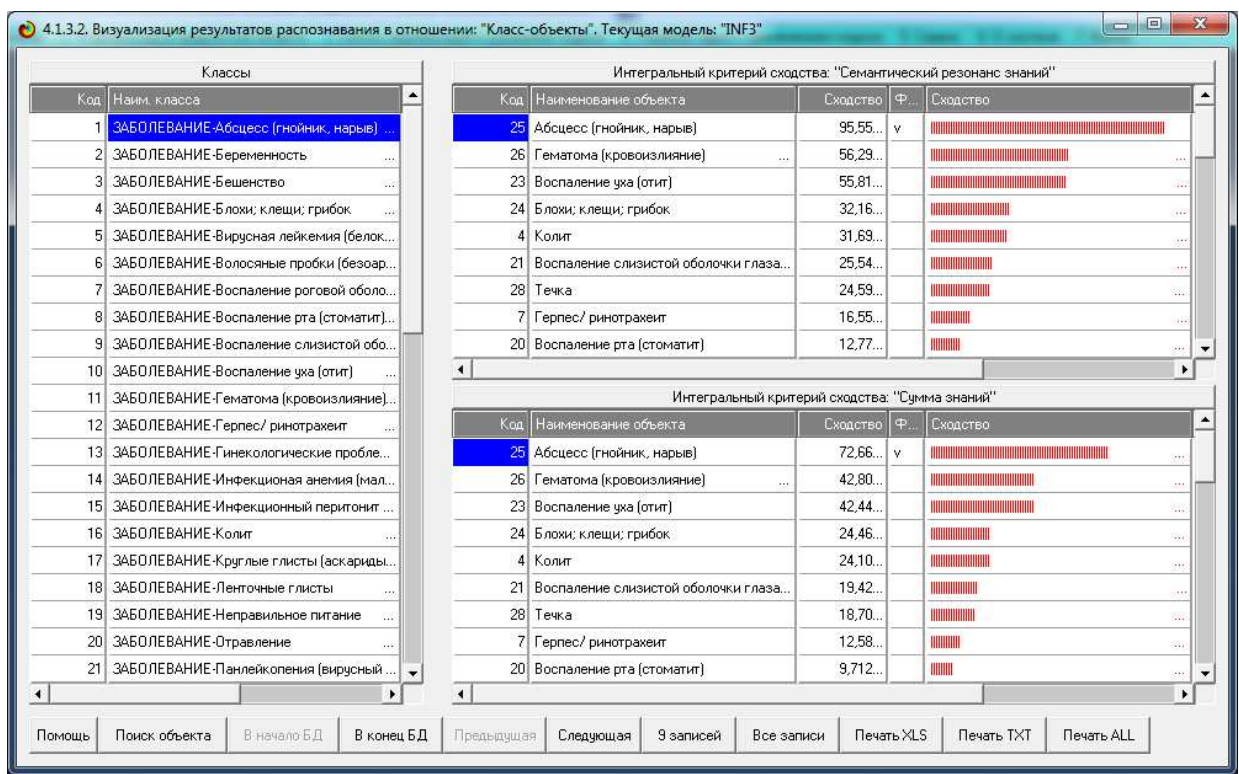

\begin{tabular}{|c|c|c|c|c|c|c|c|c|}
\hline \multicolumn{9}{|c|}{735} \\
\hline \multicolumn{3}{|c|}{ Код Интегральный критерий } & \multicolumn{6}{|c|}{ Пояснения по смыслу частных и интегральных критериев } \\
\hline \multicolumn{2}{|c|}{2 Сумма знаний } & & Частн.крит. 7 моделей знаний & \multicolumn{2}{|c|}{ Инт.крит:.: "Сумма знаний" } & \multicolumn{3}{|c|}{ Инт.крит.: "Резонанс знаний" } \\
\hline \begin{tabular}{|l|} 
Kag \\
обьекта \\
распозн. \\
выборки \\
\end{tabular} & $\begin{array}{l}\text { Наименование объекта } \\
\text { распознававмой выборки }\end{array}$ & $\begin{array}{l}\text { Kon } \\
\text { Knacod } \\
\text { cMAx } \\
\text { yp.cson. }\end{array}$ & 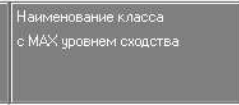 & 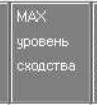 & \begin{tabular}{|l} 
Koa \\
Knacoa \\
cMIN \\
yp.ckod
\end{tabular} & $\begin{array}{l}\text { Haименование класса } \\
\text { o MIN yровнем схадства }\end{array}$ & \begin{tabular}{|l|} 
MIN \\
yposent \\
cxogctвa
\end{tabular} & $\begin{array}{l}\text { Lloci- } \\
\text { Bep- } \\
\text { Hoct: }\end{array}$ \\
\hline 1 & Панлейкопения (вирусный з. & 21 & ЗАЕОЛЕВАНИЕ-Панлейкопения... & 82.014 & 11 & ЗАБОЛЕВАНИЕ-Гематома [КрОв... & -36.691 & 59 \\
\hline 2 & Пищевое отравление/гастр... & 22 & ЗАБОЛЕВАНИЕ-Пищевое отрав... & 69.065 & 4 & ЗАБОЛЕВАНИЕ-Блохи: клеши; $r .$. & -28.058 & 48 \\
\hline 3 & Волосяные пробки (безоар... & 6 & ЗАБОЛЕВАНИЕ-ВолосянЫе про... & 64.388 & 25 & ЗАБОЛЕВАНИЕ-Респираторная ... & -21.942 & 43 \\
\hline 4 & Колит & 16 & ЗАЕОЛЕВАНИЕ-КолИт & 72.662 & 24 & ЗАБОЛЕВАНИЕ-РАК & -67.626 & 70 \\
\hline 5 & Бешенство & 3 & ЗАБОЛЕВАНИЕ-Бешенство & 71.942 & 17 & ЗАБОЛЕВАНИЕ-Круглые глисты... & -35.971 & 53 \\
\hline 6 & Респираторная вирусная ин.. & 25 & ЗАЕОЛЕВАНИЕ-Респираторная ... & 74.820 & 24 & ЗАБОЛЕВАНИЕ-РаК & -33.094 & 53 \\
\hline 7 & Герпес/ринотрахеит & 12 & ЗАБОЛЕВАНИЕ-Герпес/ рИНОТр... & 71.942 & 20 & ЗАБОЛЕВАНИЕ-ОТравление ... & -46.763 & 59 \\
\hline 8 & Инфекционая анемия (мало. & 14 & ЗАБОЛЕВАНИЕ-Инфекционая а.. & 61.151 & 24 & ЗАБОЛЕВАНИЕ-РАК & -35.971 & 48 \\
\hline 9 & Вирусная пейкемия (белокр.. & 5 & 3АБОЛЕВАНИЕ-ВИрусная лейке... & 65.108 & 1 & ЗАБОЛЕВАНИЕ-Абсцесс (гнойн... & -37.410 & 51 \\
\hline 10 & Инфекционный перитонит (... & 15 & ЗАБОЛЕВАНИЕ-ИнфекЦионный... & 69.784 & 16 & ЗАБОЛЕВАНИЕ-Колит & -32.734 & 51 \\
\hline 11 & Урологический синаром / /м. & 30 & ЗАЕОЛЕВАНИЕ-Урологический.... & 71.583 & 24 & ЗАБОЛЕВАНИЕ-РаК & -47.122 & 59 \\
\hline 12 & Почечная недостаточность ... & 23 & ЗАЕОЛЕВАНИЕ-Почечная недос... & 71.583 & 24 & ЗАБОЛЕВАНИЕ-РаК & -30.935 & 51 \\
\hline 13 & Сердечная недостаточность... & 26 & ЗА.БОЛЕВАНИЕ-Сердечная недо... & 75.899 & 21 & ЗАБОЛЕВАНИЕ-Панлейкопения ... & -37.410 & 56 \\
\hline 14 & Тепловой уаар & 27 & ЗАБОЛЕВАНИЕ-Тепловой уаар . & 72.662 & 24 & ЗАБОЛЕВАНИЕ-РаК & -40.647 & 56 \\
\hline 15 & Рак & 24 & ЗАБОЛЕВАНИЕ-РАК & 100.000 & 16 & ЗАБОЛЕВАНИЕ-КолИт & -40.288 & 70 \\
\hline${ }_{16}$ & Honnsecismune mimsulia & 19 & 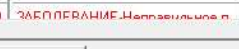 & af onal & 25 & 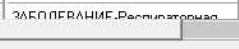 & -25 & $\sqrt[51]{1-1}$ \\
\hline 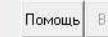 & \begin{tabular}{l|l|} 
Hачало БД & В конец БД
\end{tabular} & Предьваушан 0 & Следующая & & & & & \\
\hline
\end{tabular}

Рисунок 16. Экранные формы по результатам идентификации 
Красным цветом показаны ситуации, наступление которых прогнозируется, синим цветом - наступление которых не прогнозируется, при этом оценка достоверности прогноза дается величиной столбика гистограммы. «Птичками» отмечены верные прогнозы.

Из рисунка 11 и рисунков 16 видно, что в наиболее достоверной модели INF3 все диагнозы однозначно идентифицируются своими описаниями, но с разной степенью обусловленности.

На пятом этапе решаются задачи диагностики, т.е. постановки диагноза по конкретной симптоматике, а также задача выработки рекомендаций.

Шаг 1-й. Подготовка и ввод данных для диагностики.

Есть два варианта подготовки и ввода в систему исходных данных для тестирования:

1. Ввод в Excel-файл с абсолютно такой же структурой (даже с колонкой для классов, хотя она и не используется), как представленный в таблице 1, но с именем Inp_rasp.xls и информацией не о симптоматике заболеваний, а о тестируемых животных (рисунок 17). В этом случае для ввода данных в систему используется тот же самый программный интерфейс, что и для ввода обучающей выборки: режима 2.3.2.2, со всеми теми же самыми опциями, кроме одной: надо задать: «Генерация распознаваемой выборки (на основе Inp_rasp)» (рисунок 18). нок 19).

2. Ввод данных непосредственно в систему в режиме 4.1.1 (рису-

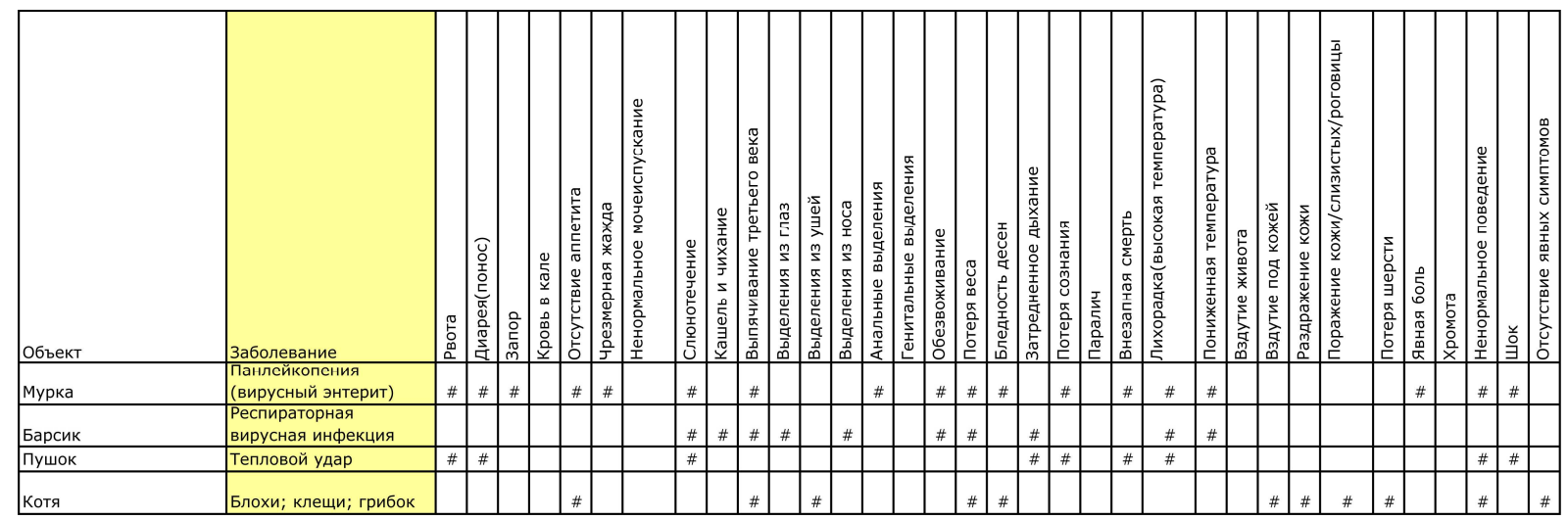

Рисунок 17. Ехсеl-файл с распознаваемой выборкой

В нашем примере Excel-файл распознаваемой выборки получен из файла исходных данных, приведенного в таблице 2 , путем удаления строк (клички животных условны). 
2.3.2.2. Универсальный программный интерфейс импорта данных в систему "ЭЙДОС-Х ++"

Автоматическая формализация предметной области: генерация классификационных и описательных шкал и градаций, а также обучающей и распознаваемой выборки на основе базы исходных данных: "Inp_data"

- Задайте тип файла искодных данных: "Inp_data":
- XLS - MS Excel-2003
C XLSX-MS Excel-2007(2010]
C DBF - DBASE IV (DBF/NTX)
$C$ CSV - Comma-Separated Values

Задайте параметры:-

C Нули и пробелы считать ОТСЧТСТВИЕМ данных

(* Нули и пробелы считать ЗНАЧЕНИЯМИ даннық

Г Создавать БД средних по классам "Inp_dav.dbf"? Требования к файлу исходных данных

Задайте диапазон столбцов классификационных шкал:

Начальный столбец классификационных шкал:

Конечный столбец классификационных шкал:

2

Задайте режим:

ᄃ Формализации предметной области (на основе "Inp_data")

- Генерации распознаваемой выборки (на основе "Inp_rasp")

Задание параметров формирования сценариев или способа интерпретации текстовых полей "Inp_data":-

6. Не применять сценарный метод АСК-анализа

ᄃ Применить сценарный метод АСК-анализа

Г Применить спец.интерпретацию текстовых полей классов

Г Применить спец. интерпретацию текстовых полей признаков

Параметры интерпретации значении́ текстовых полеи́ "Inp_data":

Интерпретация ТХТ-полей классов:

Значения полей текстовых классификационных шкал файла

исходных данных "Inp_data" рассматриваются как целое
Интерпретация ТХТ-полей признаков:

Значения полей текстовых описательных шкал файла

исходных данных "Inp_data" рассматриваются как целое

Какие наименования ГРАДАЦИЙ числовых шкал использовать:

- Только интервальные числовые значения

(например: "1/3-\{59873.0000000, 178545.6666667\}")

(. Только наименования интервальных числовых значений

С И интервальные числовые значения, и их наименования

$\underline{\underline{k}}$ Cancel

(5) 2.3.2.2. Процесс импорта данных из внешней БД "Inp_rasp" в систему "эЙдОС-Х++"

-Стадии исполнения процесса

1/2: Генерация распознаваемой выборки и базы событий "EventsKR" на основе БД "Inp_rasp" - Готово

2/2: Переиндексация всех баз данных распознаваемой выборки -Готово

ПРОЦЕСС ГЕНЕРАЦИИ РАСПОЗНАВАЕМОЙ ВЫБОРКИ ЗАВЕРШЕН ЧСПЕШНО!!!

Прогноз времени исполнения

Начало: 21:33:48

Окончание: 21:33:49

$100 \%$

Прошло: 0:00:00 Осталось: 0:00:00

Рисунок 18. Вид первого окна программного интерфейса системы Эйдос-X++ с вешней базой данных 2.3.2.2 с параметрами для ввода распознаваемой выборки 
При вводе распознаваемой выборки используются ранее созданные классификационные и описательные шкалы и градации.

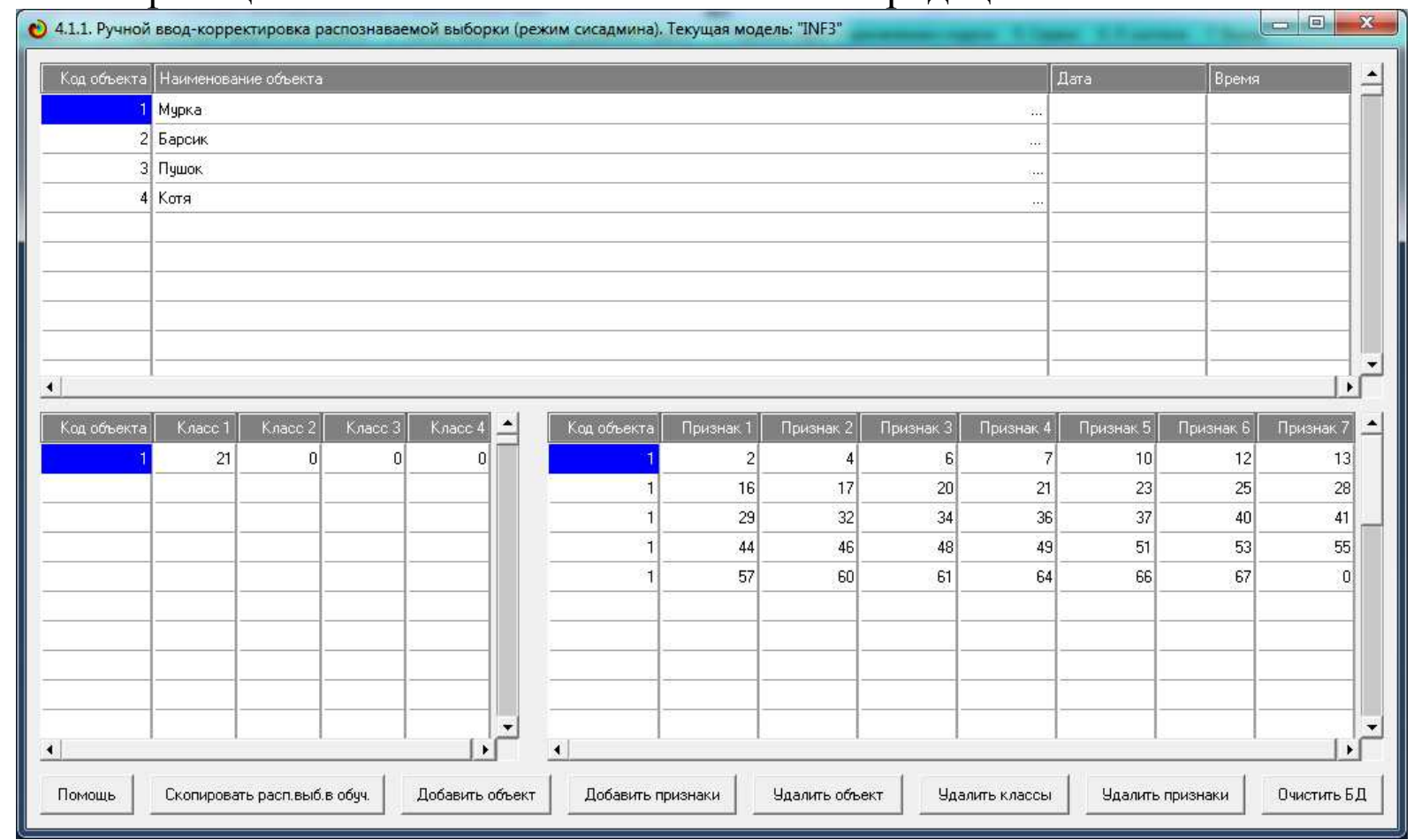

Рисунок 19. Экранная форма ручного ввода-корректировки распознаваемой выборки (вид режима администратора)

\section{Шаг 2-й. Постановка диагноза.}

По окончании ввода распознаваемой выборки в режиме 4.1.2 системы Эйдос-Х++ проводится само тестирование (распознавание, идентификация) респондентов. На рисунке 20 приведена экранная форма отображения стадии процесса тестирования после его окончания:

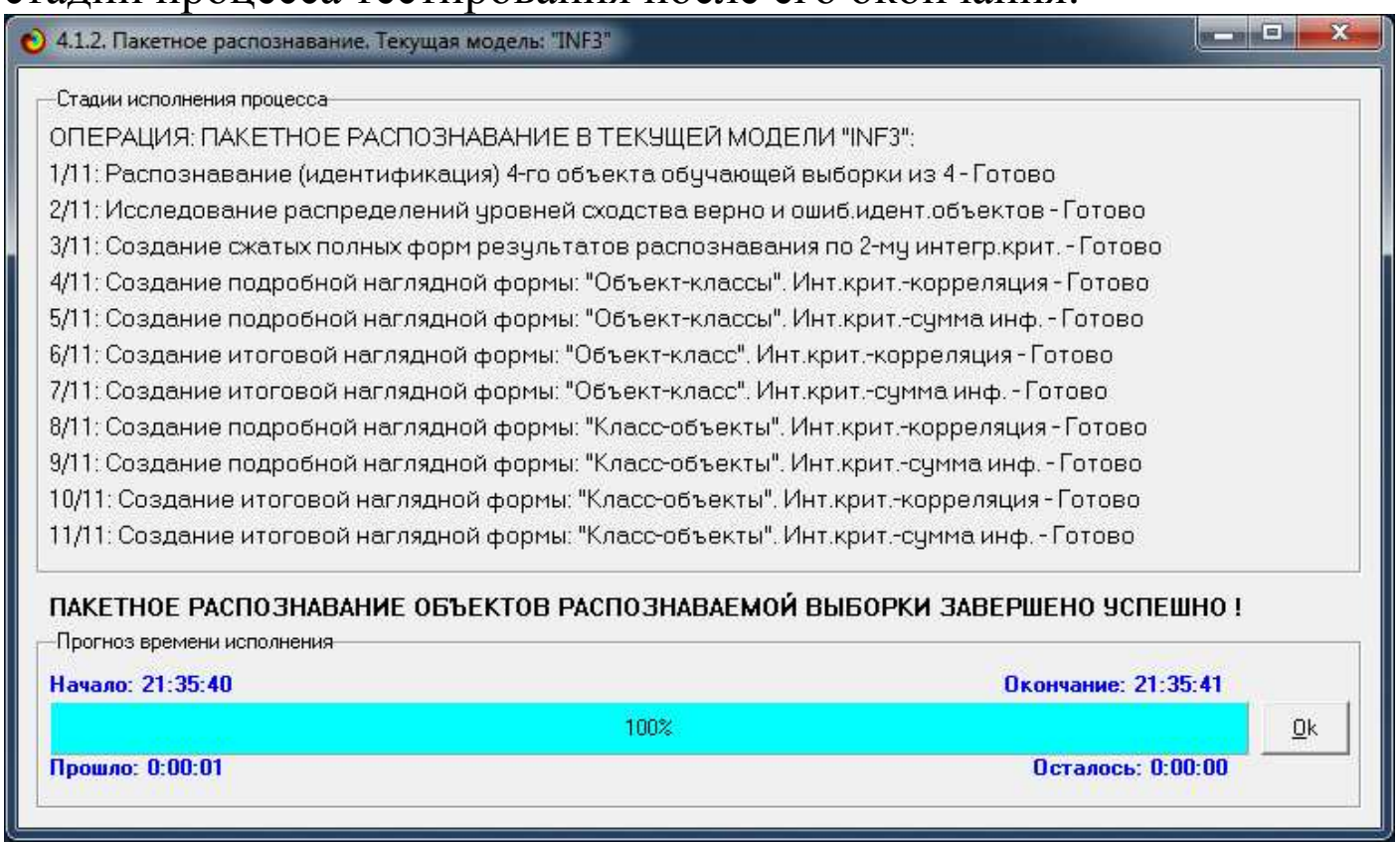

Рисунок 20. Экранная форма отображения стадии исполнения процесса идентификации объектов распознаваемой выборки 
Шаг 3-й. Отображение результатов диагностики и выработка рекомендаций по лечению.

Как видно из рисунка 20 в результате тестирования создается большое количество различных выходных форм, всесторонне с различной степенью детализации отражающих его результаты и позволяющих провести глубокий анализ этих результатов. В данной статье мы не ставим перед собой это задачи и ограничимся двумя формами:

- отображающей сходство клинической картины конкретного пациента с обобщенными нозологическими образами (рисунок 21);

- отображающей сходство клинической картины различных пациентов с заданным нозологическим образом (рисунок 22).

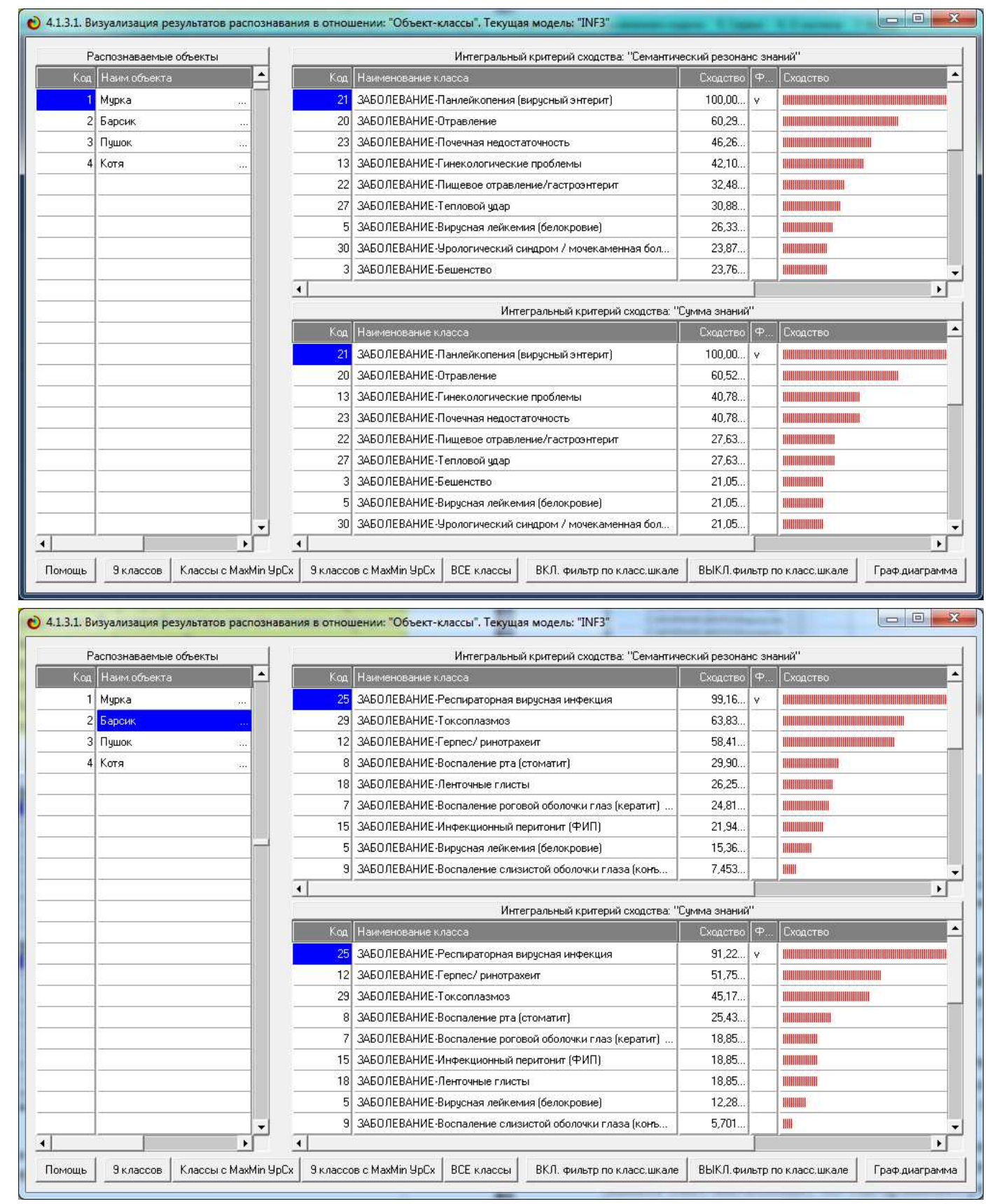




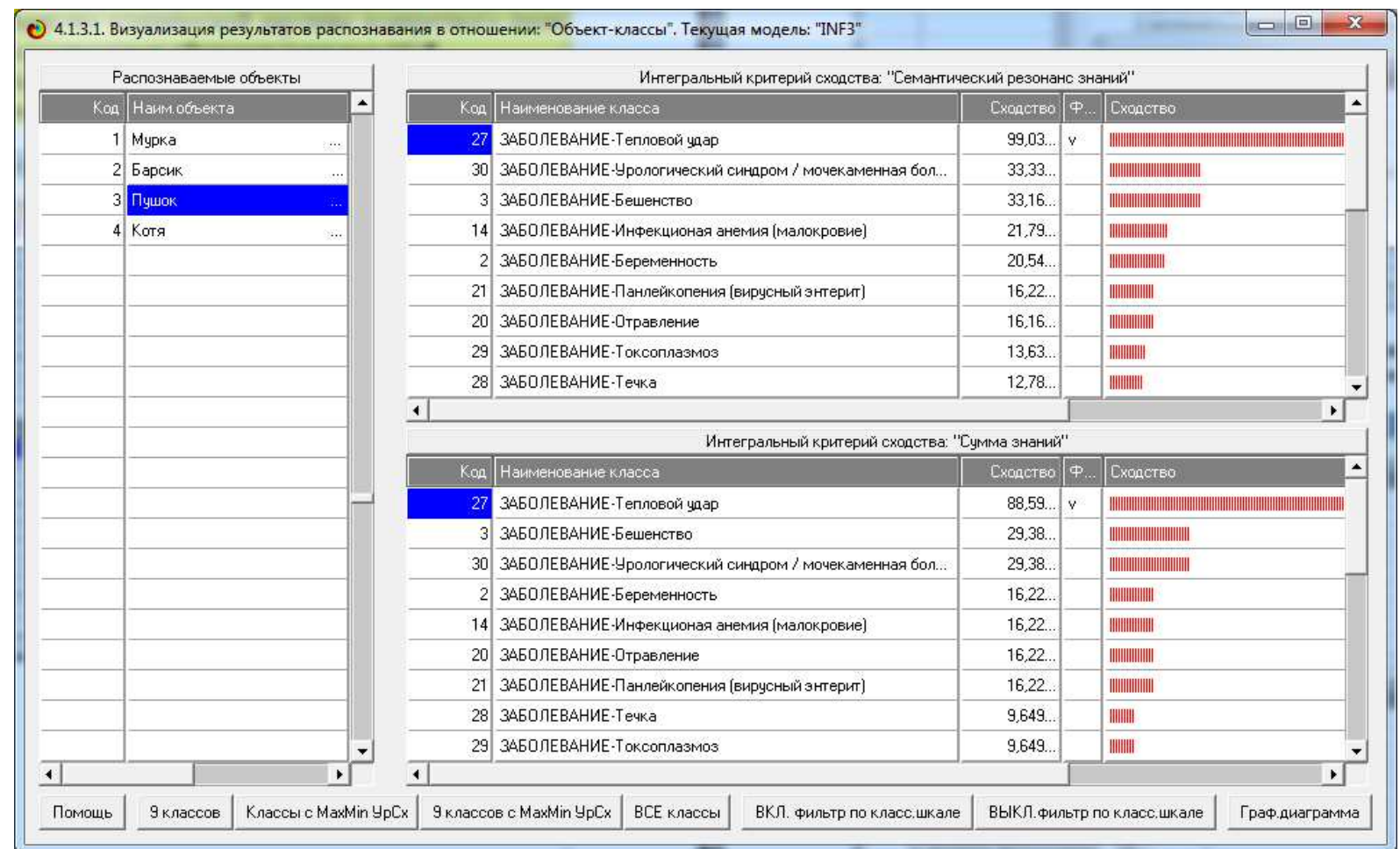

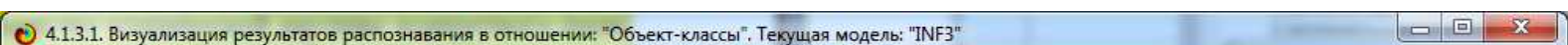

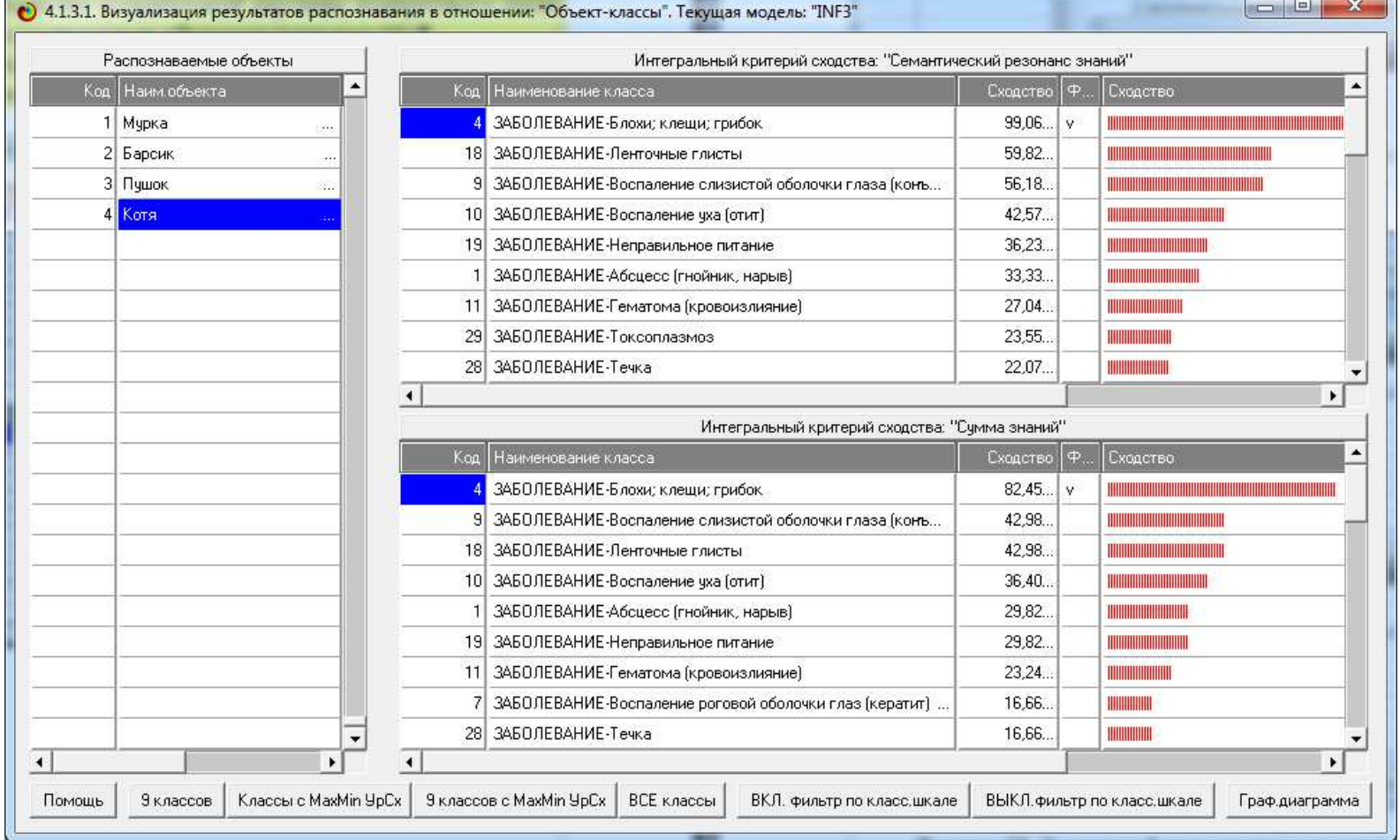

Рисунок 21. Экранная форма с результатами диагностики пациентов: «Мурка», «Барсик», «Пушок» и «Котя» (симптоматика из обучающей выборки) 


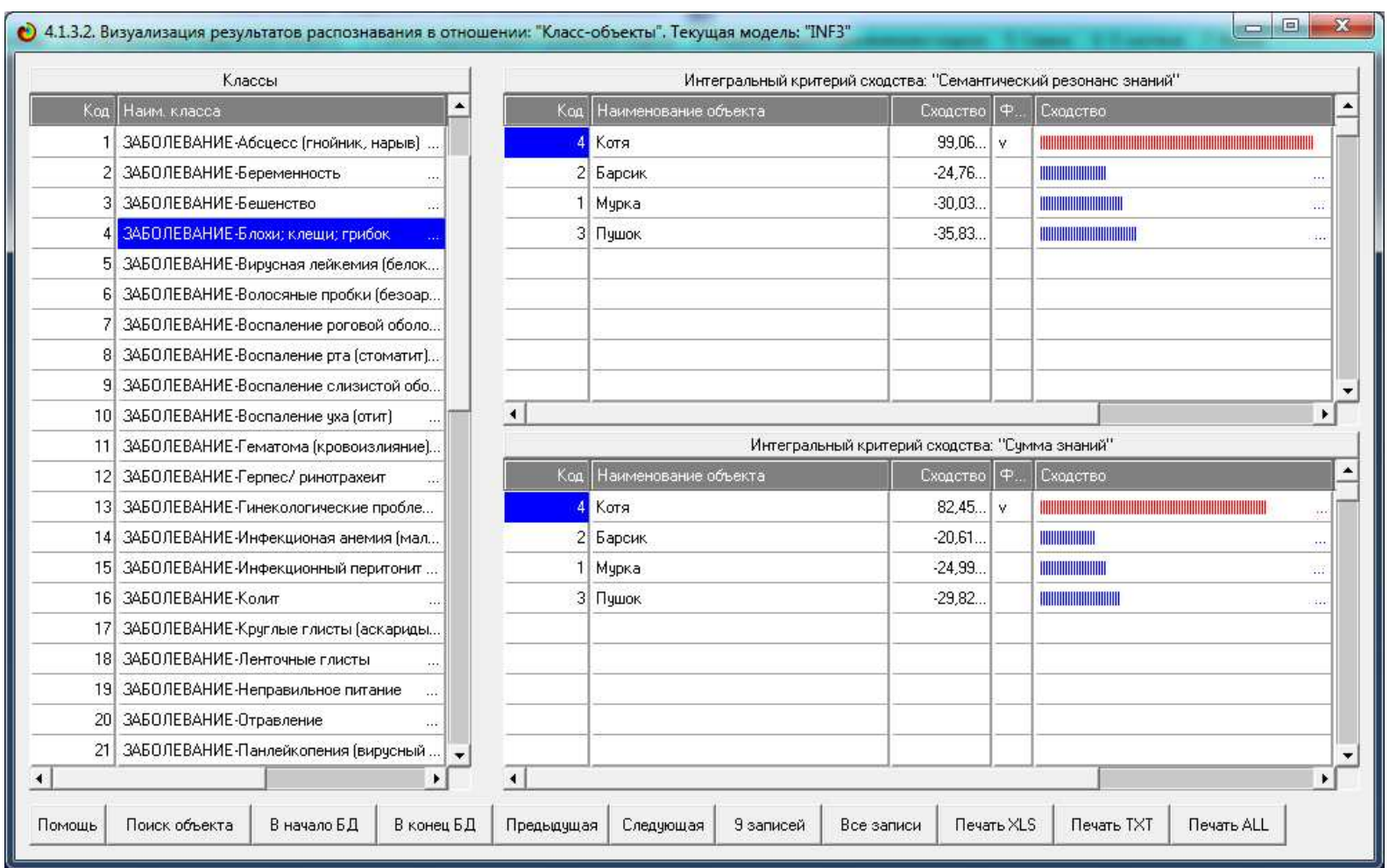

Рисунок 22. Экранная форма, отображающая сходство клинической картины различных пациентов с заданным нозологическим образом:

«Беременность»

Данные, приведенные на рисунке 21 необходимы для индивидуальной консультации врача по лечению конкретных пациентов. Однако если пациентов много, то имеет смысл сделать их группировку по предполагаемому диагнозу и провести лечение по группам, т.к. для пациентов каждой групп рекомендации будут сходными (рисунок 22).

Шаг 4-й. Выработка рекомендаций по лечению осуществляется врачом- ветеринаром на основе своего опыта и профессиональной компетенции в соответствии с действующими в данной предметной области медицинскими стандартами.

В этой связи необходимо сделать три взаимосвязанных замечания.

1. Совершенно ясно, что интеллектуальная система, хотя и может создавать такое впечатление, что она принимает решение, но поскольку сама система не является субъектом гражданского и уголовного права, т.е. не является гражданином, то необходимо выражаться аккуратнее и говорить, что система не принимает решения, а лишь поддерживает принятие решений, т.е. облегчает их для человека путем создания более комфортной информационной среды для принятия решений человеком. Понятно, что и юридическая ответственность за принимаемые решения может распространятся только на человека.

2. Система не принимает решения, а лишь консультирует специалиста. Статус интеллектуальной системы - именно статус консультанта. 
3. Но даже для придания системе статуса консультанта необходимо провести специальное юридически оформленное и имеющее соответствующие полномочия исследование того, в какой степени рекомендуемые системой решения лучше тех, которые бы принимались без системы экспертами неформализуемым путем на основе собственной интуиции и профессиональной компетенции. И если система создает преимущества в степени адекватности и других аспектов качества решений, то ей может быть официально придан статус консультирующей, после чего является корректным ее применение для тех целей, для которых она предназначена.

Понятно, что ворованные зарубежные разработки, нелокализованные и неадаптированные для России и предназначенные не для тех целей, для которых они фактически применяются в России, применяются совершенно некорректно и это вообще является профанацией всего этого научнопрактического направления.

На шестом этапе осуществляется исследование предметной области путем исследования ее моделей. Исследование моделей предметной области можно корректно считать исследованием самой предметной области только в том случае, если модели достаточно достоверны. В нашем случае это именно так (см. рисунки 11, 12).

На этом этапе может быть (в частности) исследована:

1. Значимость симптомов для диагностики, т.е. ценность их для дифференциации пациентов по диагнозам.

2. Характерность симптомов для тех или иных заболеваний (информационные портреты SWOT-диаграммы классов-диагнозов).

3. Диагностический смысл симптомов, т.е. их смысловая характеристика или количество информации в симптомах о заболеваниях (информационные портреты и SWOT-анализ признаков).

4. Сходство-различие нозологических образов друг с другом по их симптоматике (кластерно-конструктивный анализ классов).

5. Сходство-различие симптомов по их диагностическому смыслу (кластерно-конструктивный анализ симптомов). Выявление синдромов (устойчивых комплексов симптомов, как правило встречающихся вместе и имеющих сходный диагностический смысл).

6. Нелокальные нейроны и нейронные сети.

7. Содержательное сравнение классов друг с другом.

8. Содержательное сравнение симптомов друг с другом.

9. Интегральные когнитивные карты.

10. Когнитивные функции.

Кратко рассмотрим эти возможности исследования предметной области путем исследования ее наиболее достоверной модели INF3.

Шаг 1-й. Значимость симптомов для диагностики, т.е. ценность их для дифференциации по диагнозам. 
Значимость или иенность симптома для диагностики тем выше, чем выше вариабельность количества информации в нем о принадлежности и непринадлежности пациента с этим симптомом к каждому из заболеваний. Вся эта информация представлена в таблице 10 и на рисунке 23.

Таблица 10 - Ценность симптомов для диагностики в системно-когнитивной модели INF3

\begin{tabular}{|c|c|c|c|c|}
\hline № & $\begin{array}{c}\text { Код } \\
\text { симптома }\end{array}$ & Наименование симптома & $\begin{array}{c}\text { Код } \\
\text { Шкалы }\end{array}$ & $\begin{array}{c}\text { Значимость } \\
(\%)\end{array}$ \\
\hline 1 & 1 & PBOTA- & 1 & 1,7001259 \\
\hline 2 & 2 & PBOTA-\# & 1 & 1,7001259 \\
\hline 3 & 33 & ПОТЕРЯ ВЕСА- & 17 & 1,7001259 \\
\hline 4 & 34 & ПОТЕРЯ ВЕСА-\# & 17 & 1,7001259 \\
\hline 5 & 57 & ПОТЕРЯ ШЕРСТИ- & 29 & 1,7001259 \\
\hline 6 & 58 & ПОТЕРЯ ШЕРСТИ-\# & 29 & 1,7001259 \\
\hline 7 & 59 & ЯВНАЯ БОЛЬ- & 30 & 1,7001259 \\
\hline 8 & 60 & ЯВНАЯ БОЛЬ-\# & 30 & 1,7001259 \\
\hline 9 & 67 & ОТСУТСТВИЕ ЯВНЫХ СИМПТОМОВ- & 34 & 1,7001259 \\
\hline 10 & 68 & ОТСУТСТВИЕ ЯВНЫХ СИМПТОМОВ-\# & 34 & 1,7001259 \\
\hline 11 & 63 & НЕНОРМАЛЬНОЕ ПОВЕДЕНИЕ- & 32 & 1,6963438 \\
\hline 12 & 64 & НЕНОРМАЛЬНОЕ ПОВЕДЕНИЕ-\# & 32 & 1,6963438 \\
\hline 13 & 3 & ДИАРЕЯ(ПОНОС)- & 2 & 1,6849458 \\
\hline 14 & 4 & ДИАРЕЯ(ПОНОС)-\# & 2 & 1,6849458 \\
\hline 15 & 37 & ЗАТРЕДНЕННОЕ ДЫХАНИЕ- & 19 & 1,6657765 \\
\hline 16 & 38 & ЗАТРЕДНЕННОЕ ДЫХАНИЕ-\# & 19 & 1,6657765 \\
\hline 17 & 49 & ВЗДУТИЕ ЖИВОТА- & 25 & 1,6657765 \\
\hline 18 & 50 & ВЗДУТИЕ ЖИВОТА-\# & 25 & 1,6657765 \\
\hline 19 & 17 & КАШЕЛЬ И ЧИХАНИЕ- & 9 & 1,6385623 \\
\hline 20 & 18 & КАШЕЛЬ И ЧИХАНИЕ-\# & 9 & 1,6385623 \\
\hline 21 & 19 & ВЫПЯЧИВАНИЕ ТРЕТЬЕГО ВЕКА- & 10 & 1,6385623 \\
\hline 22 & 20 & ВЫПЯЧИВАНИЕ ТРЕТЬЕГО ВЕКА-\# & 10 & 1,6385623 \\
\hline 23 & 35 & БЛЕДНОСТЬ ДЕСЕН- & 18 & 1,6385623 \\
\hline 24 & 36 & БЛЕДНОСТЬ ДЕСЕН-\# & 18 & 1,6385623 \\
\hline 25 & 45 & ЛИХОРАДКА(ВЫСОКАЯ ТЕМПЕРАТУРА)- & 23 & 1,6385623 \\
\hline 26 & 46 & ЛИХОРАДКА(ВЫСОКАЯ ТЕМПЕРАТУРА)-\# & 23 & 1,6385623 \\
\hline 27 & 47 & ПОНИЖЕННАЯ ТЕМПЕРАТУРА- & 24 & 1,6385623 \\
\hline 28 & 48 & ПОНИЖЕННАЯ ТЕМПЕРАТУРА-\# & 24 & 1,6385623 \\
\hline 29 & 11 & ЧРЕЗМЕРНАЯ ЖАЖДА- & 6 & 1,6028941 \\
\hline 30 & 12 & ЧРЕЗМЕРНАЯ ЖАЖДА-\# & 6 & 1,6028941 \\
\hline 31 & 15 & СЛЮНОТЕЧЕНИЕ- & 8 & 1,6028941 \\
\hline 32 & 16 & СЛЮНОТЕЧЕНИЕ-\# & 8 & 1,6028941 \\
\hline 33 & 53 & РАЗДРАЖЕНИЕ КОЖИ- & 27 & 1,6028941 \\
\hline 34 & 54 & РАЗДРАЖЕНИЕ КОЖИ-\# & 27 & 1,6028941 \\
\hline 35 & 39 & ПОТЕРЯ СОЗНАНИЯ- & 20 & 1,5581912 \\
\hline 36 & 40 & ПОТЕРЯ СОЗНАНИЯ-\# & 20 & 1,5581912 \\
\hline 37 & 55 & ПОРАЖЕНИЕ КОЖИ/СЛИЗИСТЫХ/РОГОВИЦЫ- & 28 & 1,5036478 \\
\hline 38 & 56 & ПОРАЖЕНИЕ КОЖИ/СЛИЗИСТЫХ/РОГОВИЦЫ-\# & 28 & 1,5036478 \\
\hline 39 & 5 & उАПОР- & 3 & 1,4381454 \\
\hline 40 & 6 & ЗАПОР-\# & 3 & 1,4381454 \\
\hline 41 & 9 & ОТСУТСТВИЕ АППЕТИТА- & 5 & 1,4381454 \\
\hline 42 & 10 & ОТСУТСТВИЕ АППЕТИТА-\# & 5 & 1,4381454 \\
\hline 43 & 31 & ОБЕЗВОЖИВАНИЕ- & 16 & 1,4381454 \\
\hline 44 & 32 & ОБЕЗВОЖИВАНИЕ-\# & 16 & 1,4381454 \\
\hline 45 & 43 & ВНЕЗАПНАЯ СМЕРТЬ- & 22 & 1,4381454 \\
\hline 46 & 44 & ВНЕЗАПНАЯ СМЕРТЬ-\# & 22 & 1,4381454 \\
\hline 47 & 21 & ВЫДЕЛЕНИЯ ИЗ ГЛАЗ- & 11 & 1,3601008 \\
\hline 48 & 22 & ВЫДЕЛЕНИЯ ИЗ ГЛАЗ-\# & 11 & 1,3601008 \\
\hline 49 & 51 & ВЗДУТИЕ ПОД КОЖЕЙ- & 26 & 1,3601008 \\
\hline 50 & 52 & ВЗДУТИЕ ПОД КОЖЕЙ-\# & 26 & 1,3601008 \\
\hline 51 & 65 & ШОК- & 33 & 1,3601008 \\
\hline 52 & 66 & ШOK-\# & 33 & 1,3601008 \\
\hline 53 & 23 & ВЫДЕЛЕНИЯ ИЗ УШЕЙ- & 12 & 1,2671990 \\
\hline 54 & 24 & ВЫДЕЛЕНИЯ ИЗ УШЕЙ-\# & 12 & 1,2671990 \\
\hline 55 & 29 & ГЕНИТАЛЬНЫЕ ВЫДЕЛЕНИЯ- & 15 & 1,2671990 \\
\hline 56 & 30 & ГЕНИТАЛЬНЫЕ ВЫДЕЛЕНИЯ-\# & 15 & 1,2671990 \\
\hline 57 & 25 & ВЫДЕЛЕНИЯ ИЗ НОСА- & 13 & 1,1558634 \\
\hline 58 & 26 & ВЫДЕЛЕНИЯ ИЗ НОСА-\# & 13 & 1,1558634 \\
\hline 59 & 41 & ПАРАЛИЧ- & 21 & 1,1558634 \\
\hline 60 & 42 & ПАРАЛИЧ-\# & 21 & 1,1558634 \\
\hline 61 & 61 & XPOMOTA- & 31 & 1,1558634 \\
\hline 62 & 62 & XPOMOTA-\# & 31 & 1,1558634 \\
\hline 63 & 13 & НЕНОРМАЛЬНОЕ МОЧЕИСПУСКАНИЕ- & 7 & 1,0200756 \\
\hline 64 & 14 & НЕНОРМАЛЬНОЕ МОЧЕИСПУСКАНИЕ-\# & 7 & 1,0200756 \\
\hline 65 & 27 & АНАЛЬНЫЕ ВЫДЕЛЕНИЯ- & 14 & 1,0200756 \\
\hline 66 & 28 & АНАЛЬНЫЕ ВЫДЕЛЕНИЯ-\# & 14 & 1,0200756 \\
\hline 67 & 7 & КРОВЬ В КАЛЕ- & 4 & 0,8481717 \\
\hline 68 & 8 & КРОВЬ В КАЛЕ-\# & 4 & 0,8481717 \\
\hline
\end{tabular}


Из таблицы 10 видно, что симптомы имеют различную значимость, т.е. ценность, для диагностики. На рисунке 23 приведена Ценность симптомов для диагностики «нарастающим итогом» в системно-когнитивной модели INF4:

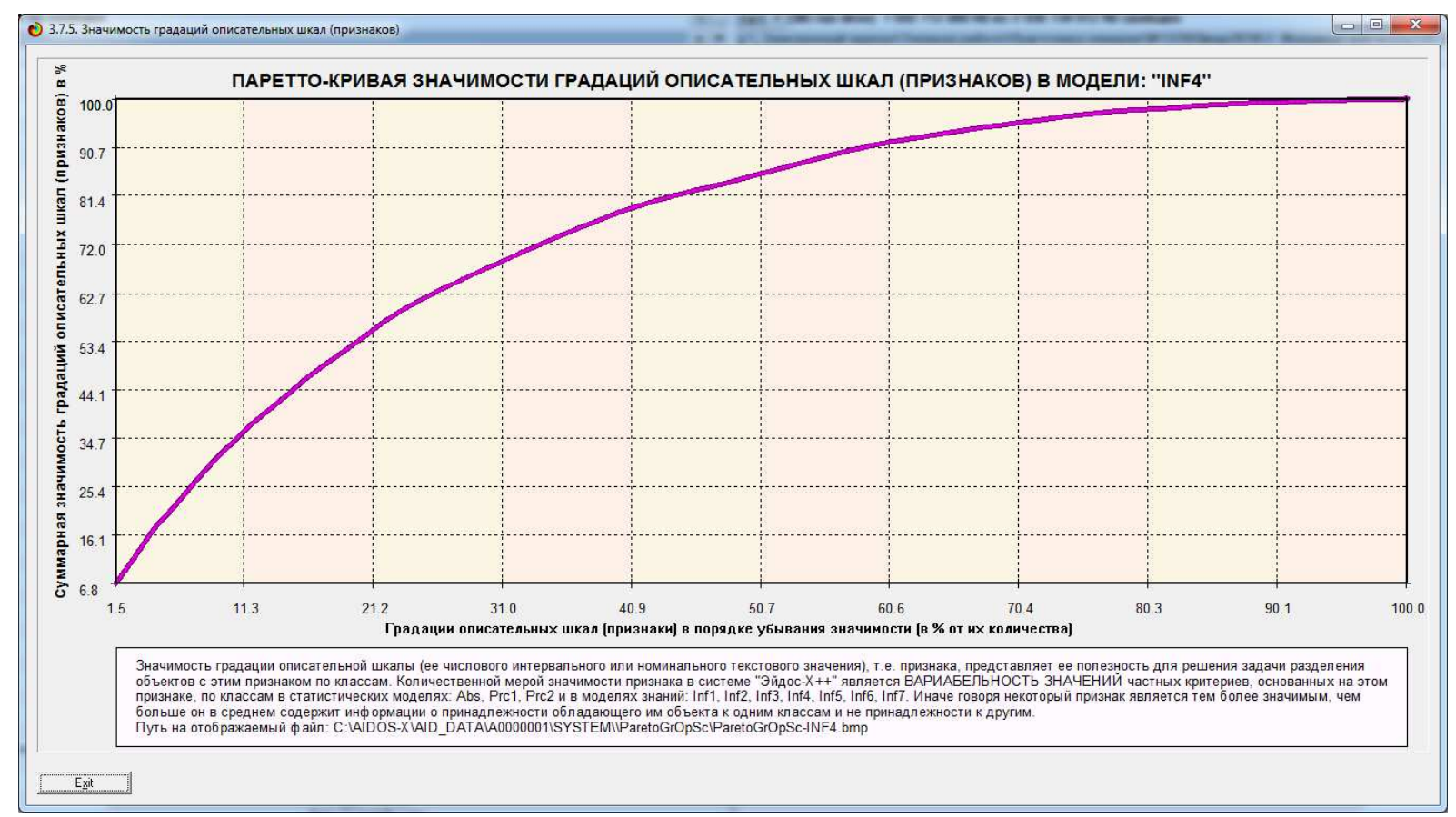

Рисунок 23. Ценность симптомов для диагностики «нарастающим итогом» в системно-когнитивной модели INF4

Из рисунка 23 видно, что 50\% наиболее значимых симптомов обеспечивают около $83 \%$ суммарной ценности системы всех симптомов, а $50 \%$ суммарной ценности обеспечивают менее $20 \%$ наиболее ценных симптомов.

Ценностью диагностической шкалы будем считать среднее значимостей ее градаций (таблица 11):

\section{Таблица 11 - Ценность описательных шкал для диагностики} в системно-когнитивной модели INF3

\begin{tabular}{|c|c|l|c|}
\hline № & $\begin{array}{c}\text { Код } \\
\text { шкалы }\end{array}$ & \multicolumn{1}{|c|}{ Наименование шкалы } & $\begin{array}{c}\text { 3начимость } \\
(\%)\end{array}$ \\
\hline 1 & 1 & РВОТА & 3,4002517 \\
\hline 2 & 17 & ПОТЕРЯ ВЕСА & 3,4002517 \\
\hline 3 & 29 & ПОТЕРЯ ШЕРСТИ & 3,4002517 \\
\hline 4 & 30 & ЯВНАЯ БОЛЬ & 3,4002517 \\
\hline 5 & 34 & ОТСУТСТВИЕ ЯВНЫХ СИМПТОМОВ & 3,4002517 \\
\hline 6 & 32 & НЕНОРМАЛЬНОЕ ПОВЕДЕНИЕ & 3,3926876 \\
\hline 7 & 2 & ДИАРЕЯ(ПОНОС) & 3,3698917 \\
\hline 8 & 19 & ЗАТРУДНЕННОЕ ДЫХАНИЕ & 3,3315530 \\
\hline 9 & 25 & ВЗДУТИЕ ЖИВОТА & 3,3315530 \\
\hline 10 & 9 & КАШЕЛЬ ИЧИХАНИЕ & 3,2771246 \\
\hline 11 & 10 & ВЫПЯЧИВАНИЕ ТРЕТЬЕГО ВЕКА & 3,2771246 \\
\hline 12 & 18 & БЛЕДНОСТЬ ДЕСЕН & 3,2771246 \\
\hline 13 & 23 & ЛИХОРАДКА(ВЫСОКАЯ ТЕМПЕРАТУРА) & 3,2771246 \\
\hline 14 & 24 & ПОНИЖЕННАЯ ТЕМПЕРАТУРА & 3,2771246 \\
\hline 15 & 6 & ЧРЕЗМЕРНАЯ ЖАЖДА & 3,2057882 \\
\hline 16 & 8 & СЛЮНОТЕЧЕНИЕ & 3,2057882 \\
\hline 17 & 27 & РАЗДРАЖЕНИЕ КОЖИ & 3,2057882 \\
\hline 18 & 20 & ПОТЕРЯ СОЗНАНИЯ & 3,1163823 \\
\hline 19 & 28 & ПОРАЖЕНИЕ КОЖИ/СЛИЗИСТЫХ/РОГОВИЦЫ & 3,0072956 \\
\hline
\end{tabular}




\begin{tabular}{|l|c|l|r|}
20 & 3 & ЗАПОР & 2,8762909 \\
\hline 21 & 5 & ОТСУТСТВИЕ АППЕТИТА & 2,8762909 \\
\hline 22 & 16 & ОБЕЗВОЖИВАНИЕ & 2,8762909 \\
\hline 23 & 22 & ВНЕЗАПНАЯ СМЕРТЬ & 2,8762909 \\
\hline 24 & 11 & ВЫДЕЛЕНИЯ ИЗ ГЛАЗ & 2,7202015 \\
\hline 25 & 26 & ВЗДУТИЕ ПОД КОЖЕИ & 2,7202015 \\
\hline 26 & 33 & ШОК & 2,7202015 \\
\hline 27 & 12 & ВЫДЕЛЕНИЯ ИЗ УШЕИ & 2,5343980 \\
\hline 28 & 15 & ГЕНИТАЛЬНЫЕ ВЫДЕЛЕНИЯ & 2,5343980 \\
\hline 29 & 13 & ВЫДЕЛЕНИЯ ИЗ НОСА & 2,3117267 \\
\hline 30 & 21 & ПАРАЛИЧ & 2,3117267 \\
\hline 31 & 31 & ХРОМОТА & 2,3117267 \\
\hline 32 & 7 & НЕНОРМАЛЬНОЕ МОЧЕИСПУСКАНИЕ & 2,0401513 \\
\hline 33 & 14 & АНАЛЬНЫЕ ВЫДЕЛЕНИЯ & 2,0401513 \\
\hline 34 & 4 & КРОВЬ В КАЛЕ & 1,6963435 \\
\hline
\end{tabular}

Из таблицы 11 видно, что ценность диагностических шкал отличается примерно в 2 раза.

Щаг 2-й. Характерность симптомов для тех или иных заболеваний (информационные портреты SWOT-диаграммы классов-диагнозов).

Информационный портрет класса - это список факторов, ранжированных в порядке убывания силы их влияния на переход объекта управления в состояние, соответствующее данному классу. Информационный портрет класса отражает систему его детерминации. Генерация информационного портрета класса представляет собой решение обратной задачи прогнозирования, т.к. при прогнозировании по системе факторов определяется спектр наиболее вероятных будущих состояний объекта управления, в которые он может перейти под влиянием данной системы факторов, а в информационном портрете мы наоборот, по заданному будущему состоянию объекта управления определяем систему факторов, детерминирующих это состояние, т.е. вызывающих переход объекта управления в это состояние. В начале информационного портрета класса идут факторы, оказывающие положительное влияние на переход объекта управления в заданное состояние, затем факторы, не оказывающие на это существенного влияния, и далее - факторы, препятствующие переходу объекта управления в это состояние (в порядке возрастания силы препятствования). Информационные портреты классов могут быть от отфильтрованы по диапазону факторов, т.е. мы можем отобразить влияние на переход объекта управления в данное состояние не всех отраженных в модели факторов, а только тех, коды которых попадают в определенный диапазон, например, относящиеся к определенным описательным шкалам. Пример информационного портрета и SWOT-диаграммы класса (нозологического образа) «Беременность» в модели Inf3 (Хи-квадрат) приведен на рисунке 24: 


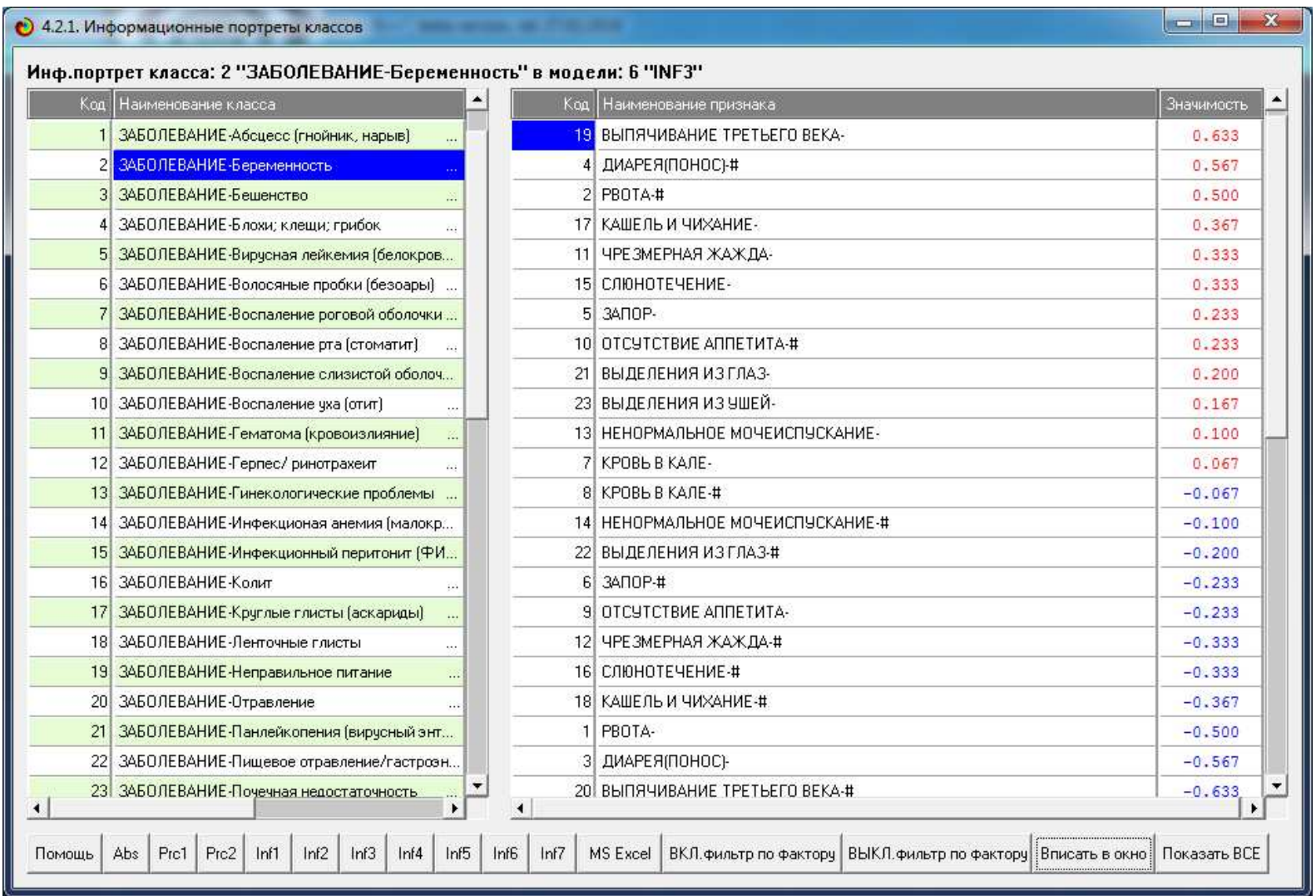

\begin{tabular}{|c|c|c|c|c|}
\hline \multicolumn{5}{|c|}{ Выбор класса, соответствующего будущему состоянию объекта управления } \\
\hline Kog & Наименование класса & Редчкцияклас. & Nagbektos [ä́c)] & Nótrektos (28) -1 \\
\hline & ЗАБОЛЕВАНИЕ-АбсцесС (гнойник, нарыЕ) & 0,4553715 & 34 & 3,3333333 \\
\hline & ЗАБОЛЕВАНИЕ-БеременНОСТЬ & 0.4019851 & 34 & 3,3333333 \\
\hline & ЗАБОЛЕВАНИЕ-БешенСТВО & 0.4509801 & 34 & 3,3333333 \\
\hline 4 & ЗАБОЛЕВАНИЕ-Блохи; Клещи; грибок & 0.4236773 & 34 & 3,3333333 \\
\hline & ЗАБОЛЕВАНИЕ-Вирусная лейкемия (белокровие) & 0.4069056 & 34 & 3,3333333 \\
\hline 4 & 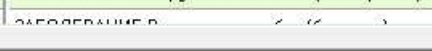 & nomenoret & 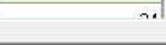 & mammer \\
\hline
\end{tabular}

SWOT-анализ класса: 2 "ЗАБОЛЕВАНИЕ-Беременность" в модели: 6 "INF3"

Способствующие фракторы и сила их влияния

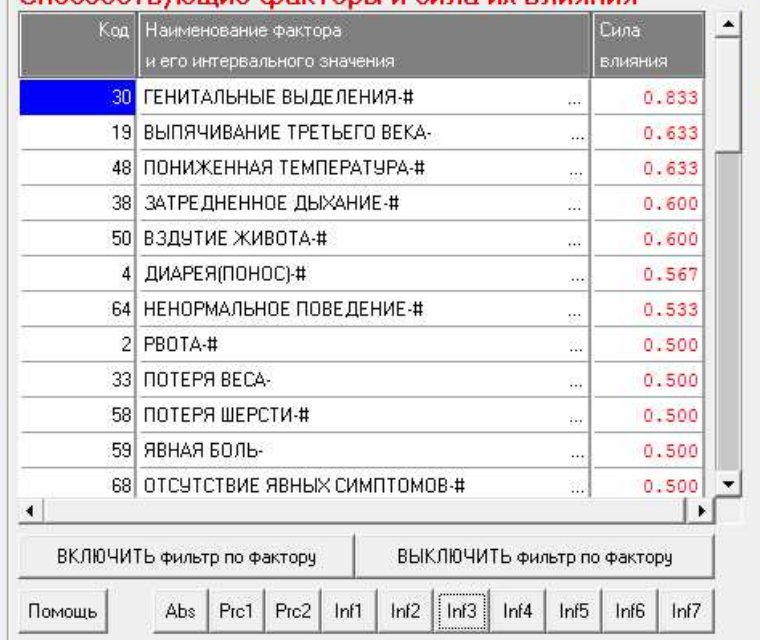

Препятствующие фракторы и сила их влияния

\begin{tabular}{|c|c|c|c|}
\hline Kon & \multicolumn{2}{|c|}{$\begin{array}{l}\text { Наименование фақтора } \\
\text { и его интервального значения: }\end{array}$} & $\begin{array}{l}\text { Сила } \\
\text { влияния }\end{array}$ \\
\hline 29 & \multicolumn{2}{|c|}{ ГЕНИТАЛЬНЫЕ ВЫДЕЛЕНИЯ- } & -0.833 \\
\hline 47 & \multicolumn{2}{|c|}{ ПОНИЖЕННАЯЯ ТЕМПЕРАТУРА. } & -0.633 \\
\hline 20 & \multicolumn{2}{|c|}{ ВЫПЯЧИВАНИЕ ТРЕТЬЕГО ВЕКА.\# } & -0.633 \\
\hline 49 & \multicolumn{2}{|l|}{ ВЗДУТИЕ ЖИВОТА- } & -0.600 \\
\hline 37 & \multicolumn{2}{|c|}{ ЗАТРЕДНЕННОЕ ДЫХАНИЕ- } & -0.600 \\
\hline 3 & \multicolumn{2}{|l|}{ ДИАРЕЯ(ПОНОС)- } & -0.567 \\
\hline 63 & \multicolumn{2}{|c|}{ НЕНОРМАЛЬНОЕ ПОВЕДЕНИЕ- } & -0.533 \\
\hline 67 & \multicolumn{2}{|c|}{ ОТСУТСТВИЕ ЯВНЫХ СИМПТОМОВ- } & -0.500 \\
\hline 60 & \multicolumn{2}{|l|}{ ЯвНАЯ БОЛЬ-\# } & -0.500 \\
\hline 57 & \multicolumn{2}{|l|}{ ПОТЕРЯ ШЕРСТИ. } & -0.500 \\
\hline 34 & \multicolumn{2}{|l|}{ ПOTEPЯ ВECA-\# } & -0.500 \\
\hline & \multicolumn{2}{|l|}{ PBOTA. } & -0.500 \\
\hline \multicolumn{4}{|c|}{ ВКлюЧИТЬ фильтр по фактору } \\
\hline Нейрон & SWOT-диarpamma & Инте & пивная карта \\
\hline
\end{tabular}




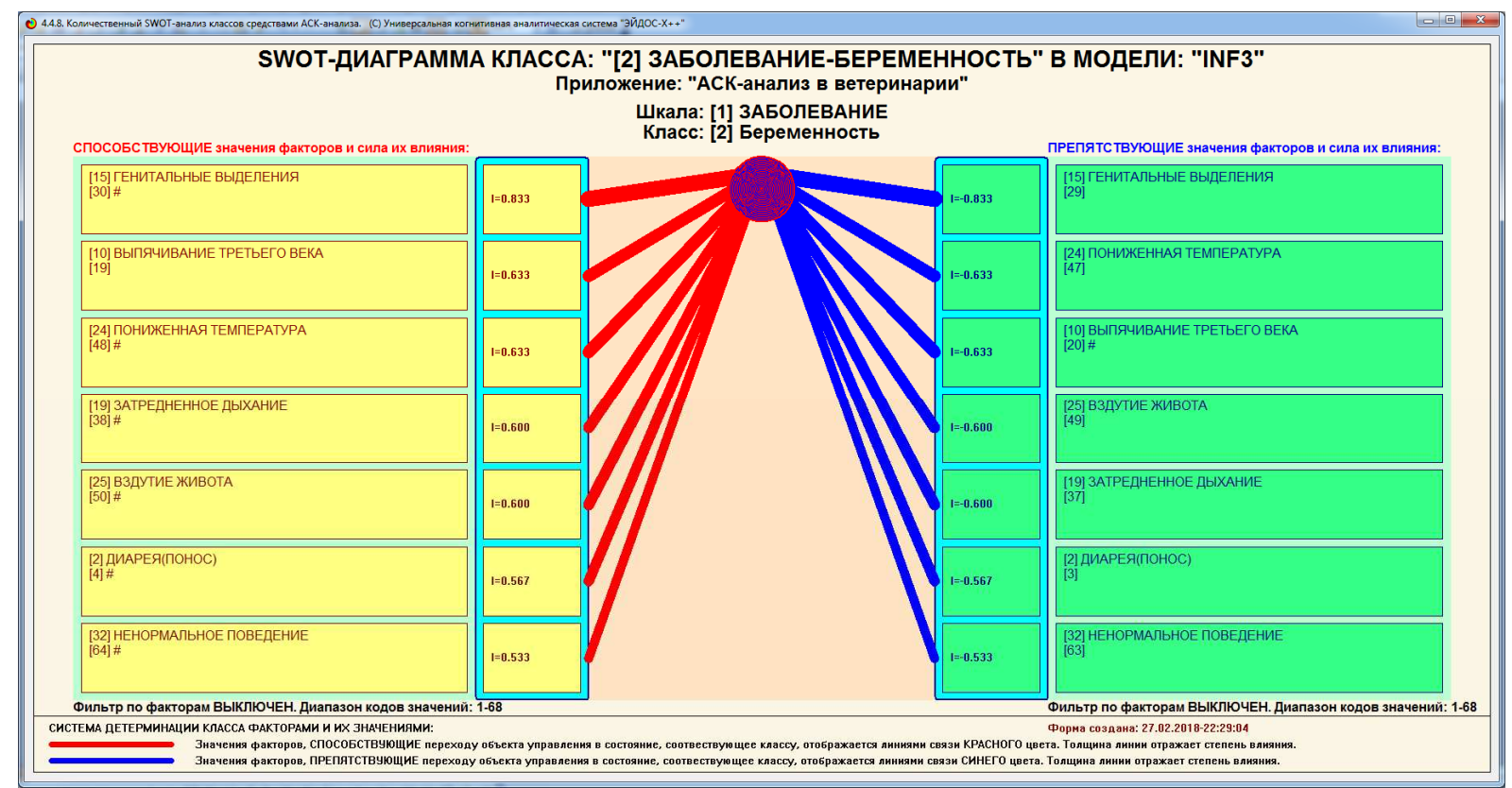

Рисунок 24. Пример информационного портрета и SWOT-диаграммы класса (нозологического образа) «Беременность» в модели Inf3 (Хи-квадрат)

Если сравнить оценку характерности симптомов в системе Эйдос$\mathrm{X}++$ на рисунке 24 по этому нозологическому образу и в таблице 1, с информацией с сайта [6], то мы увидим высокое соответствие их друг другу. Из этого можно сделать вывод, что система «Эйдос» сама может определять характерность симптомов.

Шаг 3-й. Диагностический смысл симптомов, т.е. их смысловая характеристика или количество информации в симптомах о заболеваниях (информационные портреты и SWOT-анализ признаков).

Информационный (семантический) портрет значения фактора (симптома) - это список классов, ранжированный в порядке убывания силы влияния данного фактора на переход объекта управления в состояния, соответствующие данным классам. Информационный портрет фактора называется также его семантическим портретом, т.к. в соответствии с концепцией смысла системно-когнитивного анализа, являющейся обобщением концепции смысла Шенка-Абельсона, смысл фактора состоит в том, какие будущие состояния объекта управления он детерминирует. Сначала в этом списке идут состояния объекта управления, на переход в которые данный фактор оказывает наибольшее влияние, затем состояния, на которые данный фактор не оказывает существенного влияния, и далее состояния - переходу в которые данный фактор препятствует. Информационные портреты факторов могут быть от отфильтрованы по диапазону классов, т.е. мы можем отобразить влияние данного фактора на переход объекта управления не во все возможные будущие состояния, а только в состояния, коды которых попадают в определенный диапазон, например, относящиеся к определенным классификационным шкалам. 
Пример информационного портрета и инвертированной SWOTдиаграммы симптома: «Выпячивание третьего века» в модели Inf3 (Хиквадрат) приведен на рисунке 25 [11]:

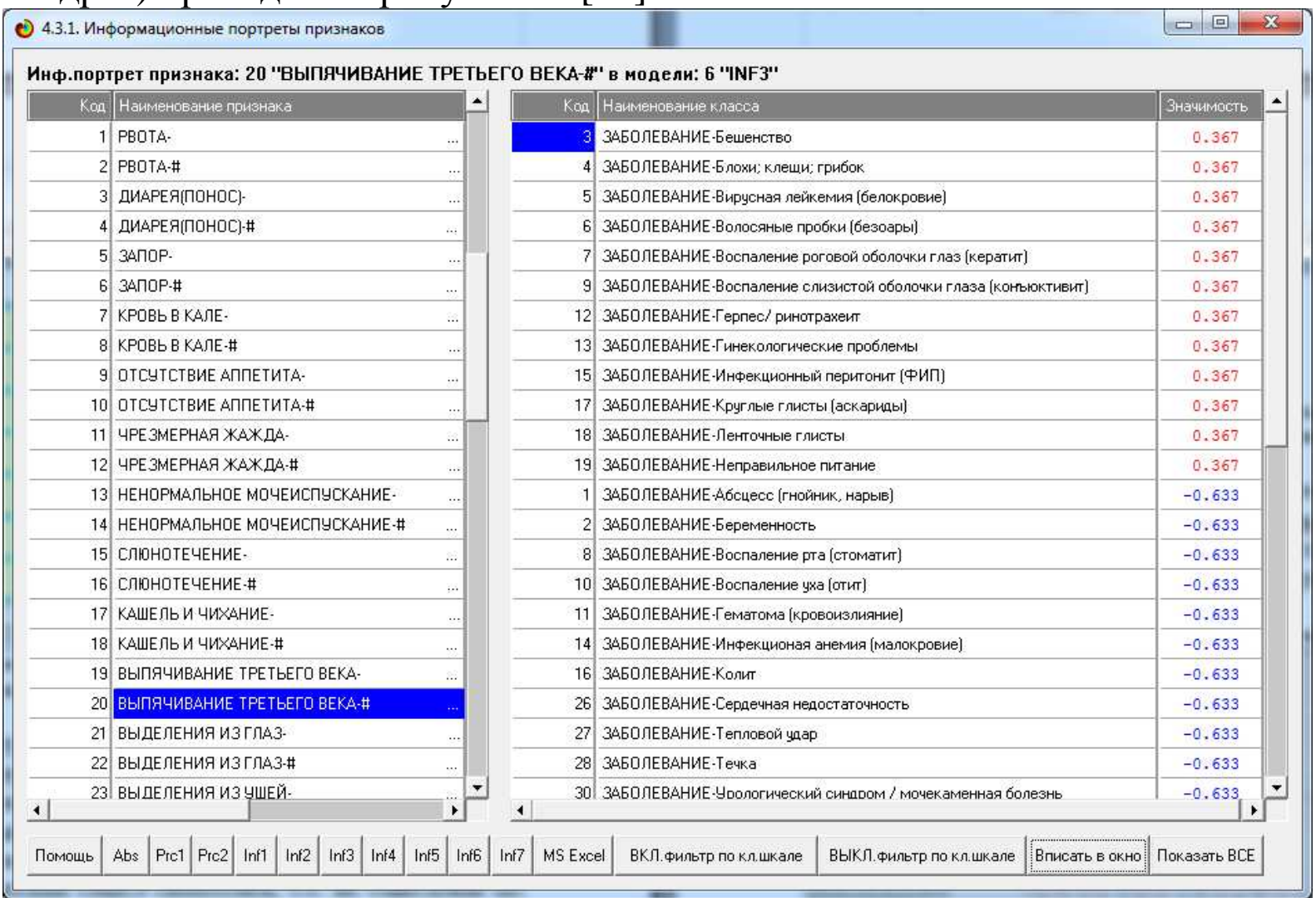

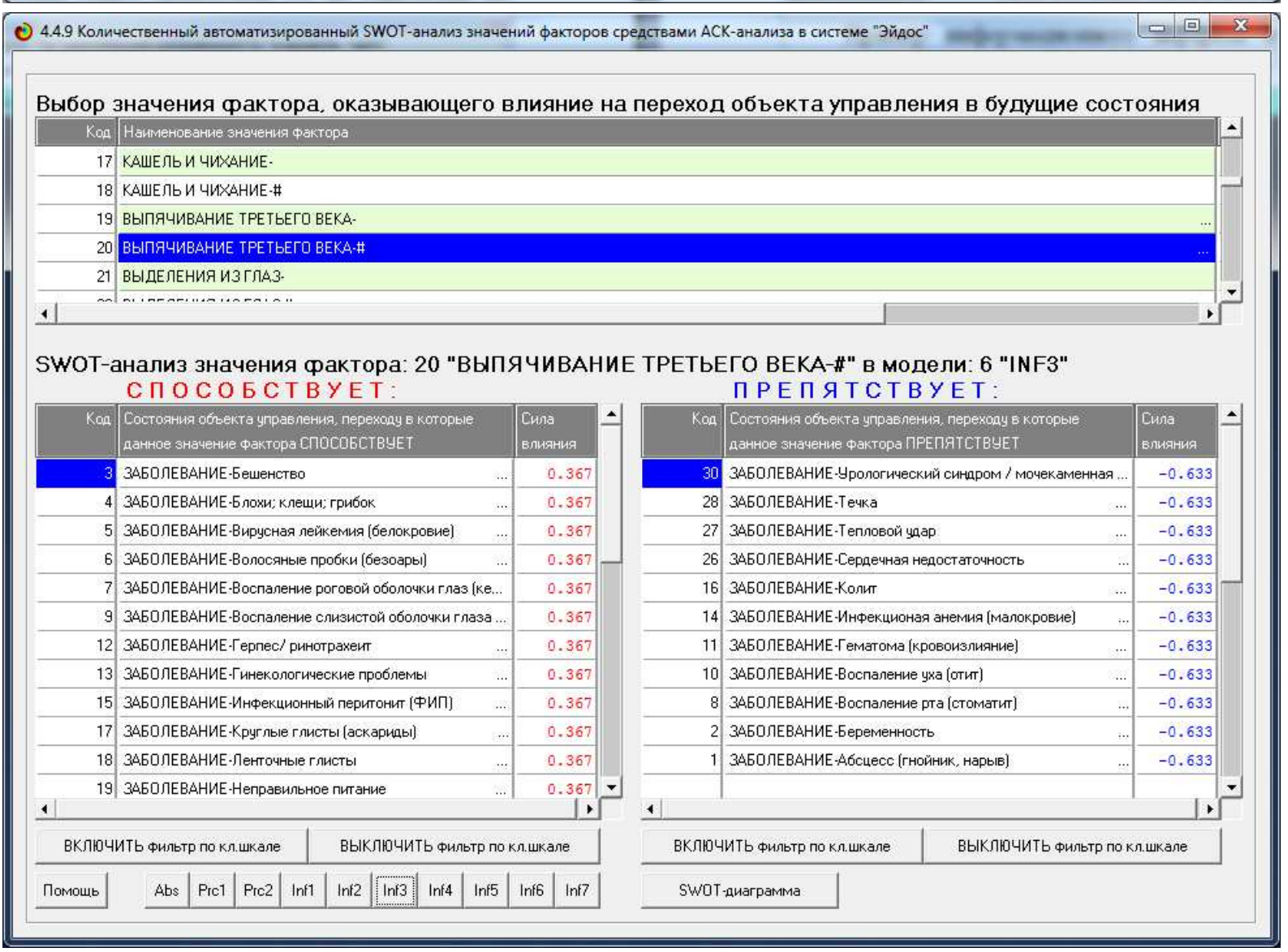




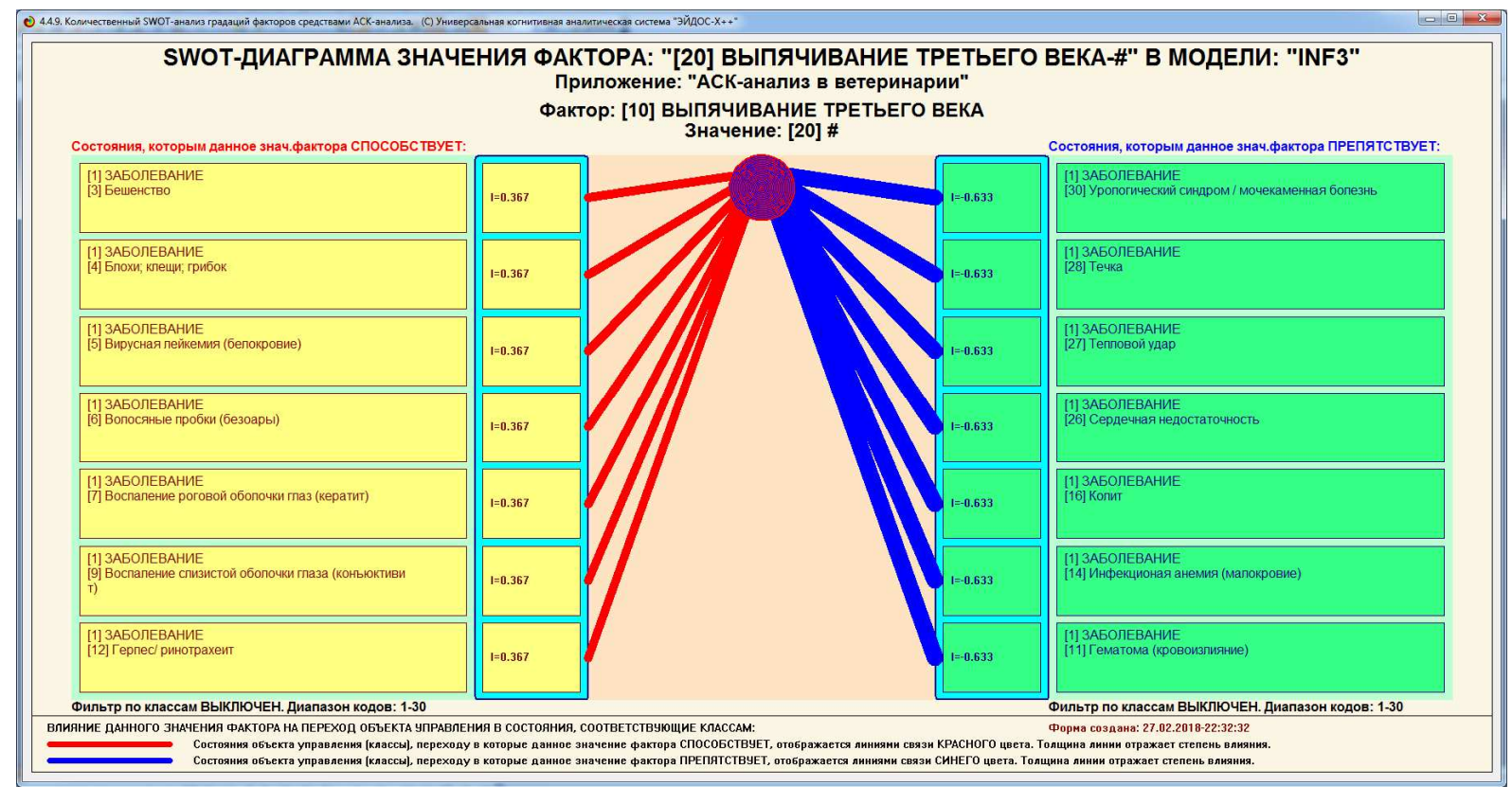

Рисунок 25. Пример информационного портрета и инвертированной SWOTдиаграммы симптома: «Выпячивание третьего века» в модели Inf3 (Хи-квадрат)

Шаг 4-й. Сходство-различие нозологических образов друг с другом по их симптоматике (кластерно-конструктивный анализ классов).

В таблице 12 приведена матрица сходства-различия нозологических образов в модели INF3, фрагмент которой в графической форме показан на рисунке 26:

Таблица 12 - Матрица сходства-различия нозологических образов в модели INF3

\begin{tabular}{|c|c|c|c|c|c|c|c|c|c|c|c|c|c|c|c|c|c|c|c|c|c|c|c|c|c|c|c|c|c|c|}
\hline 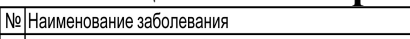 & N1 & N2 & N3 & $\mathrm{N} 4$ & N5 & N6 & N7 & N8 & N99 & N10 & N11 & N12 & $\mathrm{N} 13$ & N14 & N15 & N16 & N17 & & \begin{tabular}{|l|l|l|}
$N 19$ & 1 \\
\end{tabular} & \begin{tabular}{|l|l|l|l|l|}
$N 20$ & 1 \\
\end{tabular} & & & & \begin{tabular}{|l|l|l|l|l}
$N 24$ & $N$ \\
\end{tabular} & & N26 & N27 & \begin{tabular}{|l|l|l|}
$N 28$ & 1 \\
\end{tabular} & \begin{tabular}{|l|l|l}
$N 29$ & 1 \\
\end{tabular} & $\mathrm{~N} 30$ \\
\hline \begin{tabular}{|l|l}
1 & Абсцесс (гнойник, нарыВ) \\
\end{tabular} & 100 & -22 & 6 & 38 & -52 & -22 & 17 & 17 & 34 & 62 & 63 & 20 & -33 & -28 & -20 & 35 & -27 & 13 & -9 & \begin{tabular}{|l|}
-47 \\
\end{tabular} & \begin{tabular}{|l|l|}
-35 \\
\end{tabular} & \begin{tabular}{|l|}
-36 \\
\end{tabular} & -31 & -11 & -19 & 3 & $\mid-15$ & 33 & \begin{tabular}{c|}
-6 \\
\end{tabular} & -10 \\
\hline \begin{tabular}{|l|l|}
2 & Беременность \\
\end{tabular} & -22 & 100 & -31 & -14 & 27 & 8 & -25 & -20 & -5 & -2 & -1 & $\mid-31$ & 19 & 22 & 24 & -13 & 16 & -11 & 20 & 1 & -28 & \begin{tabular}{c|c}
6 \\
\end{tabular} & -23 & -4 & -26 & -0 & 11 & 13 & -13 & 18 \\
\hline \begin{tabular}{|l|l|}
3 & Бешенство \\
\end{tabular} & 6 & -31 & 100 & $\mid-17$ & -46 & 2 & 7 & -7 & 8 & 24 & 9 & -3 & -0 & -38 & -29 & 13 & -50 & 3 & -34 & 23 & 23 & \begin{tabular}{|c|}
-15 \\
\end{tabular} & -11 & 5 & 1 & -4 & 35 & 7 & -17 & 12 \\
\hline \begin{tabular}{|l|l|}
4 & Блохи; клещи; грибок \\
\end{tabular} & 38 & -14 & -17 & 100 & -12 & -31 & 9 & -6 & 46 & 43 & 28 & 14 & \begin{tabular}{|l|}
-13 \\
\end{tabular} & -2 & -29 & 15 & 12 & 43 & 33 & -43 & -30 & -46 & -10 & \begin{tabular}{l|l}
-6 \\
\end{tabular} & -27 & -3 & -39 & 9 & 4 & -33 \\
\hline \begin{tabular}{|l|l|}
5 & Вирусная лейкемия (белокровие) \\
\end{tabular} & -52 & 27 & -46 & -12 & 100 & 9 & -42 & -35 & -41 & -51 & -34 & -30 & 35 & 62 & 42 & -44 & 34 & -10 & 21 & 31 & 16 & 24 & 43 & 10 & 7 & 1 & -20 & -43 & 9 & -14 \\
\hline \begin{tabular}{|l|l|}
6 & Волосяные пробки (безоары) \\
\end{tabular} & -22 & 8 & 2 & -31 & 9 & 100 & -6 & 15 & -24 & -19 & -18 & -15 & 4 & 2 & 7 & -30 & 16 & -11 & 20 & 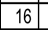 & 1 & 75 & -7 & 21 & -26 & -16 & -22 & -26 & -13 & -15 \\
\hline \begin{tabular}{|l|l}
7 & Воспаление роговой оболочки глаз (кератит) \\
\end{tabular} & 17 & -25 & 7 & 9 & -42 & -6 & 100 & 56 & 60 & 3 & 4 & 24 & -38 & -32 & -23 & 42 & -13 & -5 & -29 & -24 & -25 & -6 & -19 & -38 & 11 & -12 & -17 & 40 & 15 & 7 \\
\hline \begin{tabular}{|l|l|}
8 & Воспаление рта (стоматит) \\
\end{tabular} & 17 & -20 & -7 & -6 & -35 & 15 & 56 & 100 & 21 & 5 & 5 & 39 & -46 & -8 & -34 & 24 & -10 & -2 & -40 & -34 & -34 & 12 & -31 & -10 & 27 & 6 & -13 & 20 & 16 & -7 \\
\hline \begin{tabular}{|l|l}
9 & Воспаление слизистой оболочки глаза (конъюктивит) \\
\end{tabular} & 34 & -5 & 8 & 46 & -41 & -24 & 60 & 21 & 100 & 21 & 22 & 42 & -37 & -31 & -39 & 42 & 5 & 37 & 9 & -39 & -39 & -41 & \begin{tabular}{|l|}
-19 \\
\end{tabular} & -51 & -5 & -27 & -17 & 40 & -6 & -10 \\
\hline \begin{tabular}{|l|l|}
10 & Воспаление уха (отит) \\
\end{tabular} & 62 & -2 & 24 & 43 & \begin{tabular}{|c|}
-51 \\
\end{tabular} & -19 & 3 & 5 & 21 & 100 & 53 & -6 & \begin{tabular}{|c|}
-17 \\
\end{tabular} & -26 & -33 & 40 & -25 & 36 & -6 & -46 & -34 & -35 & \begin{tabular}{|l|}
-45 \\
\end{tabular} & -21 & -17 & -8 & 2 & 38 & -3 & -7 \\
\hline \begin{tabular}{|l|l|}
11 Гематома (кровоизлияние) \\
\end{tabular} & 63 & -1 & 9 & 28 & -34 & -18 & 4 & 5 & 22 & 53 & 100 & -6 & -45 & -7 & \begin{tabular}{|c|}
-33 \\
\end{tabular} & 25 & -24 & 36 & -6 & -46 & -46 & \begin{tabular}{|l|}
-34 \\
\end{tabular} & \begin{tabular}{|l|}
-14 \\
\end{tabular} & \begin{tabular}{|l|}
-32 \\
\end{tabular} & -2 & 21 & 3 & 21 & -2 & -6 \\
\hline \begin{tabular}{|l|l|}
12 & Герпес/ ринотрахеит \\
\end{tabular} & 20 & -31 & -3 & 14 & -30 & -15 & 24 & 39 & 42 & -6 & -6 & 100 & -41 & -21 & 2 & -2 & 25 & 21 & \begin{tabular}{|l|}
-18 \\
\end{tabular} & -42 & -29 & \begin{tabular}{|l|}
-30 \\
\end{tabular} & \begin{tabular}{|l|}
-25 \\
\end{tabular} & 5 & 58 & -4 & \begin{tabular}{|c|}
-9 \\
\end{tabular} & -11 & 38 & -47 \\
\hline \begin{tabular}{|l|l|}
13 & инекологические проблемь \\
\end{tabular} & -33 & 19 & -0 & -13 & 35 & 4 & -38 & -46 & -37 & \begin{tabular}{|c|}
-17 \\
\end{tabular} & -45 & -41 & 100 & -0 & 45 & -39 & -3 & -28 & 15 & 35 & 47 & 17 & 33 & 26 & -23 & -27 & -6 & $|-23|$ & -29 & 26 \\
\hline $14 \mid$ Инфекционая анемия (малокровие) & -28 & 22 & -38 & -2 & 62 & 2 & -32 & -8 & -31 & -26 & -7 & -21 & -0 & 100 & 2 & -19 & 29 & 3 & 16 & -3 & -4 & 1 & 22 & -8 & -15 & 11 & 7 & \begin{tabular}{|l|}
-13 \\
\end{tabular} & 24 & -21 \\
\hline \begin{tabular}{|l|l|}
15 & Инекциионный перитонит (ФИП) \\
\end{tabular} & -20 & 24 & -29 & -29 & 42 & 7 & -23 & -34 & -39 & -33 & -33 & 2 & 45 & 2 & 100 & -42 & 30 & -29 & 2 & 14 & 14 & 5 & 9 & 31 & 20 & -15 & -20 & -23 & 7 & -14 \\
\hline 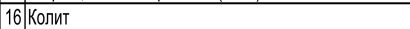 & 35 & -13 & 13 & 15 & -44 & -30 & 42 & 24 & 42 & 40 & 25 & -2 & -39 & -19 & -42 & 100 & -19 & 22 & \begin{tabular}{|c|}
-17 \\
\end{tabular} & -28 & \begin{tabular}{|l|}
-15 \\
\end{tabular} & \begin{tabular}{|l|}
-29 \\
\end{tabular} & -24 & -39 & \begin{tabular}{l|}
-12 \\
\end{tabular} & -17 & 6 & 59 & \begin{tabular}{|c|}
-16 \\
\end{tabular} & 12 \\
\hline \begin{tabular}{|l|l|}
17 Круглые глисты (аскариды) \\
\end{tabular} & -27 & 16 & -50 & 12 & 34 & 16 & -13 & -10 & 5 & -25 & -24 & 25 & -3 & 29 & 30 & \begin{tabular}{|l|}
-19 \\
\end{tabular} & 100 & 18 & 43 & \begin{tabular}{|l|}
-18 \\
\end{tabular} & \begin{tabular}{|l|}
-32 \\
\end{tabular} & -2 & -13 & 3 & \begin{tabular}{l|l}
-1 \\
\end{tabular} & 7 & -27 & \begin{tabular}{|l|}
-32 \\
\end{tabular} & 17 & \begin{tabular}{|l|}
-36 \\
\end{tabular} \\
\hline \begin{tabular}{|l|l|}
18 & Ленточн \\
\end{tabular} & 13 & -11 & 3 & 43 & -10 & -11 & -5 & -2 & 37 & 36 & 36 & 21 & \begin{tabular}{|l|}
-28 \\
\end{tabular} & 3 & -29 & 22 & 18 & 100 & 23 & \begin{tabular}{|l|}
-62 \\
\end{tabular} & \begin{tabular}{|l|l|}
-47 \\
\end{tabular} & -31 & \begin{tabular}{l|l}
-7 \\
\end{tabular} & -44 & 7 & 0 & \begin{tabular}{|l|}
-23 \\
\end{tabular} & 15 & 32 & -34 \\
\hline ное питание & -9 & 20 & -34 & 33 & 21 & 20 & -29 & -40 & 9 & -6 & -6 & -18 & 15 & 16 & 2 & \begin{tabular}{|l|}
-17 \\
\end{tabular} & 43 & 23 & 100 & -3 & -3 & 1 & 5 & \begin{tabular}{l|l|}
-7 \\
\end{tabular} & -44 & -4 & -25 & -11 & -18 & -19 \\
\hline 20 Отравление & -47 & 1 & 23 & \begin{tabular}{|l|}
-43 \\
\end{tabular} & 31 & 16 & -24 & -34 & -39 & -46 & -46 & \begin{tabular}{|l|}
-42 \\
\end{tabular} & 35 & -3 & 14 & -28 & -18 & -62 & \begin{tabular}{|c|c|}
-3 \\
\end{tabular} & 100 & 66 & 41 & 29 & \begin{tabular}{l|l}
33 \\
\end{tabular} & -12 & -4 & 30 & \begin{tabular}{|l|}
-25 \\
\end{tabular} & \begin{tabular}{|l|}
-48 \\
\end{tabular} & 36 \\
\hline \begin{tabular}{|l|l|}
21 Панлейкопения (вирусный энтерит) \\
\end{tabular} & -35 & -28 & 23 & -30 & 16 & 1 & -25 & -34 & -39 & \begin{tabular}{|c|}
-34 \\
\end{tabular} & -46 & -29 & 47 & -4 & 14 & -15 & -32 & -47 & -3 & \begin{tabular}{|c|}
66 \\
\end{tabular} & 100 & 27 & 42 & 33 & 0 & -29 & 30 & -26 & -32 & 22 \\
\hline \begin{tabular}{|l|l|}
22 & Пищевое отравление/гастроэнтерит \\
\end{tabular} & -36 & 6 & -15 & -46 & 24 & 75 & -6 & 12 & -41 & -35 & -34 & -30 & 17 & 1 & 5 & -29 & -2 & -31 & 1 & 41 & 27 & 100 & 8 & 19 & -10 & -16 & -6 & \begin{tabular}{|l|}
-25 \\
\end{tabular} & \begin{tabular}{|l|}
-13 \\
\end{tabular} & 16 \\
\hline \begin{tabular}{|l|l|}
23 & Почечная недостаточность \\
\end{tabular} & -31 & -23 & -11 & -10 & 43 & -7 & -19 & -31 & -19 & -45 & -14 & -25 & 33 & 22 & 9 & -24 & -13 & -7 & 5 & 29 & 42 & 8 & 100 & -1 & 8 & -12 & -17 & -20 & -8 & 18 \\
\hline \begin{tabular}{|l|l|}
24 & Pak \\
\end{tabular} & -11 & -4 & 5 & -6 & 10 & 21 & -38 & -10 & $\mid-51$ & -21 & \begin{tabular}{|c|}
-32 \\
\end{tabular} & 5 & 26 & -8 & 31 & -39 & 3 & -44 & $-7 \mid$ & 33 & 33 & 19 & $-1 \mid$ & 100 & -3 & 13 & -11 & \begin{tabular}{|l|}
-52 \\
\end{tabular} & \begin{tabular}{|l|}
-18 \\
\end{tabular} & -18 \\
\hline \begin{tabular}{|l|l|}
25 Рспираторная вирусная инфекция \\
\end{tabular} & -19 & -26 & 1 & $\mid-27$ & 7 & -26 & 11 & 27 & -5 & $\mid-17$ & -2 & 58 & -23 & -15 & 20 & \begin{tabular}{|c|}
-12 \\
\end{tabular} & -1 & 7 & \begin{tabular}{|c|}
-44 \\
\end{tabular} & -12 & 0 & -10 & 8 & \begin{tabular}{l|l}
-3 & -1 \\
\end{tabular} & 100 & -1 & 9 & \begin{tabular}{|l|}
-22 \\
\end{tabular} & 42 & -28 \\
\hline \begin{tabular}{|l|l|}
26 & Сердечная недостаточность \\
\end{tabular} & 3 & -0 & -4 & -3 & 1 & -16 & -12 & 6 & -27 & -8 & 21 & -4 & -27 & 11 & -15 & -17 & 7 & 0 & -4 & -4 & \begin{tabular}{|l|l|l|}
-29 \\
\end{tabular} & -16 & \begin{tabular}{|l|}
-12 \\
\end{tabular} & 13 & -1 & 100 & 3 & \begin{tabular}{|l|}
-12 \\
\end{tabular} & 34 & 9 \\
\hline \begin{tabular}{|l|}
27 \\
Тепловой удар \\
\end{tabular} & -15 & 11 & 35 & -39 & -20 & -22 & -17 & -13 & \begin{tabular}{|c|}
-17 \\
\end{tabular} & 2 & 3 & -9 & -6 & 7 & -20 & 6 & -27 & -23 & \begin{tabular}{|l|}
-25 \\
\end{tabular} & 30 & 30 & 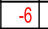 & \begin{tabular}{|l|}
-17 \\
\end{tabular} & -11 & 9 & 3 & 100 & -1 & \begin{tabular}{c|}
-6 \\
\end{tabular} & 34 \\
\hline \begin{tabular}{|l|l|}
28 & Течка \\
\end{tabular} & 33 & 13 & 7 & 9 & -43 & -26 & 40 & 20 & 40 & 38 & 21 & -11 & -23 & -13 & -23 & 59 & -32 & 15 & -11 & -25 & -26 & -25 & 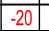 & -52 & -22 & -12 & -1 & 100 & -8 & 23 \\
\hline \begin{tabular}{|l|l|}
29 & Токсоплазм03 \\
\end{tabular} & -6 & -13 & -17 & 4 & 9 & -13 & 15 & 16 & -6 & -3 & -2 & 38 & -29 & 24 & 7 & -16 & 17 & 32 & \begin{tabular}{|c|}
-18 \\
\end{tabular} & 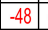 & \begin{tabular}{|c|}
-32 \\
\end{tabular} & \begin{tabular}{|c|}
-13 \\
\end{tabular} & -8 & -18 & 42 & 34 & -6 & -8 & 100 & -36 \\
\hline \begin{tabular}{|l|l|}
30 & Урологический синдром / мочекаменная болезнь \\
\end{tabular} & -10 & 18 & 12 & -33 & -14 & -15 & 7 & -7 & -10 & -7 & -6 & $\mid-47$ & 26 & -21 & -14 & 12 & -36 & -34 & \begin{tabular}{|l|}
-19 \\
\end{tabular} & 36 & 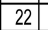 & 16 & 18 & \begin{tabular}{|c|}
-18 \\
\end{tabular} & \begin{tabular}{|l|}
-28 \\
\end{tabular} & 9 & 34 & 23 & -36 & 100 \\
\hline
\end{tabular}

Отметим, что для улучшения восприятия на рисунке 26 число классов уменьшено до 12. 


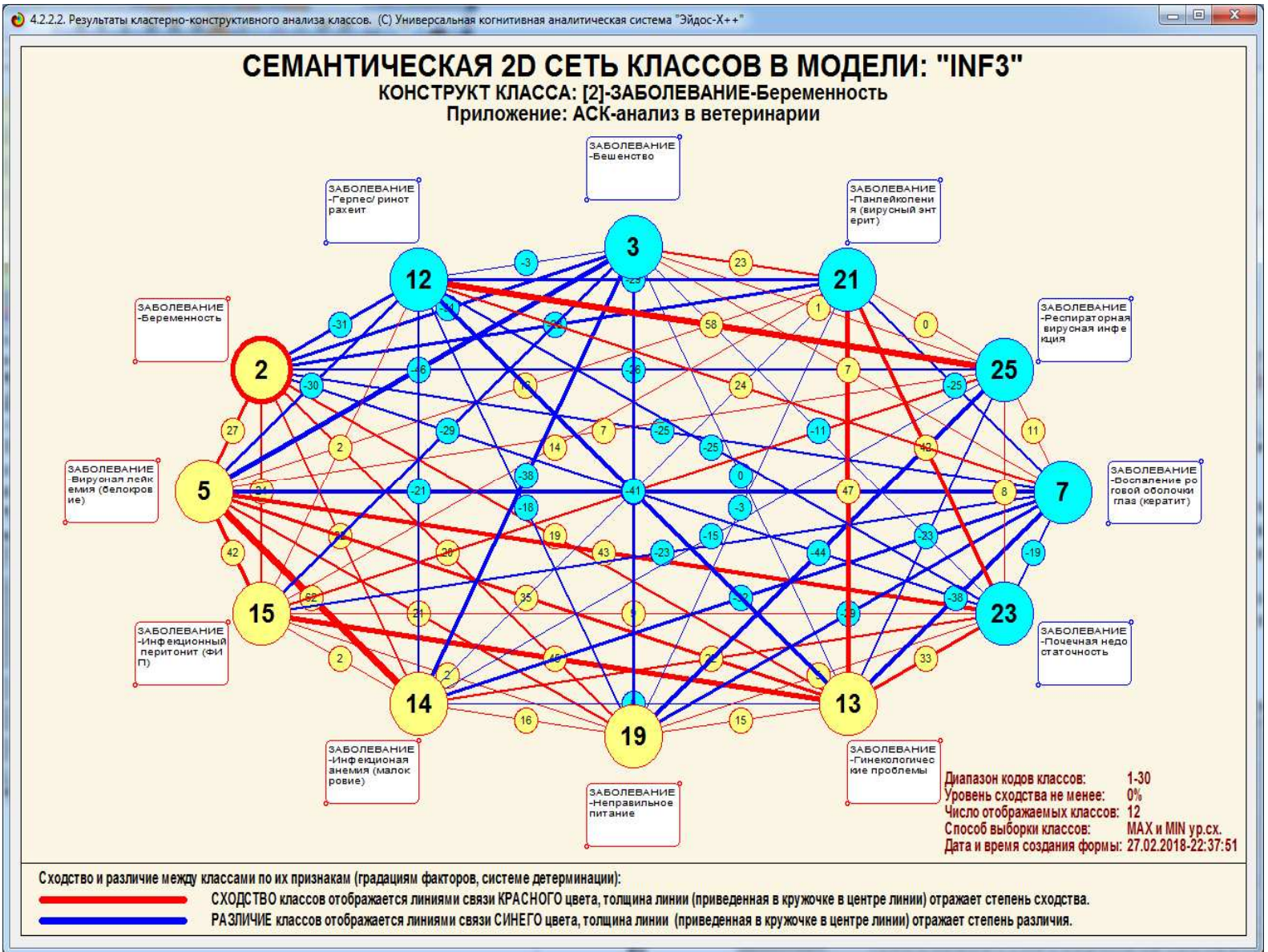

\section{Рисунок 26. Пример когнитивной диаграммы сходства-различия нозологических} образов (классов) в модели Inf3 (Хи-квадрат) (фрагмент)

Шаг 5-й. Сходство-различие симптомов по их диагностическому смыслу (кластерно-конструктивный анализ симптомов). Выявление синдромов (устойчивых комплексов симптомов, как правило встречающихся вместе и имеющих сходный диагностический смысл).

В таблице 13 приведена матрица сходства-различия симптомов в модели INF3, фрагмент которой в графической форме показан на рисунке 27:

\section{Таблица 13 - Матрица сходства-различия симптомов в модели INF3}

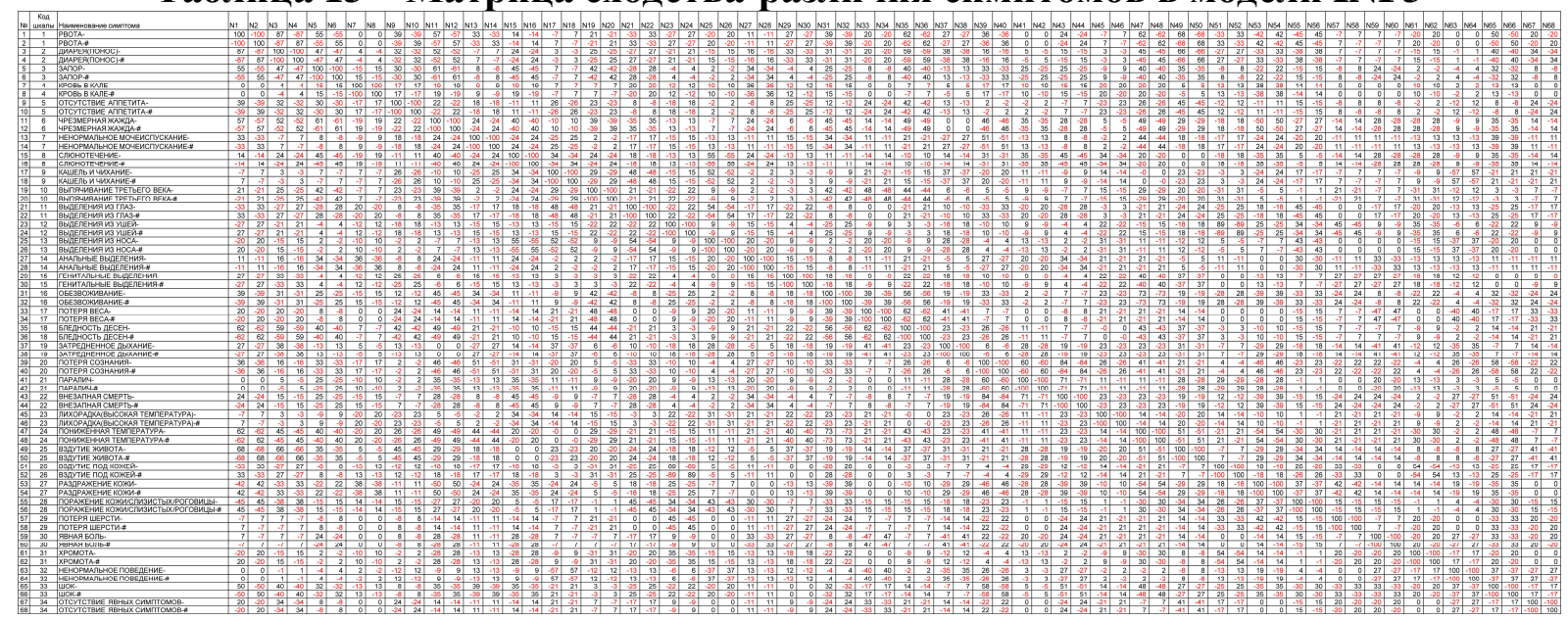




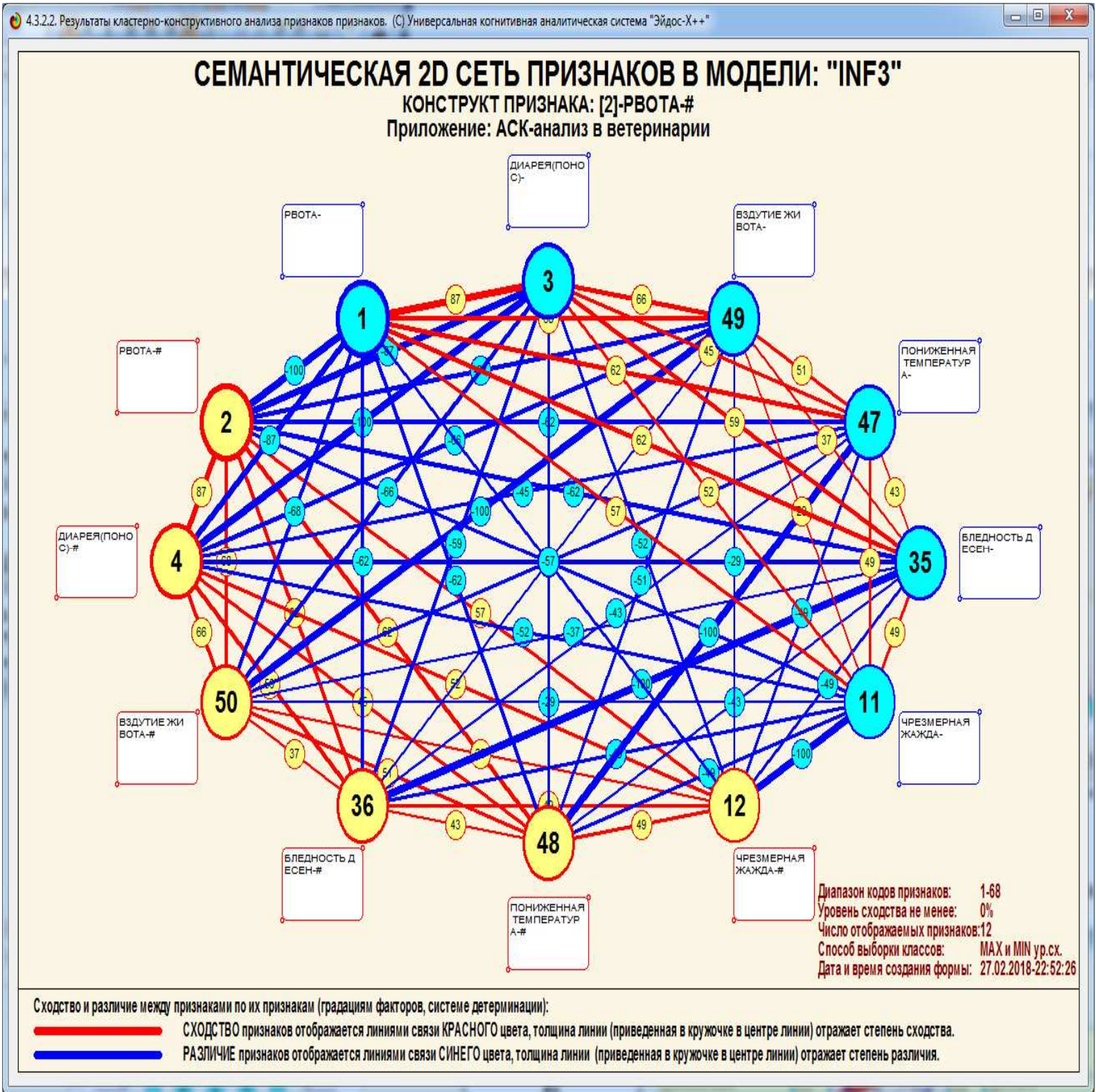

Рисунок 27. Пример когнитивной диаграммы сходства-различия симптомов в модели Inf3 (Хи-квадрат) (фрагмент)

Красные линии на рисунке 27 соединяют симптомы, имеющие сходный диагностический смысл и обычно встречающиеся вместе, т.е. синдромы.

Шаг 6-й.. Нелокальные нейроны и нейронные сети.

На рисунках 28 и 29 приведены фрагменты нелокальных нейронов и нелокальной нейронной сети в модели INF3 [8]: 


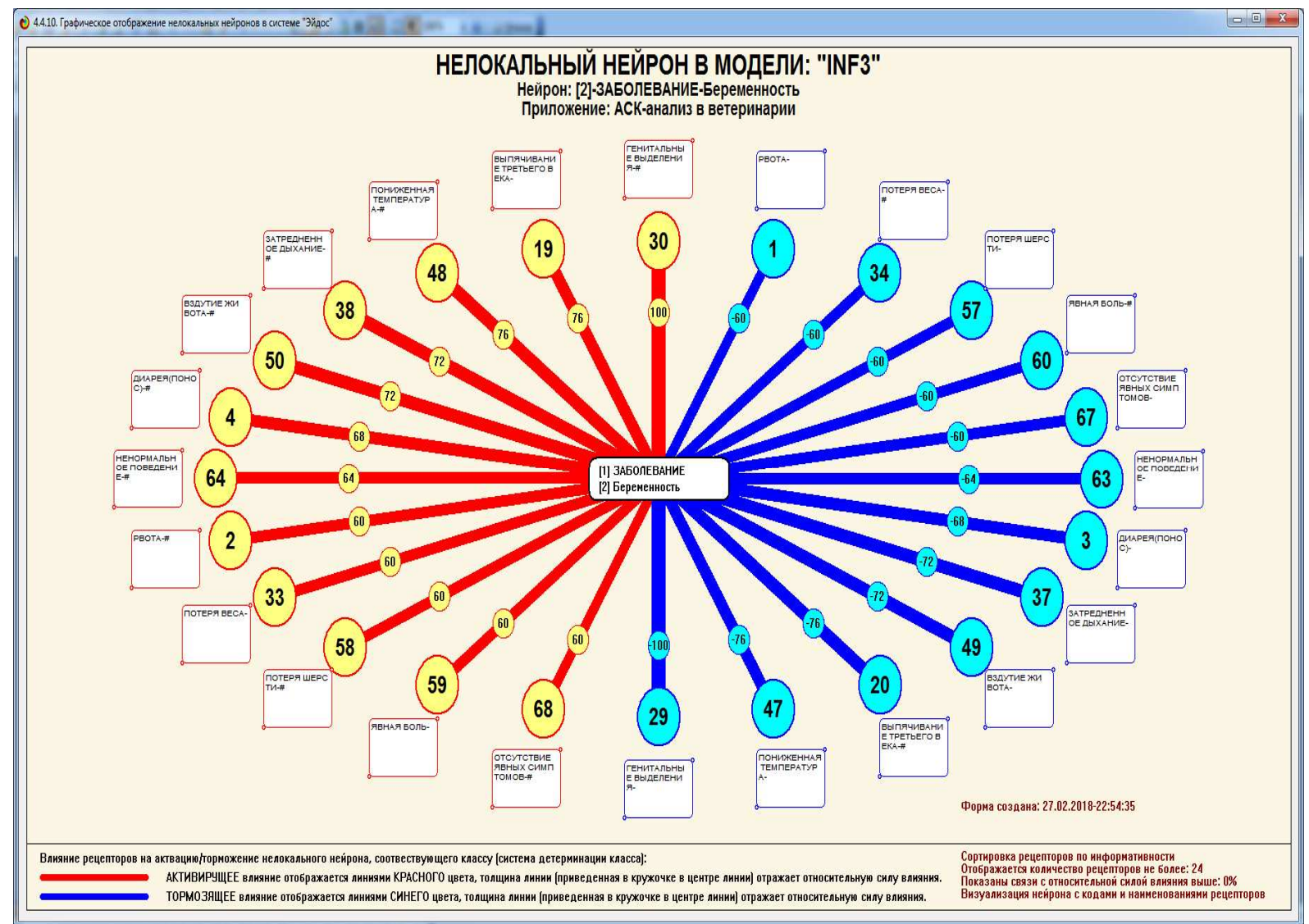

Рисунок 28. Фрагмент нелокального нейрона в системно-когнитивной модели Inf3 (Хи-квадрат)

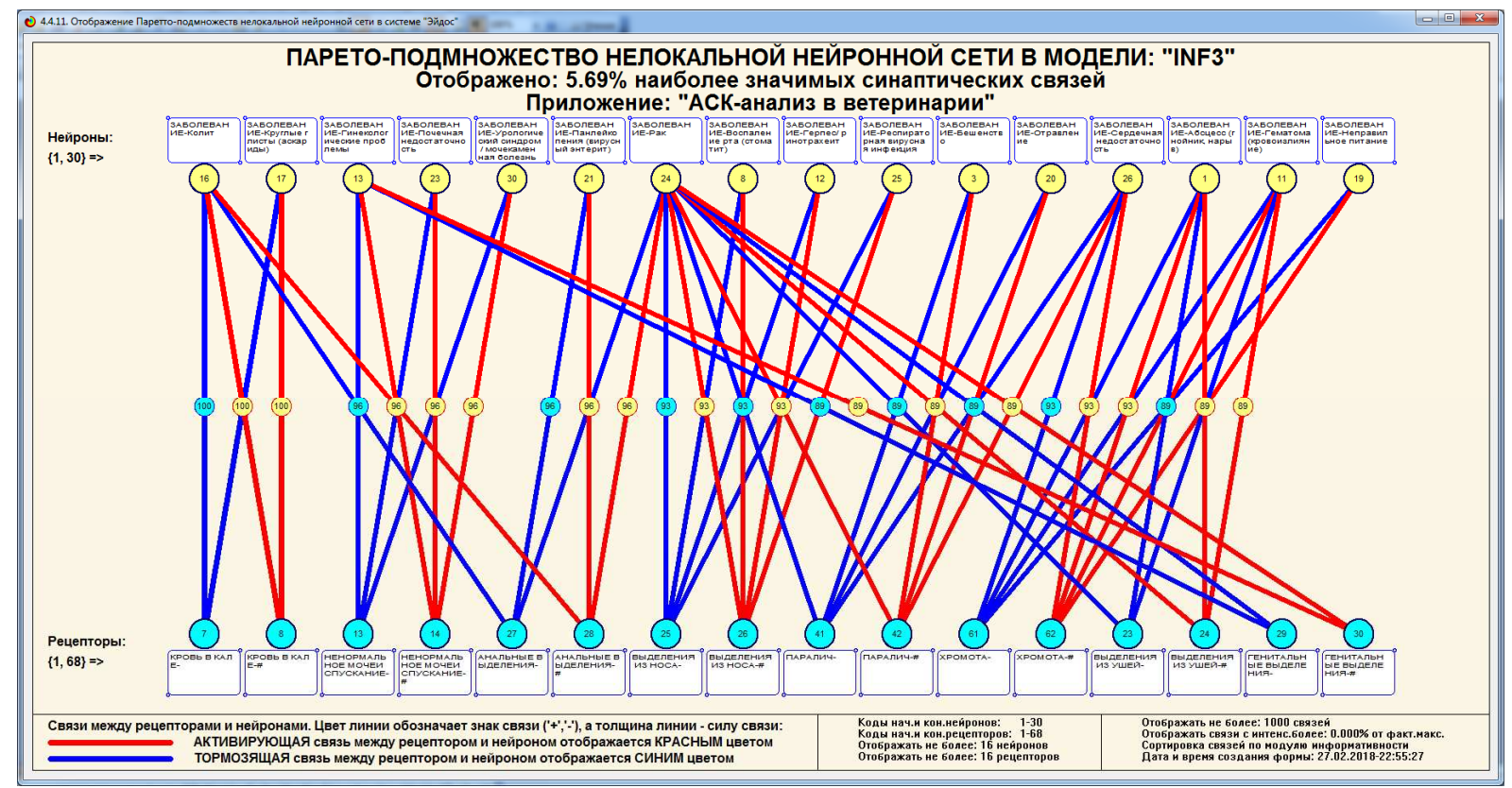

Рисунок 29. Фрагмент слоя нелокальной нейронной сети в системно-когнитивной модели Inf3 (Хи-квадрат)

Шаг 7-й. Содержательное сравнение классов друг с другом.

Пример когнитивной диаграммы содержательного сравнения двух классов в модели Inf3 (Хи-квадрат) приведен на рисунке 30: 

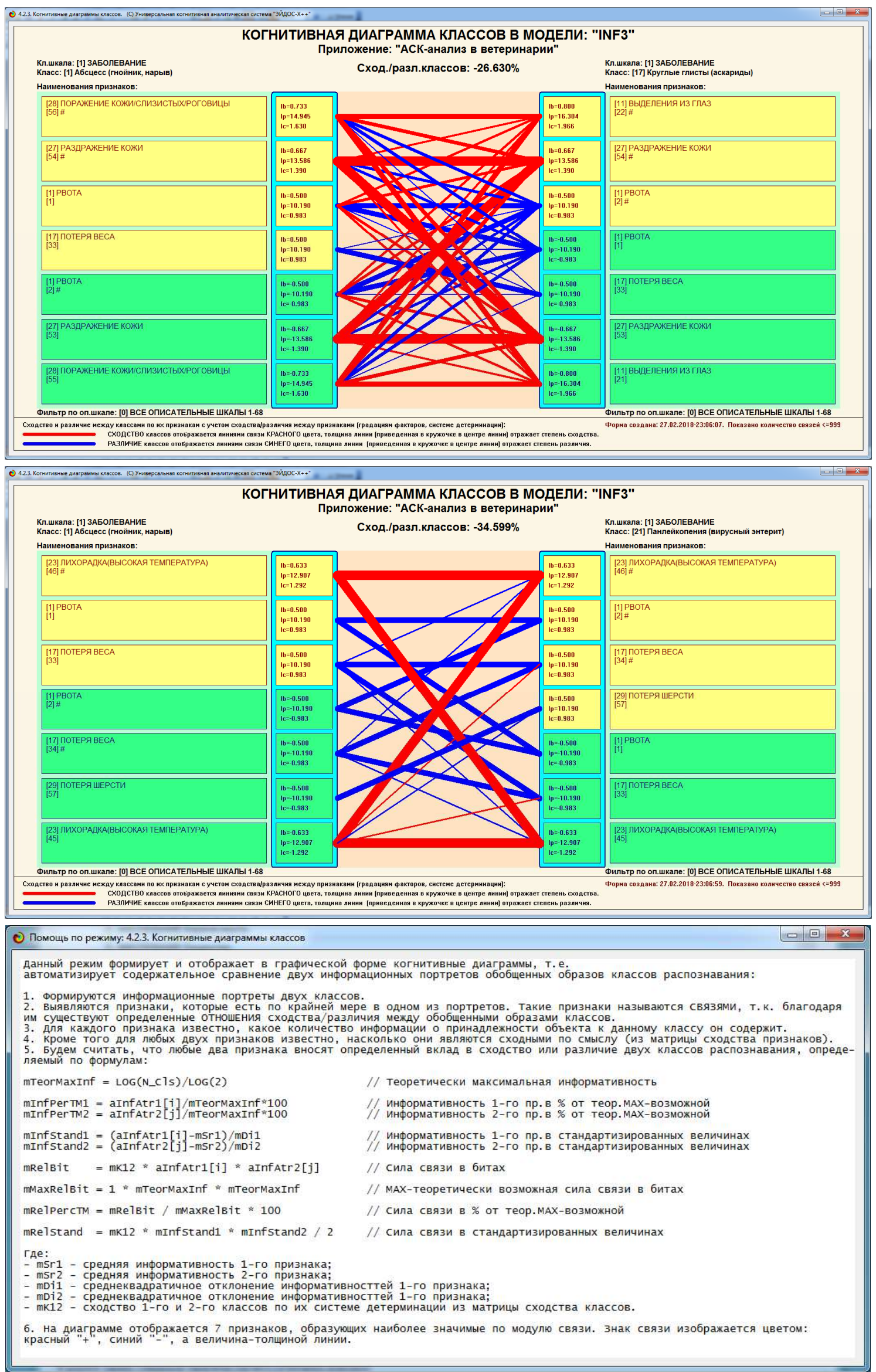

Рисунок 30. Пример когнитивной диаграммы содержательного сравнения двух классов в модели Inf3 (Хи-квадрат) (фрагмент) 
Шаг 8-й. Содержательное сравнение симптомов друг с другом. Пример когнитивной диаграммы содержательного сравнения двух симптомов в модели Inf3 (Хи-квадрат) приведен на рисунке 31:

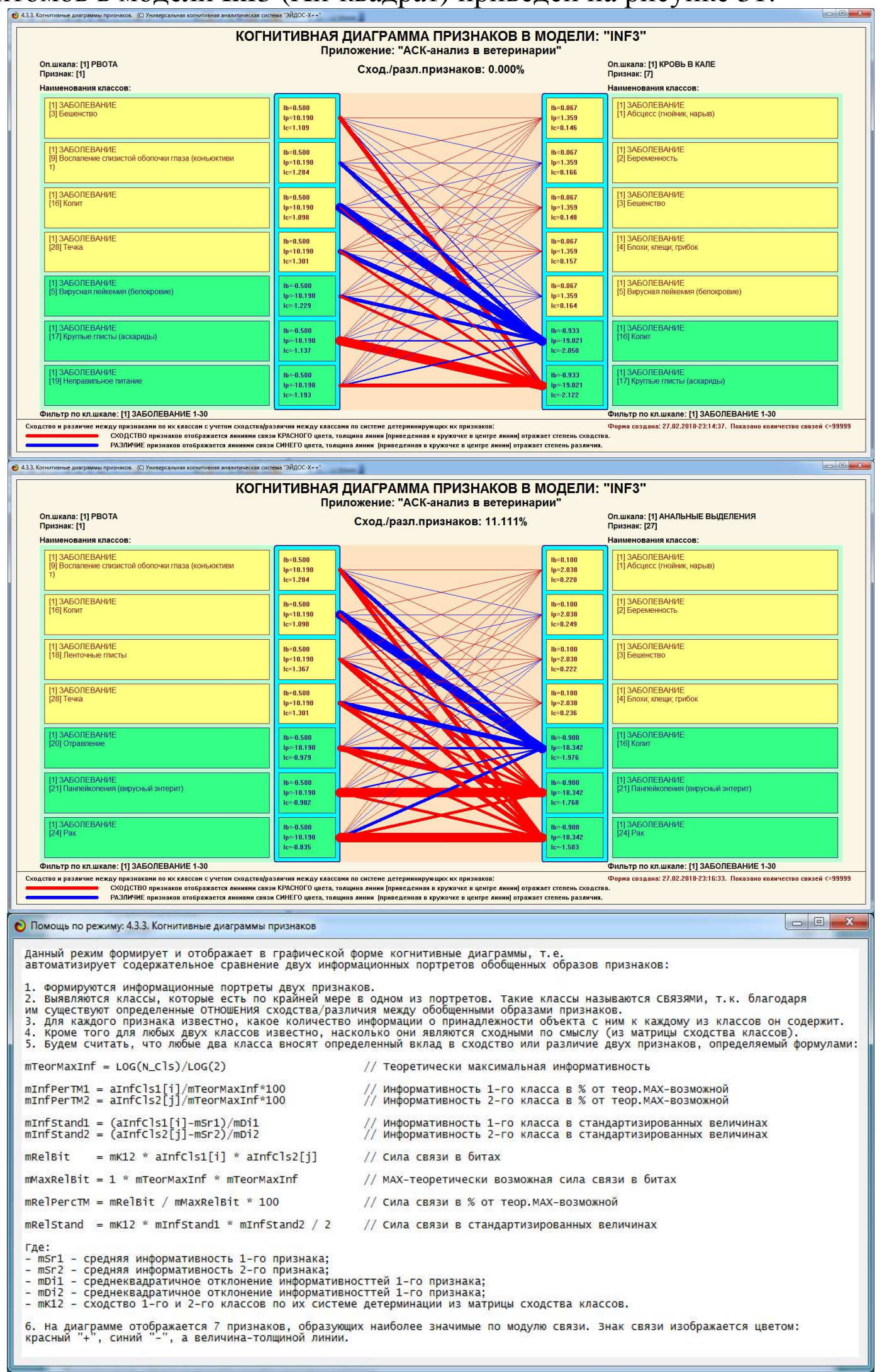

Рисунок 31. Пример когнитивной диаграммы содержательного сравнения двух симптомов в модели Inf3 (Хи-квадрат) (фрагмент) 
Шаг 9-й. Интегральные когнитивные карты.

Система «Эйдос» обеспечивает формирование и отображение когнитивных диаграмм (рисунок 32), объединяющих нейронную сеть (рисунок 26), когнитивные диаграммы сходства различия классов (рисунок 26) и когнитивные диаграммы сходства различия симптомов (рисунок 27):

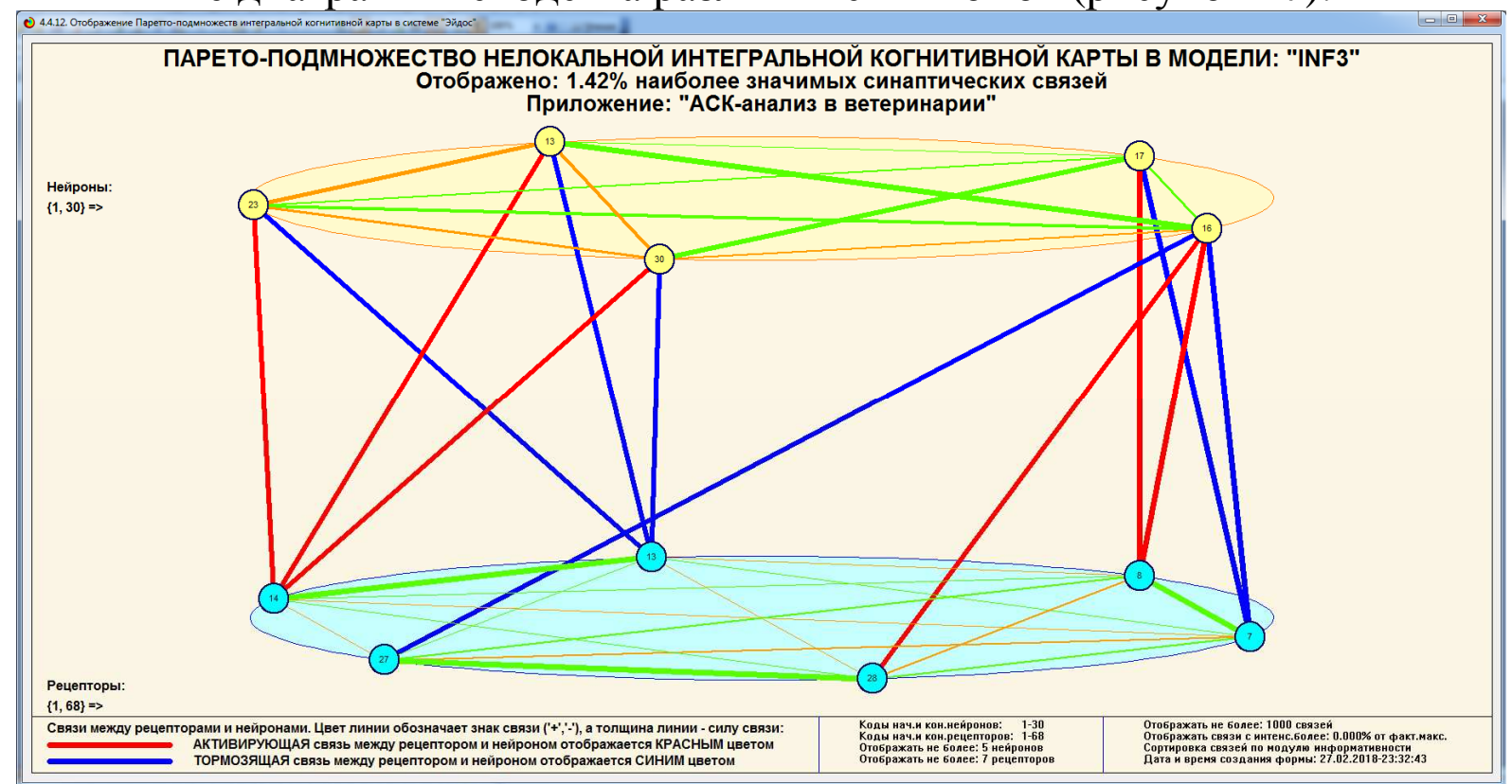

\section{Рисунок 32. Пример интегральной когнитивной карты в модели Inf3 (Хи-квадрат) (фрагмент)}

Шаг 10-й. Когнитивные функции.

На экранной форме, приведенной на рисунке 33 , дано общее представление о когнитивных функциях:

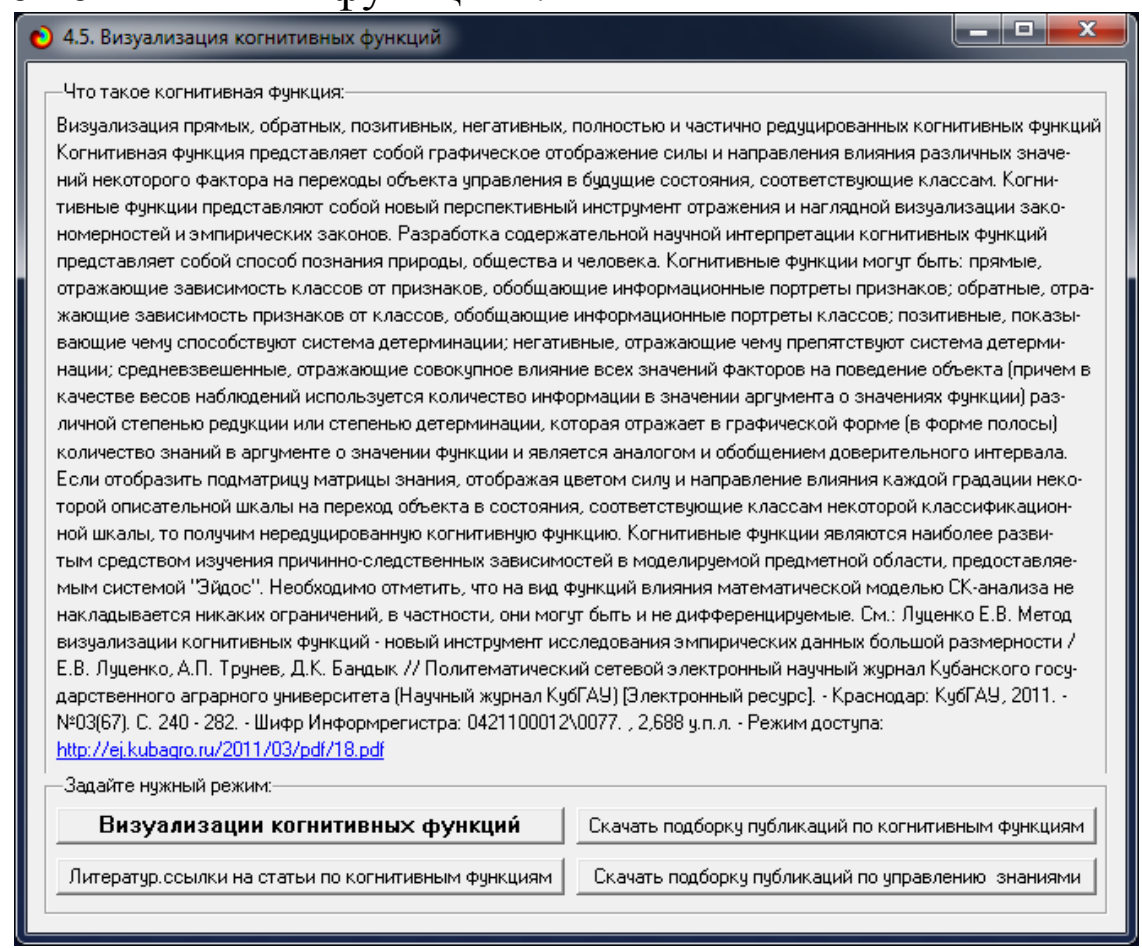

Рисунок 33. Пояснение по смыслу понятия: «Когнитивные функции» 
Подробнее это понятие раскрыто в ряде работ автора $[4]^{3}$.

Примеры самих когнитивных функций приведены на рисунке 34:

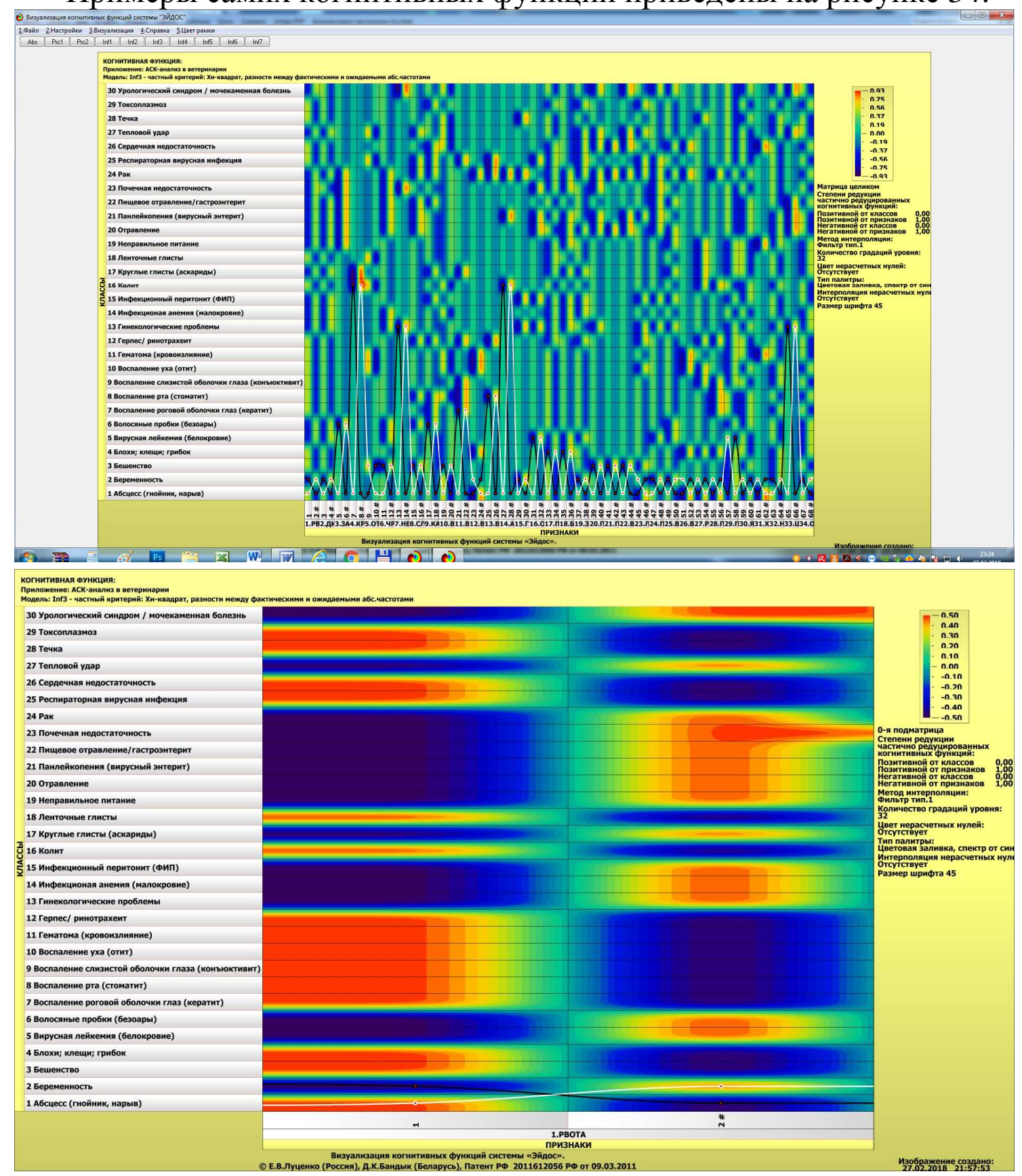

Рисунок 34. Когнитивная функция системн соно-когнитивной модели Inf3 (Хи-квадрат)

\section{Выводы}

Таким образом, можно сделать обоснованный вывод о том, что применение интеллектуальной системы «Эйдос-Х++» обеспечивает реализацию уже разработанных ветеринарных и медицинских диагностических тестов без программирования в форме, удобной для массового тестирования, анализа его результатов и выработки индивидуальных рекомендаций.

https://www.twirpx.com/file/775236/ 
Материалы данной статьи могут быть использованы в учебном процессе при преподавании дисциплин: «Интеллектуальные информационные системы», «представление знаний в информационных системах», «Современные технологии в образовании (магистратура)», «Управление знаниями (магистратура)», «Введение в искусственный интеллект», «Интеллектуальные и нейросетевые технологии в образовании (магистратура)», «Основы искусственного интеллекта» и других.

\section{Перспективы продолжения исследований и разработок}

Планируется продолжить направление исследований и разработок, представленное в данной статье, по следующим направлениям:

1. Разработка в среде интеллектуальной системы Эйдос-Х++ ветеринарных диагностических тестов и проведение научных исследований на основе эмпирических данных (данных наблюдений и экспериментов).

2. Интеграция в среде интеллектуальной системы Эйдос-X++ без программирования нескольких диагностических тестов в батарею тестов или в супертест с одной общей моделью.

Этим и другим применениям способствует и то, что система «Эйдос» является мультиязычной интеллектуальной on-line средой для обучения и научных исследований и находится в полном открытом бесплатном доступе (причем с подробно комментированными открытыми исходными текстами: http://lc.kubagro.ru/_AIDOS-X.txt) на сайте автора по адресу: http://lc.kubagro.ru/aidos/_Aidos-X.htm. Это дает свои результаты: за год систему «Эйдос» в мире запускали около 10 тысяч раз во многих странах (Белоруссия, Бельгия, Дания, Канада, Китай, Египет, Франция, Германия, Гонконг, Казахстан, Нидерланды, Португалия, Россия, Словакия, Словения, Украина, США, Англия и др.) (рисунок 35) $[9,10]^{4}$.

Автор благодарен всем ученым, коллегам и соавторам, поддержавшим его в разработке и применении Автоматизированного системнокогнитивного анализа (АСК-анализ) и его программного инструментария интеллектуальной системы «Эйдос»: Засл. деятель науки РФ, д. т. н. , проф. Лойко В. И. , к. ф. -м. н. , Рh. D. , проф. , Трунев А. П. (Канада), д. э. н. , д. т. н. , к. ф. -м. н. , проф. Орлов А. И. , к. т. н. , доц. Коржаков В. Е. , д. э. н. , проф. Барановская Т. П. , д. э. н. , к. т. н. , проф. Ермоленко В. В. , к. пс. н. Наприев И. Л. , к. пс. н. , доц. Некрасов С. Д. , к. т. н. , доц. Лаптев В. Н. , к. пс. н, доц. Третьяк В. Г. , к. пс. н. , Щукин Т. Н. , д. т. н. , проф. Симанков В. С. , д. э. н. , проф. Ткачев А. Н. , д. т. н., проф. Сафронова Т. И. , д. э. н. , доц. Горпинченко К. Н. , к. э. н. , доц. Макаревич О. А. , к. э. н. , доц. Макаревич Л. О. , к. м. н. Сергеева Е. В. (Лаптева Е. В. ), Бандык Д. К. (Белоруссия), Чередниченко Н. А. , к. ф. -м. н. Артемов А. А. , д. э. н. , проф. Крохмаль В. В. , д. т. н. , проф. Рябцев В. Г. , к. т. Н. , доц. Марченко А. Ю. , д. т. н. , проф. Фролов В. Ю. , д. ю. н, проф. Швец С. В. , Засл. дея-

$4 \quad$ http://lc.kubagro.ru/aidos/Presentation_Aidos-online.pdf

http://ej.kubagro.ru/2018/03/pdf/31.pdf 
тель науки Кубани, д. б. н. , проф. Трошин Л. П. , Засл. изобр. РФ, д. т. н. , проф. Серга Г. В. , Сергеев А. С. , д. б. н. , проф. Стрельников В. В. и другие.

Автор благодарен разработчику языка программирования, на котором написана система «Эйдос» Роджеру Доннэю (США) и всем специалистам со всего мира, которые общаются на его форуме ${ }^{5}$ и бескорыстно помогают друг другу.

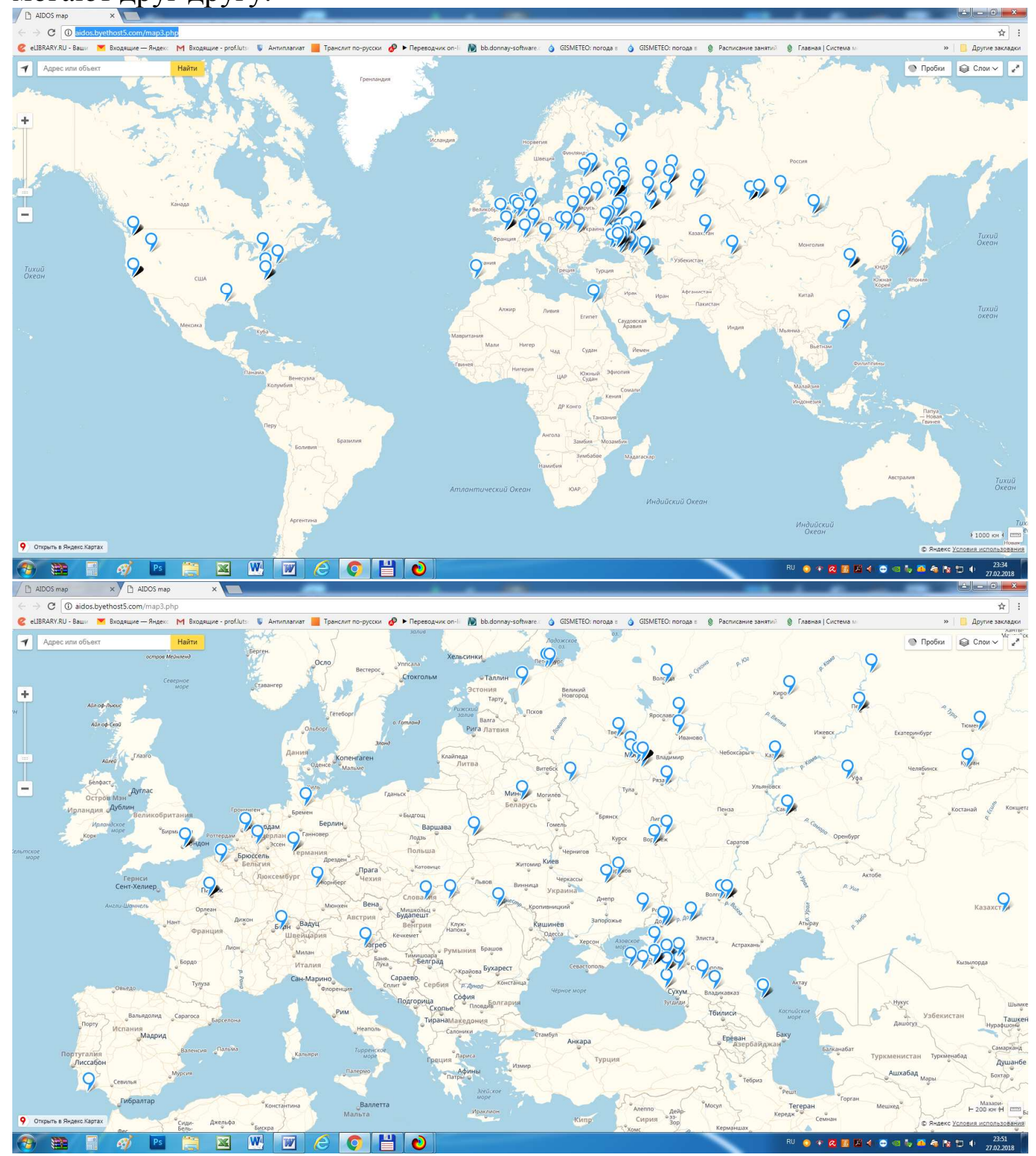

Рисунок 35. Запуски системы «Эйдос» в мире и Европе за период с 9.12.2016 по 27.02.2018

$5 \quad$ http://bb.donnay-software.com/donnay/viewforum.php? $\mathrm{f}=2$ 


\section{Список литературы}

1. Луценко Е.В. Автоматизированный системно-когнитивный анализ в управлении активными объектами (системная теория информации и ее применение в исследовании экономических, социально-психологических, технологических и организационно-технических систем): Монография (научное издание). - Краснодар: КубГАУ. 2002. -605 c. http://elibrary.ru/item.asp?id=18632909

2. Луценко Е.В. Универсальная когнитивная аналитическая система «Эйдос". Монография (научное издание). - Краснодар, КубГАУ. 2014. - 600 с. ISBN 978-594672-830-0. http://elibrary.ru/item.asp?id=22401787

3. Сайт автора АСК-анализа и системы «Эйдос» проф. Е.В.Луценко: http://lc.kubagro.ru/

4. Орлов А.И., Луценко Е.В. Системная нечеткая интервальная математика. Монография (научное издание). - Краснодар, КубГАУ. 2014. - 600 с. ISBN 978-5-94672757-0. http://elibrary.ru/item.asp?id=21358220

5. Луценко Е.В. Теоретические основы и технология адаптивного семантического анализа в поддержке принятия решений (на примере универсальной автоматизированной системы распознавания образов "ЭЙДОС-5.1"). - Краснодар: КЮИ МВД РФ, 1996. - 280c. http://elibrary.ru/item.asp?id=21745340

6. Сайт: http://mau.ru/pub/health/?p=table

7. Луценко Е.В. Метризация измерительных шкал различных типов и совместная сопоставимая количественная обработка разнородных факторов в системнокогнитивном анализе и системе «Эйдос» / Е.В. Луценко // Политематический сетевой электронный научный журнал Кубанского государственного аграрного университета (Научный журнал КубГАУ) [Электронный ресурс]. - Краснодар: КубГАУ, 2013. №08(092). С. 859 - 883. - IDA [article ID]: 0921308058. - Режим доступа: http://ej.kubagro.ru/2013/08/pdf/58.pdf, 1,562 у.п.л.

8. Луценко Е.В. Системная теория информации и нелокальные интерпретируемые нейронные сети прямого счета / Е.В. Луценко // Политематический сетевой электронный научный журнал Кубанского государственного аграрного университета (Научный журнал КубГАУ) [Электронный ресурс]. - Краснодар: КубГАУ, 2003. №01(001). С. 79 - 91. - IDA [article ID]:0010301011. - Режим доступа: http://ej.kubagro.ru/2003/01/pdf/11.pdf, 0,812 у.п.л.

9. Луценко Е.В. Открытая масштабируемая интерактивная интеллектуальная online среда для обучения и научных исследований на базе АСК-анализа и системы «Эйдос» / Е.В. Луценко // Политематический сетевой электронный научный журнал Кубанского государственного аграрного университета (Научный журнал КубГАУ) [Электронный ресурс]. - Краснодар: КубГАУ, 2017. - №06(130). С. 1 - 55. - IDA [article ID]: 1301706001. - Режим доступа: http://ej.kubagro.ru/2017/06/pdf/01.pdf, 3,438 у.п.л.

10. Луценко Е.В., Открытая масштабируемая интерактивная интеллектуальная оnline среда «Эйдос» («Эйдос-online»). Свид. РосПатента РФ на программу для ЭВМ, Заявка № 2017618053 от 07.08.2017, Гос.рег.№ 2017661153, зарегистр. 04.10.2017. - Peжим доступа: http://lc.kubagro.ru/aidos/2017661153.jpg, 2 у.п.л.

11. Луценко Е.В. Количественный автоматизированный SWOT- и PEST-анализ средствами АСК-анализа и интеллектуальной системы «Эйдос-X++» / Е.В. Луценко // Политематический сетевой электронный научный журнал Кубанского государственного аграрного университета (Научный журнал КубГАУ) [Электронный ресурс]. - Краснодар: КубГАУ, 2014. - №07(101). С. 1367 - 1409. - IDA [article ID]: 1011407090. - Pежим доступа: http://ej.kubagro.ru/2014/07/pdf/90.pdf, 2,688 у.п.л.

12. Луценко Е.В. Моделирование сложных многофакторных нелинейных объектов управления на основе фрагментированных зашумленных эмпирических данных боль- 
шой размерности в системно-когнитивном анализе и интеллектуальной системе «Эйдос-Х++» / Е.В. Луценко, В.Е. Коржаков // Политематический сетевой электронный научный журнал Кубанского государственного аграрного университета (Научный журнал КубГАУ) [Электронный ресурс]. - Краснодар: КубГАУ, 2013. - №07(091). С. 164 188. - IDA [article ID]: 0911307012. - Режим доступа: http://ej.kubagro.ru/2013/07/pdf/12.pdf, 1,562 у.п.л.

13. Луценко Е.В. Интеллектуальная консалтинговая система выявления технологических знаний и принятия решений по их эффективному применению на основе системно-когнитивного анализа бизнес-процессов / Е.В. Луценко, В.Е. Коржаков, А.И. Ладыга // Политематический сетевой электронный научный журнал Кубанского государственного аграрного университета (Научный журнал КубГАУ) [Электронный ресурс]. - Краснодар: КубГАУ, 2010. - №05(059). С. 79 - 110. - Шифр Информрегистра: 0421000012\0091, IDA [article ID]: 0591005007. - Режим доступа: http://ej.kubagro.ru/2010/05/pdf/07.pdf, 2 у.п.л.

14. Луценко Е.В. Инвариантное относительно объемов данных нечеткое мультиклассовое обобщение F-меры достоверности моделей Ван Ризбергена в АCК-анализе и системе «Эйдос» / Е.В. Луценко // Политематический сетевой электронный научный журнал Кубанского государственного аграрного университета (Научный журнал КубГАУ) [Электронный ресурс]. - Краснодар: КубГАУ, 2017. - №02(126). С. 1 - 32. IDA [article ID]: 1261702001. - Режим доступа: http://ej.kubagro.ru/2017/02/pdf/01.pdf, 2 У.П.Л.

15. Artem Artemov, Eugeny Lutsenko, Edward Ayunts, Ivan Bolokhov/ Informational Neurobayesian Approach to Neural Networks Training. Opportunities and Prospects // arXiv Computer Science, Learning (cs.LG) /larXiv preprint arXiv:1710.07264. - Режим доступа: https://arxiv.org/pdf/1710.07264

16. Луценко Е.В. Метод когнитивной кластеризации или кластеризация на основе знаний (кластеризация в системно-когнитивном анализе и интеллектуальной системе «Эйдос») / Е.В. Луценко, В.Е. Коржаков // Политематический сетевой электронный научный журнал Кубанского государственного аграрного университета (Научный журнал КубГАУ) [Электронный ресурс]. - Краснодар: КубГАУ, 2011. - №07(071). С. 528 576. - Шифр Информрегистра: 042110001210253, IDA [article ID]: 0711107040. - Режим доступа: http://ej.kubagro.ru/2011/07/pdf/40.pdf, 3,062 у.п.л.

17. Луценко Е.В. Автоматизация Функционально-стоимостного анализа и метода "Директ-костинг" на основе АСК-анализа и системы "Эйдос" (автоматизация управления натуральной и финансовой эффективностью затрат без содержательных технологических и финансово-экономических расчетов на основе информационных и когнитивных технологий и теории управления) / Е.В. Луценко // Политематический сетевой электронный научный журнал Кубанского государственного аграрного университета (Научный журнал КубГАУ) [Электронный ресурс]. - Краснодар: КубГАУ, 2017. №07(131). С. 1 - 18. - IDA [article ID]: 1311707001. - Режим доступа: http://ej.kubagro.ru/2017/07/pdf/01.pdf, 1,125 у.п.л.

18. Луценко Е.В. Проблемы и перспективы теории и методологии научного познания и автоматизированный системно-когнитивный анализ как автоматизированный метод научного познания, обеспечивающий содержательное феноменологическое моделирование / Е.В. Луценко // Политематический сетевой электронный научный журнал Кубанского государственного аграрного университета (Научный журнал КубГАУ) [Электронный ресурс]. - Краснодар: КубГАУ, 2017. - №03(127). С. 1 - 60. - IDA [article ID]: 1271703001. - Режим доступа: http://ej.kubagro.ru/2017/03/pdf/01.pdf, 3,75 у.п.л. 
19. Луценко Е.В., Лойко В.И., Семантические информационные модели управления агропромышленным комплексом. Монография (научное издание). - Краснодар: КубГАУ. 2005. - 480 c. http://elibrary.ru/item.asp?id=21720635

\section{Spisok literatury}

1. Lucenko E.V. Avtomatizirovannyj sistemno-kognitivnyj analiz $\mathrm{v}$ upravlenii aktivnymi ob\#ektami (sistemnaja teorija informacii $\mathrm{i}$ ee primenenie $\mathrm{v}$ issledovanii jekonomicheskih, social'no-psihologicheskih, tehnologicheskih i organizacionno-tehnicheskih sistem): Monografija (nauchnoe izdanie). - Krasnodar: KubGAU. 2002. - 605 s. http://elibrary.ru/item.asp?id=18632909

2. Lucenko E.V. Universal'naja kognitivnaja analiticheskaja sistema «Jejdos". Monografija (nauchnoe izdanie). - Krasnodar, KubGAU. 2014. - 600 s. ISBN 978-5-94672830-0. http://elibrary.ru/item.asp?id=22401787

3. Sajt avtora ASK-analiza i sistemy «Jejdos» prof. E.V.Lucenko: http://lc.kubagro.ru/

4. Orlov A.I., Lucenko E.V. Sistemnaja nechetkaja interval'naja matematika. Monografija (nauchnoe izdanie). - Krasnodar, KubGAU. 2014. - 600 s. ISBN 978-5-94672757-0. http://elibrary.ru/item.asp?id=21358220

5. Lucenko E.V. Teoreticheskie osnovy i tehnologija adaptivnogo semanticheskogo analiza v podderzhke prinjatija reshenij (na primere universal'noj avtomatizirovannoj sistemy raspoznavanija obrazov "JeJDOS-5.1"). - Krasnodar: KJuI MVD RF, 1996. - 280s. http://elibrary.ru/item.asp?id=21745340

6. Sajt: http://mau.ru/pub/health/?p=table

7. Lucenko E.V. Metrizacija izmeritel'nyh shkal razlichnyh tipov i sovmestnaja sopostavimaja kolichestvennaja obrabotka raznorodnyh faktorov $\mathrm{v}$ sistemno-kognitivnom analize i sisteme «Jejdos» / E.V. Lucenko // Politematicheskij setevoj jelektronnyj nauchnyj zhurnal Kubanskogo gosudarstvennogo agrarnogo universiteta (Nauchnyj zhurnal KubGAU) [Jelektronnyj resurs]. - Krasnodar: KubGAU, 2013. - №08(092). S. 859 - 883. - IDA [article ID]: 0921308058. - Rezhim dostupa: http://ej.kubagro.ru/2013/08/pdf/58.pdf, 1,562 u.p.1.

8. Lucenko E.V. Sistemnaja teorija informacii i nelokal'nye interpretiruemye nejronnye seti prjamogo scheta / E.V. Lucenko // Politematicheskij setevoj jelektronnyj nauchnyj zhurnal Kubanskogo gosudarstvennogo agrarnogo universiteta (Nauchnyj zhurnal KubGAU) [Jelektronnyj resurs]. - Krasnodar: KubGAU, 2003. - №01(001). S. 79 - 91. - IDA [article ID]: 0010301011. - Rezhim dostupa: http://ej.kubagro.ru/2003/01/pdf/11.pdf, 0,812 u.p.1.

9. Lucenko E.V. Otkrytaja masshtabiruemaja interaktivnaja intellektual'naja on-line sreda dlja obuchenija i nauchnyh issledovanij na baze ASK-analiza i sistemy «Jejdos» / E.V. Lucenko // Politematicheskij setevoj jelektronnyj nauchnyj zhurnal Kubanskogo gosudarstvennogo agrarnogo universiteta (Nauchnyj zhurnal KubGAU) [Jelektronnyj resurs]. - Krasnodar: KubGAU, 2017. - №06(130). S. 1 - 55. - IDA [article ID]: 1301706001. Rezhim dostupa: http://ej.kubagro.ru/2017/06/pdf/01.pdf, 3,438 u.p.1.

10. Lucenko E.V., Otkrytaja masshtabiruemaja interaktivnaja intellektual'naja on-line sreda «Jejdos» («Jejdos-online»). Svid. RosPatenta RF na programmu dlja JeVM, Zajavka № 2017618053 ot 07.08.2017, Gos.reg.№ 2017661153, zaregistr. 04.10.2017. - Rezhim dostupa: http://lc.kubagro.ru/aidos/2017661153.jpg, 2 u.p.l.

11. Lucenko E.V. Kolichestvennyj avtomatizirovannyj SWOT- i PEST-analiz sredstvami ASK-analiza i intellektual'noj sistemy «Jejdos-H++» / E.V. Lucenko // Politematicheskij setevoj jelektronnyj nauchnyj zhurnal Kubanskogo gosudarstvennogo agrarnogo universiteta (Nauchnyj zhurnal KubGAU) [Jelektronnyj resurs]. - Krasnodar: KubGAU, 2014. - №07(101). S. 1367 - 1409. - IDA [article ID]: 1011407090. - Rezhim dostupa: http://ej.kubagro.ru/2014/07/pdf/90.pdf, 2,688 u.p.1.

12. Lucenko E.V. Modelirovanie slozhnyh mnogofaktornyh nelinejnyh ob\#ektov upravlenija na osnove fragmentirovannyh zashumlennyh jempiricheskih dannyh bol'shoj 
razmernosti v sistemno-kognitivnom analize i intellektual'noj sisteme «Jejdos-H++» / E.V. Lucenko, V.E. Korzhakov // Politematicheskij setevoj jelektronnyj nauchnyj zhurnal Kubanskogo gosudarstvennogo agrarnogo universiteta (Nauchnyj zhurnal KubGAU) [Jelektronnyj resurs]. - Krasnodar: KubGAU, 2013 - №07(091). S. 164 - 188. - IDA [article ID]: 0911307012. - Rezhim dostupa: http://ej.kubagro.ru/2013/07/pdf/12.pdf, 1,562 u.p.l.

13. Lucenko E.V. Intellektual'naja konsaltingovaja sistema vyjavlenija tehnologicheskih znanij i prinjatija reshenij po ih jeffektivnomu primeneniju na osnove sistemno-kognitivnogo analiza biznes-processov / E.V. Lucenko, V.E. Korzhakov, A.I. Ladyga // Politematicheskij setevoj jelektronnyj nauchnyj zhurnal Kubanskogo gosudarstvennogo agrarnogo universiteta (Nauchnyj zhurnal KubGAU) [Jelektronnyj resurs]. - Krasnodar: KubGAU, 2010. №05(059). S. 79 - 110. - Shifr Informregistra: 042100001210091, IDA [article ID]: 0591005007. - Rezhim dostupa: http://ej.kubagro.ru/2010/05/pdf/07.pdf, 2 u.p.l.

14. Lucenko E.V. Invariantnoe otnositel'no ob\#emov dannyh nechetkoe mul'tiklassovoe obobshhenie F-mery dostovernosti modelej Van Rizbergena v ASK-analize i sisteme «Jejdos» / E.V. Lucenko // Politematicheskij setevoj jelektronnyj nauchnyj zhurnal Kubanskogo gosudarstvennogo agrarnogo universiteta (Nauchnyj zhurnal KubGAU) [Jelektronnyj resurs]. - Krasnodar: KubGAU, 2017. - №02(126). S. 1 - 32. - IDA [article ID]: 1261702001. Rezhim dostupa: http://ej.kubagro.ru/2017/02/pdf/01.pdf, 2 u.p.l.

15. Artem Artemov, Eugeny Lutsenko, Edward Ayunts, Ivan Bolokhov/ Informational Neurobayesian Approach to Neural Networks Training. Opportunities and Prospects // arXiv Computer Science, Learning (cs.LG) //arXiv preprint arXiv:1710.07264. - Rezhim dostupa: https://arxiv.org/pdf/1710.07264

16. Lucenko E.V. Metod kognitivnoj klasterizacii ili klasterizacija na osnove znanij (klasterizacija v sistemno-kognitivnom analize i intellektual'noj sisteme «Jejdos») / E.V. Lucenko, V.E. Korzhakov // Politematicheskij setevoj jelektronnyj nauchnyj zhurnal Kubanskogo gosudarstvennogo agrarnogo universiteta (Nauchnyj zhurnal KubGAU) [Jelektronnyj resurs]. - Krasnodar: KubGAU, 2011. - №07(071). S. 528 - 576. - Shifr Informregistra: 0421100012\0253, IDA [article ID]: 0711107040. - Rezhim dostupa: http://ej.kubagro.ru/2011/07/pdf/40.pdf, 3,062 u.p.1.

17. Lucenko E.V. Avtomatizacija Funkcional'no-stoimostnogo analiza i metoda "Direktkosting" na osnove ASK-analiza i sistemy "Jejdos" (avtomatizacija upravlenija natural'noj i finansovoj jeffektivnost'ju zatrat bez soderzhatel'nyh tehnologicheskih i finansovojekonomicheskih raschetov na osnove informacionnyh i kognitivnyh tehnologij i teorii upravlenija) / E.V. Lucenko // Politematicheskij setevoj jelektronnyj nauchnyj zhurnal Kubanskogo gosudarstvennogo agrarnogo universiteta (Nauchnyj zhurnal KubGAU) [Jelektronnyj resurs]. - Krasnodar: KubGAU, 2017. - №07(131). S. 1 - 18. - IDA [article ID]: 1311707001. - Rezhim dostupa: http://ej.kubagro.ru/2017/07/pdf/01.pdf, 1,125 u.p.1.

18. Lucenko E.V. Problemy i perspektivy teorii i metodologii nauchnogo poznanija i avtomatizirovannyj sistemno-kognitivnyj analiz kak avtomatizirovannyj metod nauchnogo poznanija, obespechivajushhij soderzhatel'noe fenomenologicheskoe modelirovanie / E.V. Lucenko // Politematicheskij setevoj jelektronnyj nauchnyj zhurnal Kubanskogo gosudarstvennogo agrarnogo universiteta (Nauchnyj zhurnal KubGAU) [Jelektronnyj resurs]. - Krasnodar: KubGAU, 2017. - №03(127). S. 1 - 60. - IDA [article ID]: 1271703001. Rezhim dostupa: http://ej.kubagro.ru/2017/03/pdf/01.pdf, 3,75 u.p.l.

19. Lucenko E.V., Lojko V.I., Semanticheskie informacionnye modeli upravlenija agropromyshlennym kompleksom. Monografija (nauchnoe izdanie). - Krasnodar: KubGAU. 2005. - 480 s. http://elibrary.ru/item.asp?id=21720635 